Utah State University

DigitalCommons@USU

$5-2011$

\title{
Prize-Based Contingency Management: A Vehicle Miles of Travel Reduction Intervention
}

Joshua D. Marquit

Utah State University

Follow this and additional works at: https://digitalcommons.usu.edu/etd

Part of the Psychiatry and Psychology Commons

\section{Recommended Citation}

Marquit, Joshua D., "Prize-Based Contingency Management: A Vehicle Miles of Travel Reduction Intervention" (2011). All Graduate Theses and Dissertations. 991.

https://digitalcommons.usu.edu/etd/991

This Dissertation is brought to you for free and open access by the Graduate Studies at DigitalCommons@USU. It has been accepted for inclusion in All Graduate Theses and Dissertations by an authorized administrator of DigitalCommons@USU. For more information, please contact digitalcommons@usu.edu.

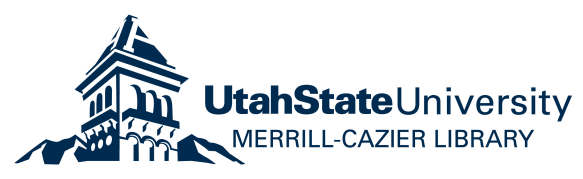




\title{
PRIZE-BASED CONTINGENCY MANAGEMENT: A VEHICLE MILES \\ OF TRAVEL REDUCTION INTERVENTION
}

\author{
by
}

Joshua D. Marquit

A dissertation submitted in partial fulfillment

of the requirements for the degree

of

DOCTOR OF PHILOSOPHY

in

Psychology

Approved:

Jamison D. Fargo, Ph.D.

Major Professor

$\overline{\text { Melanie M. Domenech Rodriguez, Ph.D. }}$

Committee Member

Mark W. Brunson, Ph.D.

Committee Member
Amy L. Odum, Ph.D.

Committee Member

Edward H. Redd, M.D.

Committee Member

Byron R. Burnham, Ed. D.

Dean of Graduate Studies

\section{UTAH STATE UNIVERSITY}

Logan, Utah 
Copyright (C) Joshua D. Marquit 2011

All Rights Reserved 


\author{
ABSTRACT \\ Prize-Based Contingency Management: A Vehicle Miles of Travel \\ Reduction Intervention \\ by \\ Joshua D. Marquit, Doctor of Philosophy \\ Utah State University, 2011
}

Major Professor: Jamison D. Fargo, Ph.D.

Department: Psychology

During the past 50 years, air pollution has become a growing problem throughout the Intermountain West because of increases in personal vehicle ownership and usage. Scientists continue to design interventions to improve air quality by encouraging people to reduce their personal vehicle miles of travel (VMT). However, results of these interventions have only seen modest reductions in VMT because of some methodological and measurement issues. To address these limitations, a 14-week driving reduction intervention was conducted in Cache County, Utah. This intervention employed a prizebased contingency management system within a single-subject, A-B-A withdrawal research design that rewarded participants with prizes if they were able to reduce their VMT below their baseline mean. The VMT was measured each day with an in-car GPS electronic tracking device. Results of this intervention indicate both short- and long-term reductions in VMT as a result of the treatment. Specifically, 6 of the 10 participants 
showed a statistically significant reduction from the baseline to the intervention stage and maintenance of this reduction during the return-to-baseline stage. The other four participants exhibited a similar pattern but their change in vehicle miles of travel was not statistically significant. Interaction effects were not found between the "Choose Clean Air" social marketing campaign, gas prices, temperature, and PM 2.5 levels. Despite some problems with the transmission and recording of VMT data, this intervention provides further evidence for the application of prize-based contingency management systems to the reduction of a problematic behavior or encouragement of proenvironmental or pro-social behaviors. The in-car GPS devices improved VMT data collection and quality of the data but hardware and software improvements are still needed to prevent data loss. Further replication is necessary to determine the efficacy of driving reduction intervention that employs prize-based contingency management systems at the community or group level. Future research should also test the possible demographic differences between those that respond favorably to this type of intervention and those that do not, and the differences between prize delivery systems (immediate versus delayed) and prize magnitude (low- versus high-dollar amounts) on driving behaviors. 


\section{ACKNOWLEDGMENTS}

I would like to thank my family for all their patience, support, and encouragement throughout my time in graduate school at Utah State University. Specifically, I would like to thank my wife, Miranda, whose strength and honesty have carried me through my schooling and work. I would also like to thank my parents, Wayne and Maria Marquit, for their love and support.

Additionally, I would also like to express my deepest gratitude to and appreciation for the faculty and staff of the psychology department at Utah State University for their knowledge, professional support, and guidance during my time in this program. Especially to my mentor and former dissertation committee chair, Dr. Richard N. Roberts, whose listening ear and wise counsel was a welcomed aid throughout my academic career and my dissertation research project. I will always remember his honest feedback, unwavering loyalty, and fierce dedication toward my academic and professional success. I would also like to thank my current mentor and committee chair, Dr. Jamison D. Fargo. His professional counsel, content expertise, and kind heart have made my transition from a student to an experimental psychologist easier and more enjoyable. I would also like to express my appreciation for the kindness, support, vision, counsel, and expertise from Dr. Edward H. Redd at the Bear River Health Department. Finally, I would like to give thanks to Dr. Britt L. Mace, who strongly encouraged me to pursue a doctoral degree and inspired my passion for environmental psychology and has always been a trusted colleague and friend.

Joshua D. Marquit 


\section{CONTENTS}

ABSTRACT.

iii

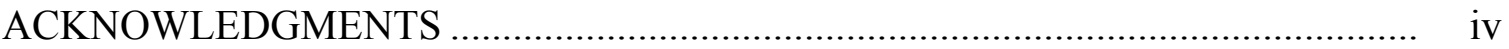

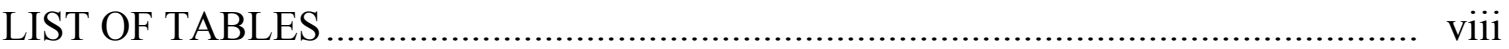

LIST OF FIGURES ….......................................................................... xi

\section{CHAPTER}

I. INTRODUCTION AND PROBLEM STATEMENT …........................... 1

II. LITERATURE REVIEW ............................................................. 5

Vehicle-Related Air Pollution..................................................................... 5

Driving Reduction Interventions...................................................... 7

Meta-Analysis: Driving Reduction Intervention Research...................... 8

Research Questions ....................................................................... 27

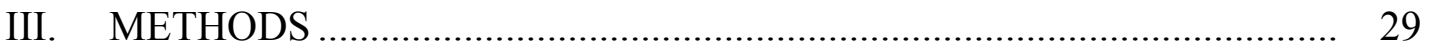

Design ...................................................................................... 29

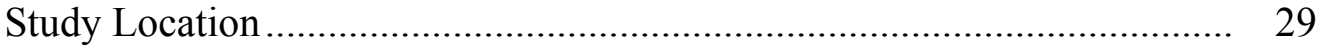

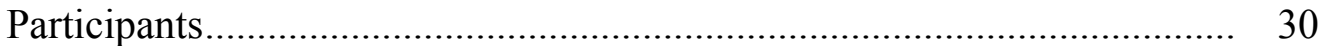

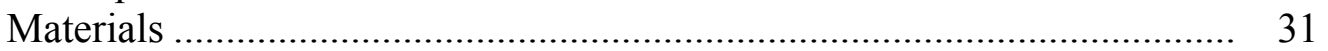

Procedure .................................................................................. 36

Study Period ..................................................................................... 39

Human Subjects Approval ............................................................ 40

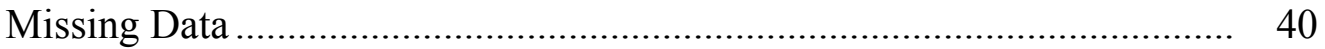

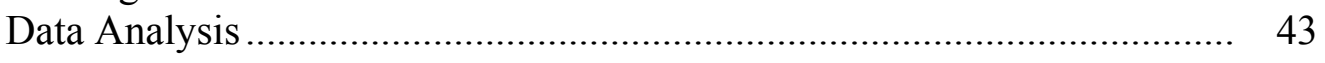

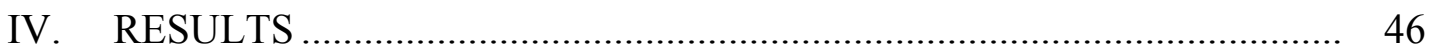

Sample Demographics .................................................................. 46

Results from the Research Question 1 and 2 ...................................... 51

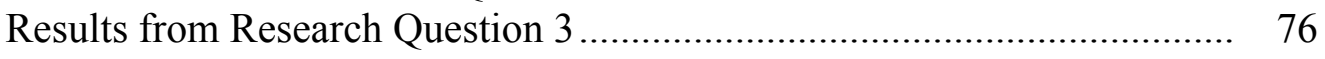

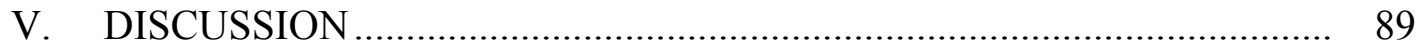


Treatment Efficacy....................................................................... 89

Support for Prize-Based Contingency Management Systems .................. 93

Prize-Based Contingency Management with Donations .......................... 94

Implications for Psychological Theory ............................................. 94

Measurement Issues ...................................................................... 95

Practical Significance and Future Recommendations........................... 97

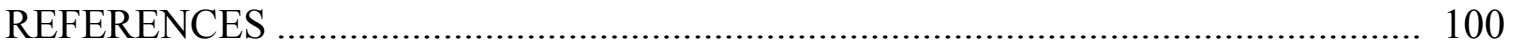

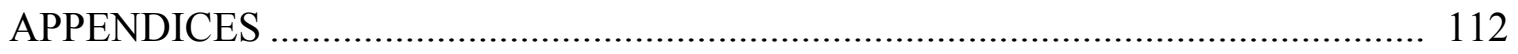

Appendix A: Recruitment Advertisement .......................................... 113

Appendix B: Preintervention Questionnaire ........................................ 115

Appendix C: CT630 Picture and Technical Specifications ..................... 120

Appendix D: Contract With Dycaon, Inc. ......................................... 123

Appendix E: Behavioral Contract .................................................. 125

Appendix F: Informed Consent: Baseline Data Collection ................... 127

Appendix G: Informed Consent: Intervention ...................................... 131

Appendix H: Suggestion List to Reduce Vehicle Miles of Travel ........... 136

Appendix I: Donation Solicitation Email.......................................... 138

Appendix J: Exit Questionnaire ................................................. 140

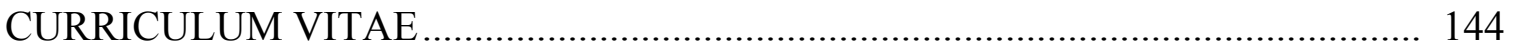




\section{LIST OF TABLES}

Table

1. Summary of the Meta-analysis for the Driving Reduction Interventions 10

2. Summary of the Prizes for the 8-Week Intervention.

3. Summary of the Community Driving Intervention with Prize-Based Contingency Management and A-B-A Withdrawal Design.

4. Summary GPS- and Server-Based Data Points

5. Demographic Information for Preintervention Questionnaire and Screened Sample

6. Political Summary for PreIntervention Questionnaire and Screened Sample.....

7. VMT Estimates for Preintervention Questionnaire and Screened Sample

8. Descriptive Statistics for the Environmental Perception Questionnaire Items for the Preintervention Questionnaire and Screened Sample

9. Descriptive Statistics for the Server- and GPS-Based Vehicle Miles of Travel by the Stage of the Intervention for Screened Sample.

10. Descriptive Statistics for the Server-Based, GPS-Based, and Adjusted VMT by Week of the Intervention for Screened Sample

11. Descriptive Statistics for the Server- and GPS-Based VMT for Participant $1 \ldots$.

12. Descriptive Statistics for the Server- and GPS-Based VMT for Participant 2....

13. Descriptive Statistics for the Server- and GPS-Based VMT for Participant 3....

14. Descriptive Statistics for the Server- and GPS-Based VMT for Participant 4... 63

15. Descriptive Statistics for the Server- and GPS-Based VMT for Participant 5... 65

16. Descriptive Statistics for the Server- and GPS-Based VMT for Participant 6... 68

17. Descriptive Statistics for the Server- and GPS-Based VMT for Participant 7 ... 70 
Table

18. Descriptive Statistics for the Server- and GPS-Based VMT for Participant 8... 72

19. Descriptive Statistics for the Server- and GPS-Based VMT for Participant 9... 74

20. Descriptive Statistics for the Server- and GPS-based VMT for Participant 10 .. 76

21. Descriptive Statistics for Variables Used in Server-Based VMT MixedEffects Model

22. Descriptive Statistics for Variables Used in GPS-Based VMT MixedEffects Model

23. Results of the Server-Based VMT Mixed-Effects Model

24. Results of the GPS-Based VMT Mixed-Effects Model

25. Descriptive Statistics for the Perception Items on the Exit Questionnaire from the Screened Sample.

26. Summary of the Open-Ended Questionnaire Item, "What did you like most about the intervention?"

27. Summary of the Open-Ended Questionnaire Item, "What did you like least about the intervention?"

28. Summary of the Open-Ended Questionnaire Item, "What did you do to reduce your driving?"

29. Summary of the Open-Ended Questionnaire Item, "Which prizes did you like most?"

30. Summary of the Open-ended Questionnaire item, "Which prizes did you like least?"

31. Summary of the Open-Ended Questionnaire Item, "What did you like most about the weekly drawings?"

32. Summary of the Open-Ended Questionnaire Item, "What did you like least about the weekly drawings?"

33. Summary of the Reason Why They Would Participate in a Driving Reduction Intervention like This in the Future 
34. Descriptive Summary of the Suggestions to Improve the Driving Reduction Intervention 


\section{LIST OF FIGURES}

$\begin{array}{ll}\text { Figure } & \text { Page }\end{array}$

1. Stage VMT means and medians for the screened participants ........................ 54

2. Weekly VMT means and medians for the screened participants .................... 54

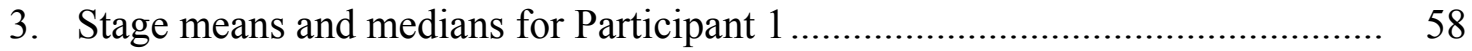

4. Weekly means and medians for Participant 1 .......................................... 58

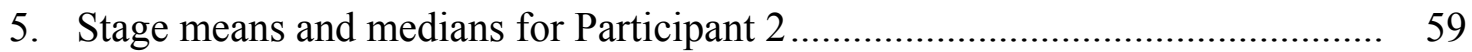

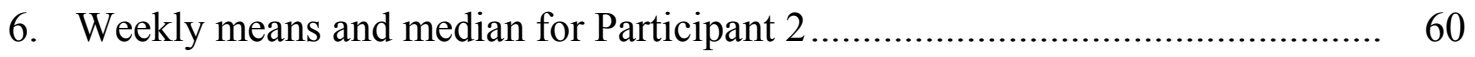

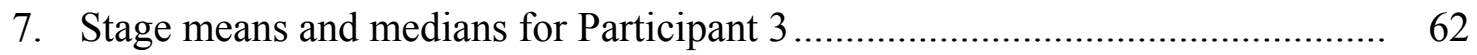

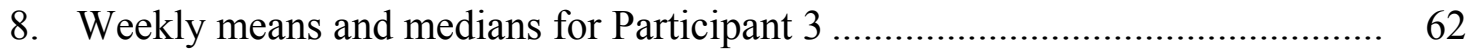

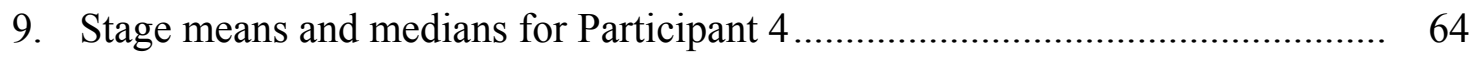

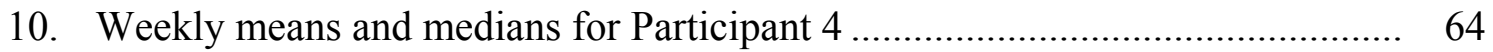

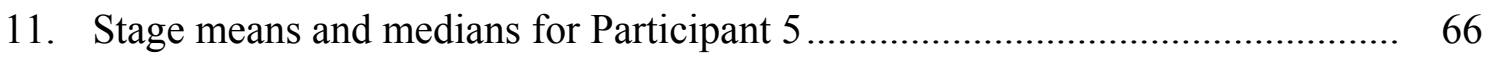

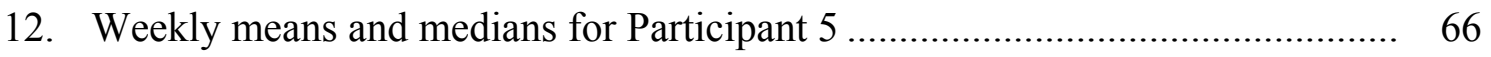

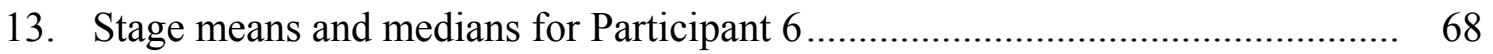

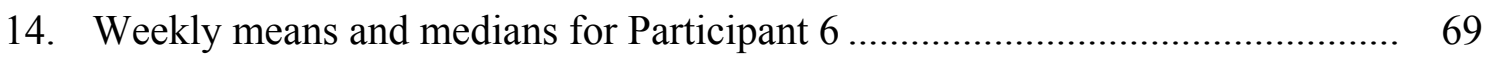

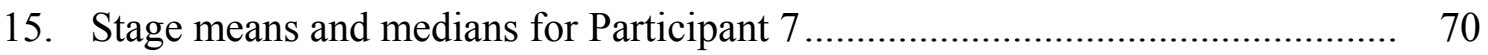

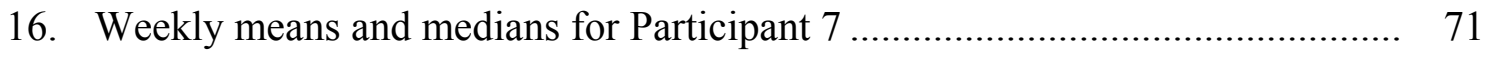

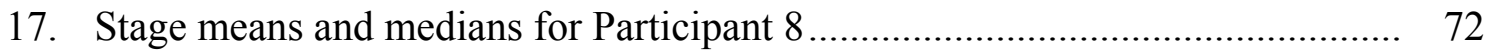

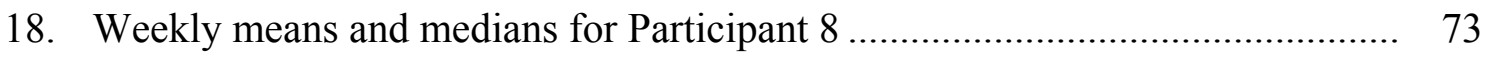

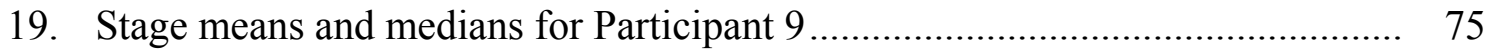

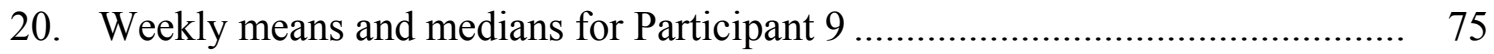


Figure $\quad$ Page

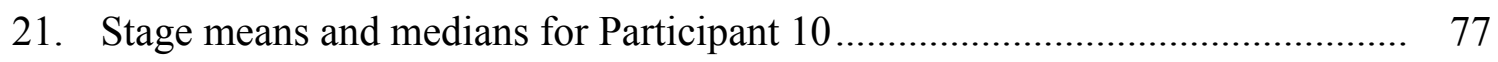

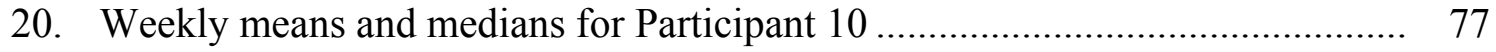




\section{CHAPTER I}

\section{INTRODUCTION AND PROBLEM STATEMENT}

Over the past 50 years, air pollution has increased in frequency and intensity throughout the world. Air pollution is caused by both human and natural sources (Environmental Protection Agency [EPA], 2009a). Vehicular emissions represent the most significant contributor to air pollution on a global scale (e.g., Gardner \& Stern, 2002; Garling \& Steg, 2005; Plitnik, 1998; Steg \& Vlek, 2009). Vehicular emissions include a number of toxic pollutants including nitrogen oxide, sulfur dioxide, ammonia, carbon monoxide, carbon dioxide, and hydrocarbons (EPA, 2009a; Plitnik, 1998). Research has found that these toxic pollutants have an adverse impact on human health (e.g., Brunekreef \& Holgate, 2002; EPA, 2009b; Holgate, Samet, Maynard, \& Koren, 1999; Moshammer et al., 2006) and the global environment (e.g., EPA, 2009b;

Greenland, 1983; Plitnik, 1998). Clearly, minimizing or abating vehicular emissions has both short- and long-term implications for the health, wellbeing, and sustainability of the planet and humans (Garling, Garling, \& Loukopoulos, 2002).

Interventions that have been designed to encourage people to reduce their personal vehicle use specifically targeting vehicle miles of travel (VMT) as the variable of interest. A meta-analysis on driving reduction interventions indicated that some of these interventions have shown modest reductions in driving behavior for short periods of time. These modest results may be directly attributed to four primary concerns: (a) measurement issues, (b) treatment efficacy, (c) treatment dosage or length, and (d) absence of a control group. 
Measurement of behavior change in current driving reduction intervention research relies heavily on self-report data collection techniques. Self-report data collection techniques, such as travel diaries, focus primarily on what people intend to do or estimations of what they have done rather than what they actually do (e.g., Deutscher, 1973; Steg \& Vlek, 2009; Vining \& Ebreo, 2002). A substantial body of research from a variety of academic disciplines has found numerous issues with both the validity and reliability of self-report data collection techniques. Some of the documented issues include informant inaccuracy, social desirability problems, and memory failure (e.g., Bernard, Killworth, Kronenfeld, \& Sailor, 1984; Stone et al., 2000). In an effort to improve the measurement of driving behaviors, global positioning system (GPS) tracking devices are becoming more widely used in travel and driving research as a supplement or replacement for self-report data collection techniques (Wolf, Hallmark, Oliveira, Guensler, \& Sarasua, 1999). GPS tracking devices have been found to be more reliable, more precise, less intrusive, and do not require participants to measure or estimate their own driving behavior than more traditional self-report measures of driving behavior (e.g., Bellemans, Kochan, Janssens, \& Wets, 2005; Ohmori, Nakazato, \& Harata, 2005; Wolf et al., 1999).

Current findings from driving reduction intervention research suggest that the efficacy of some treatments such as educational programs may be questionable in promoting reductions in driving behavior. An alternative treatment may be prize-based contingency management, a theoretically sound, evidence-based system that has showed promise in promoting behavior change in a variety of settings (Lewis, 2008; Petry, 2000). 
Specifically, prize-based contingency management systems have been found to be an effective treatment to encourage medication compliance, clinical behaviors, drug abstinence, treatment attendance and retention (e.g., Lewis, 2008; Petry, 2000), and proenvironmental environmental behaviors such as paper recycling (e.g., Witmer \& Geller, 1976).

In addition to treatment efficacy, treatment dosage or length of the interventions may be problematic. On average, many of these previous driving reduction interventions last approximately a week in length. This may not be an adequate amount of time to determine the efficacy of an intervention, promote behavior change, and monitor the variability of the behavior over time.

Finally, some of the driving reduction interventions lack a control group or baseline data for comparison purposes. The true treatment effects can only be determined and substantiated when a control group or behavior baseline is included in the intervention.

To address these methodological limitations in the current driving reduction intervention research, a community-based driving reduction intervention was designed and conducted in Cache County, Utah. This intervention employed a prize-based contingency management system (e.g., Petry, 2000) within a single-subject, A-B-A withdrawal research design (e.g., Hersen \& Barlow, 1976). To accurately measure the participants' daily vehicle miles of travel, an in-car GPS electronic tracking device (designed by Dyacon Inc.) was installed in their personal vehicle. To encourage reductions in vehicle miles of travel during the intervention stage of the study, 
participants were rewarded each day with an opportunity to pull a slip from a fishbowl that contained prizes that ranged in value from $\$ 1$ to $\$ 250$ for reductions below their baseline average. This intervention lasted 14 weeks and was conducted with residents of Cache County, Utah. In an effort to determine the treatment effect of the intervention, the project had three phases: a 3-week baseline data collection period (October to December 2009), an 8-week community-based intervention (January to March 2010), and a 3-week return-to-baseline (March and April 2010). This period of time is significant because Cache County experiences severe episodes of air pollution and residents have been strongly encouraged by the local health department social marketing campaign to reduce vehicle miles of travel. 


\section{CHAPTER II}

\section{LITERATURE REVIEW}

The purpose of this review is to explore the current literature and research on vehicle-related air pollution and its impact on the health of humans and the environment; and provide a summary of driving reduction interventions. A meta-analysis of driving reduction intervention studies is presented. The results of the meta-analysis indicate previous driving reduction intervention have found modest reductions in vehicle miles of travel. Theses modest reductions may be due in part to some methodological and measurement issues. These issues are reviewed in this section and include: (a) measurement issues, (b) treatment efficacy, (c) treatment dosage or length, and (d) absence of a control group.

\section{Vehicle-Related Air Pollution}

Air pollution is defined as any substance (vapor) or particulate material (matter) that is added to the atmosphere by human activities or natural processes that may adversely impact or become toxic to humans and the environment (Greenland, 1983; Plitnik, 1998). The EPA currently recognizes 188 chemicals as hazardous air pollutants including carbon oxides, sulfur oxides, nitrogen oxides, ammonia, volatile organic compounds, hydrocarbons, and a variety of other fine particulate matter (EPA, 2009a). There are a variety of man-made and natural causes of air pollution including vehicular emissions, industrial sources (i.e., factories), agricultural decomposition, windblown dust, and soot from wild fires and other sources of burning materials (EPA, 2009a; Greenland, 
1983; Nickerson, 2003; Plitnik, 1998).

Air pollutants are problematic for a number of reasons including: contaminating the environment, drinking water, and soil used for agricultural purposes (EPA, 2009a; Greenland, 1983; Nickerson, 2003; Plitnik, 1998); and adversely impacting human health (e.g., Evans \& Jacobs, 1982; Holgate et al., 1999). Specifically, research on the effects of air pollution on human health has found that air pollution directly and negatively impacts psychological well-being (Bullinger, 1989), a variety of human behaviors (Evans \& Jacobs, 1981), psychiatric admissions in hospitals (Briere, Downes, \& Spensely, 1983; Rotton \& Frey, 1984), asthma-related emergency room visits (Fauroux, Sampil, Quenel, \& Lemoullec, 2000; Weisel, Cody, \& Lioy, 1995), stress and anxiety (Chattopadhyay, Som, \& Mukhopadhyay, 1995; Evans \& Campbell, 1983; Evans, Colome, \& Shearer, 1988; Zeidener \& Shechter, 1988), respiratory problems and disease (Chattopadhyay et al., 1995; Holgate et al., 1999), general human health (Evans \& Jacobs, 1982; Holgate et al., 1999), eye irritation (Chattopadhyay et al., 1995), health of children (Holgate et al., 1999; Moshammer et al., 2006), increased mortality in adults (Pope et al., 2002), economic health and visibility costs (Delucchi, Murphy, \& McCubbin, 2002), and quality of life (Gifford \& Steg, 2005).

The most significant man-made contributors to air pollution in the United States are automobiles and other vehicles (Plitnik, 1998). Some of the most toxic vehicular emissions include nitrogen oxide, sulfur dioxide, ammonia, carbon monoxide, carbon dioxide, and hydrocarbons (EPA, 2009a; Plitnik, 1998). The adverse impacts associated with vehicle emissions are increasing exponentially as the number of people that own and 
use vehicles increases (Goodwin, 1996; Greene \& Wegener, 1997; Stern, 1992).

Research on personal vehicle use and emissions has revealed a myriad of other problems including noise pollution, traffic congestion, reduced visibility, global climate change, acid rain, human fatalities and accidents, and increased fossil fuel consumption (c.f., Garling et al., 2002; Garling \& Steg, 2005). These problems associated with personal vehicle use have both short- and long-term consequences on human and environmental health and wellbeing. Reducing personal vehicle use would also significantly improve air quality and minimize other vehicle-related problems such as insufficient parking and accidents (Goodwin, 1996).

\section{Driving Reduction Interventions}

Efforts continue to be made at the federal, state, and community level to encourage people to reduce their personal vehicle use. Driving reduction interventions are some of the most commonly used techniques designed to encourage people to reduce their driving behavior. These driving reduction interventions include behavioral, psychological, economic, and social modification techniques. Some of the most commonly used interventions or strategies are travel feedback programs (TFP; e.g., Eriksson, Garvill, \& Nordlund, 2008; Fujii \& Taniguchi, 2005; Garling, Garling, \& Johansson, 2000; Garling, Gillholm, \& Garling, 1998; Garling \& Marell, 1992; Jakobsson, Fujii, \& Garling, 2002; Tertoolen, Van Kreveld, \& Verstraten, 1998), travel demand management measures (TDM; e.g., Garling, Eek, et al., 2002; Jakobsson, 2004; Litman, 2003; Loukopoulos, 2007), or mobility management measures (e.g., Litman, 2003). These interventions vary by level of coerciveness; with travel feedback programs 
being the least coercive and travel demand management programs such as a tax on vehicle miles of travel being the most coercive.

Generally, travel feedback programs are educational strategies that use detailed, personal information about the participant's driving behaviors and patterns to promote awareness, knowledge, and behavior change. Specifically, the participants are educated about the potential impact their driving behaviors have on their personal, communal, and environmental health. Finally, they are educated on the potential benefits associated with reduced driving and how to alter their personal driving behaviors. Some more intensive travel feedback programs use this information to design trip plans that an individual or household can commit to and attempt to follow.

Travel demand management measures include taxations for car usage and fuel, tollbooths, decreasing speed limits, carpooling, social marketing campaigns, public transit, and infrastructure improvements. Litman (2003) conducted an extensive review of travel demand management measures. Each travel demand management measure differs in financial, political, and technical feasibility. Some evidence has been found for the successful application of these travel demand management strategies in reducing driving mileage (e.g., Garling \& Loukopoulos, 2005; Goodwin, 2005; Steg \& Schuitema, 2005).

\section{Meta-Analysis: Driving Reduction Intervention Research}

A systematic search of the literature on driving reduction intervention research was conducted using a number of computer-based databases including Academic Search Premier, Environmental Index, GreenFILE, Dissertation Abstracts Database, Psychology 
and Behavioral Science Collection, PsycINFO, and Google Scholar. Reference lists from peer-reviewed journals and book chapters were also searched. The following keywords were used in some combination: intervention, driving, car use, reduce, trips, miles, travel feedback, travel demand, and vehicle. The initial search yielded approximately 1,000 unique articles. The inclusion criteria for this meta-analysis included: experimental research (interventions) and measurement of driving behaviors (miles or trips) either through self-report, electronic measures, or both. After reviewing abstracts, only eight studies met all of these inclusion criteria. Also presented is a meta-analysis of driving reduction interventions that use travel feedback and mobility management programs that were conducted in Japan by Taniguchi, Suzuki, and Fujii (2007). Their meta-analysis included 31 research projects that were split into three settings: residential, workplace, school TFPs. Only the residential TFPs $(n=17)$ will be included in this review. Table 1 contains a brief summary of the driving reduction interventions. Included in the table is author(s), sample size $(N)$, type of intervention employed, duration of the intervention, presence of a control group, type of measurement method, outcome variable, and effect size. Effect sizes have been calculated using Cohen's $d$. Effect sizes have not been calculated for interventions that do not contain a control or comparison group.

Based on the results of the meta-analysis, many of these driving reduction interventions have produced minimal reductions in driving behaviors. These modest results may be directly attributed to four primary sources: (a) measurement issues, (b) treatment efficacy, (c) treatment dosage or length, and (d) absence of a control group. First, most interventions primarily use self-report data collection methods such as travel 
Table 1

Summary of the Meta-analysis for the Driving Reduction Interventions

\begin{tabular}{|c|c|c|c|c|c|c|c|c|}
\hline Authors & Year & $N$ & Intervention & Duration & $\begin{array}{l}\text { Control } \\
\text { Group }\end{array}$ & Measurement & $\begin{array}{c}\text { Outcome } \\
\text { Variable(s) }\end{array}$ & Effect Size (Cohen's $d$ ) \\
\hline $\begin{array}{l}\text { Garling \& } \\
\text { Marell }\end{array}$ & 1992 & 78 & $\begin{array}{l}\text { Travel Feedback Program } \\
\text { 1. Household Interview } \\
\text { 2. Individualized Plan }\end{array}$ & 1 week & Yes & $\begin{array}{l}\text { Travel diary } \\
\text { Odometer } \\
\text { readings }\end{array}$ & Number of trips & .55 \\
\hline $\begin{array}{l}\text { Tertoolen \& } \\
\text { Verstraten }\end{array}$ & 1995 & 350 & $\begin{array}{l}\text { Travel Feedback Program } \\
\text { 1. Environmental } \\
\text { Consequences } \\
\text { 2. Financial } \\
\text { Consequences } \\
\text { 3. Individualized Plan }\end{array}$ & $\begin{array}{l}\text { Four } 2 \text { week } \\
\text { sessions }(8 \\
\text { weeks total) }\end{array}$ & Yes & Travel diary & Car use & N/A \\
\hline Garling et al. & 1998 & 130 & $\begin{array}{l}\text { Travel Feedback Program } \\
\text { 1. Household Interview } \\
\text { 2. Individualized Plan } \\
\text { 3. Access to public transit } \\
\text { information }\end{array}$ & 1 week & Yes & $\begin{array}{l}\text { Travel diary } \\
\text { Odometer } \\
\text { readings }\end{array}$ & Number of trips & .04 \\
\hline Tertoolen et al. & 1998 & 350 & $\begin{array}{l}\text { Travel Feedback Program } \\
\text { 1.Individualized } \\
\text { Environmental and } \\
\text { Financial Consequences } \\
\text { 2. Individualized Plan } \\
\text { 3. Information on public } \\
\text { transit } \\
\text { 4. Commitment }\end{array}$ & $\begin{array}{l}\text { Four } 2 \text { week } \\
\text { sessions }(8 \\
\text { weeks total) }\end{array}$ & Yes & Travel diary & $\begin{array}{l}\text { Number of } \\
\text { kilometers } \\
\text { traveled }\end{array}$ & 0 \\
\hline Garling et al. & 2000 & 113 & $\begin{array}{l}\text { Travel Feedback Program } \\
\text { 1. Household Interview } \\
\text { 2. Individualized Plan }\end{array}$ & 8 days & No & Travel diary & Number of trips & $\mathrm{N} / \mathrm{A}$ \\
\hline
\end{tabular}




\begin{tabular}{|c|c|c|c|c|c|c|c|c|}
\hline Authors & Year & $N$ & Intervention & Duration & $\begin{array}{l}\text { Control } \\
\text { Group }\end{array}$ & Measurement & $\begin{array}{c}\text { Outcome } \\
\text { Variable(s) }\end{array}$ & Effect Size (Cohen's $d$ ) \\
\hline $\begin{array}{l}\text { Jakobsson et } \\
\text { al. }\end{array}$ & 2002 & 82 & $\begin{array}{l}\text { Economic disincentives } \\
\text { (TDM) and Trip Planning } \\
\text { (TFP) } \\
\text { 1. Household planning } \\
\text { visit } \\
\text { 2. Individualized Plan } \\
\text { 3. Increase in driving cost } \\
\text { (\$1.20 USD per } 10 \mathrm{~km})\end{array}$ & 4 to 6 weeks & Yes & $\begin{array}{l}\text { Travel diary } \\
\text { Odometer } \\
\text { Readings }\end{array}$ & $\begin{array}{l}\text { Number of trips } \\
\text { Number of } \\
\text { kilometers } \\
\text { traveled }\end{array}$ & $\begin{array}{c}\text { Charge Trip: } .03 \\
\text { Charge + Plan Trip: } .33 \\
\text { Extended Charge + Plan } \\
\text { Trip: } .23 \\
\text { Charge KM: } .12 \\
\text { Charge + Plan KM: } .08 \\
\text { Extended Charge + Plan } \\
\text { KM: } .04\end{array}$ \\
\hline Cleland & 2007 & 75 & $\begin{array}{l}\text { Travel Feedback Program } \\
\text { 1. Customized Travel } \\
\text { Information } \\
\text { 2. Environmental } \\
\text { consequences } \\
\text { 3. Public transit } \\
\text { information }\end{array}$ & $\begin{array}{l}2 \text { week } \\
\text { (Two, one- } \\
\text { week } \\
\text { periods) }\end{array}$ & Yes & Travel diary & $\begin{array}{l}\text { Number of } \\
\text { kilometers } \\
\text { traveled } \\
\text { Number of trips }\end{array}$ & $\begin{array}{l}\text { KM Period 1: } .11 \\
\text { KM Period 2:.11 } \\
\text { Trip Period 1: .70 } \\
\text { Trip Period 2:.17 }\end{array}$ \\
\hline Eriksson et al. & 2008 & 71 & $\begin{array}{l}\text { Travel Feedback Program } \\
\text { 1. Household interview } \\
\text { 2. Review of car reducing } \\
\text { strategies } \\
\text { 3. Individualized Plan }\end{array}$ & 2 weeks & Yes & Travel diary & Number of trips & 0 \\
\hline
\end{tabular}


diaries to collect data on driving behavior. Self-report data collection methods have a variety of validity and reliability issues such as inaccurate behavioral estimates and social desirability concerns. Second, the intervention or treatment (i.e., trip planning) efficacy may not be adequate to promote behavioral change because it relies heavily on the theory that education leads to immediate action. Third, driving reduction interventions may be too short in length to determine the efficacy of any intervention.

Most interventions have not lasted more than 2 weeks with most lasting about a week. Fourth, many of the driving reduction intervention studies do not contain a control group or collect baseline driving behavior data. Without a control group or baseline of the target behavior it is difficult to determine treatment effects.

\section{Measurement Issues}

All eight of the interventions used self-report techniques such as a travel diary. Only three of eight studies (37.5\%) in the meta-analysis report using both travel diaries and odometer readings (observable behavior) (e.g., Garling et al., 1998; Garling \& Marell, 1992; Jakobsson, 2004). All of the seventeen studies included in the metaanalysis conducted Taniguchi and colleagues (2007) used a travel diary or survey to collect driving behavior data. Travel dairies are the most commonly used data collection technique in driving behavior research and are often self-administered, paper-and-pencil (PAPI) questionnaires that collect data on trip purpose, location of departure and destinations, departure and travel time, trip time, vehicle miles traveled, and trip frequency (Peterson \& Hamburg, 1986). Generally, these questionnaires are completed successively throughout the day when the participant uses their personal vehicle. 
Research using these travel diaries have yielded some useful driving behavior data however, there are some validity and reliability issues associated with their use (e.g., Bellemans et al., 2005; Ohmori et al., 2005). First, the travel diaries require a good deal of time on the part of both the researcher to train the participant on how to use them and participant to learn how fill them out. Additionally, follow-up contacts are often required to ensure the proper completion of these forms. Second, travel diaries can be quite intrusive and time-consuming, often altering the participant's daily routines and schedule. For this reason, some participants may decide not to fully complete their travel diary especially for relatively short trips (Zhou \& Golledge, 2000). Third, using travel diaries for long intervals of time can increase levels of attrition and inaccuracy in the collected data. Participants may forget or grow tired of filling out trip logs.

Fourth, travel diaries rely exclusively on the participant's ability to accurately recall or estimate their driving behavior. Fifth, travel diaries may also be subject to social desirability biases. Social desirability refers to the notion that people will often overreport good behaviors (i.e., driving fewer miles on poor air quality days) and under-report bad behaviors (i.e., speeding) because of their desire to look favorable in the eyes of other people (Edwards, 1957; Fisher, 1993). It may be that participants under-report their vehicle miles of travel to please or find favor with the researchers. Finally, travel diaries are expensive to print, distribute, collect, process, analyze; and cannot be reused. Overall, travel diaries can be impractical data collection method over long intervals of time. Also, these travel diaries may provide incomplete or inaccurate driving behavior data. Research on alternative measurement tools has found that electronic data collection devices such as 
GPS tracking devices generally yield higher quality and more accurate driving behavior data than travel diaries alone (e.g., Kalfs \& Saris, 1997; Wolf et al., 1999).

In the 1970s, the GPS, a global navigation satellite system, was created by the United States Department of Defense for the purpose of aiding navigational military procedures. Currently, GPS is used for a variety of civilian and governmental purposes including driving directions, map making, land management and surveying, tracking human and animal behavior, and a myriad of other scientific uses (Hofmann-Wellenhof, Lichtenegger, \& Collins, 1997). GPS provides the user with valuable spatial and temporal information through a triangulation of highly accurate satellite signals in the GPS constellation. The GPS constellation contains approximately 24 satellites.

Over the past 20 years, GPS tracking devices have been developed for use in a number of scientific applications. These devices can be easily attached to cell phones, computers, or other small electronic devices with a power supply to track human activity and behavior. Recently, a modified version of this device has been designed to fit inside automobiles and other vehicles to accomplish the same task. In-vehicle GPS tracking devices also have the ability to automatically and discretely monitor driving behaviors and travel patterns that can be used to evaluate the effectiveness of car-use reduction policy, plan public transit routes, design city infrastructure, and create interventions to reduce personal vehicle use.

GPS tracking devices are quickly becoming the gold standard in the measurement of driving behavior because of their data collection precision and reliability. Research has found these GPS data collection devices to be both a reliable and accurate measure of 
travel behaviors (e.g., Kochan, Janssens, Bellemans, \& Wets, 2005; Ohmori, Harata, \& Ohta, 2004; Stopher, FitzGerald, \& Xu, 2007; Wolf et al., 1999; Zhou \& Golledge, 2000). The first documented use of GPS in travel research was a study conducted by the US Department of Transportation in Lexington, Kentucky, in 1996 (Wagner, 1997).

When directly compared to travel dairies or logs, GPS tracking devices have been found to provide a number of advantages (e.g., Bellemans et al., 2005; Ohmori et al., 2004, 2005; Ohmori, Nakazato, Harata, Sasaki, \& Nishii, 2006). Some scientists suggest that GPS tracking devices could eliminate the need for travel diary use in driving research (e.g., Wolf, Guensler, \& Bachman, 2001; Wolf, Oliveira, \& Thompson, 2003).

A number of authors reviewed the potential advantages GPS-added data collection in tracking driving behaviors (e.g., Stopher \& Greaves, 2007; Wolf et al., 1999, 2003). There are numerous documented advantages. First, GPS tracking devices automatically record detailed travel behavior information without burdening the participant. Some of the travel behavior that can be recorded by these devices includes departure and arrival time, trip mileage, number of trips taken per day, travel patterns, and travel locations. With this detailed travel behavior, researchers can better examine and evaluate travel activity totals, patterns, and tendencies. Second, these devices do not rely on the participants' ability to remember their travel behaviors. These devices automatically and unobtrusively record driving behavior. Third, GPS devices are more reliable and cost effective than travel diaries in the long-term. After the initial purchasing price, these GPS devices can be used many times over long periods of time. Fourth, using these devices require no training period for the participants. The device is just installed in 
the participant's vehicle and powered by a battery for the duration of the study. Fifth, the GPS tracking device records driving data with no interruptions in the participants' daily activities thereby reducing the possible influence of testing fatigue and self-monitoring effects. Sixth, the software in these devices can check for errors internally, improving reliability and validity of the data collected (quality control). Finally, the device can transmit the data wirelessly to a secure server or the researcher's computer.

There are also a few disadvantages of using GPS devices in travel behavior research (e.g., Bellemans et al., 2005; Ohmori et al., 2005, 2006; Wolf et al., 1999; Zhou $\&$ Golledge, 2000). First, the GPS device needs a reliable power source. These devices can be wired directly into the vehicles electrical system, cigarette lighter, or be powered by batteries. Cigarette-lighter-powered GPS devices were problematic because they only ran when vehicle's ignition was operating. Also, the participant may remove the cord and adaptor to charge or power other electronic devices. If batteries are used to power the device, the batteries must be monitored diligently to prevent stoppages in data collection. Second, the software in the device can malfunction and interrupt data collection or corrupt in the data. Third, the storage capacity of the device, although large, does have some limitations. Some GPS devices when memory capacity has been reached will write or record over previously recorded data. Fourth, the device can experience some technological difficulties connecting with the satellites (e.g., Wolf et al., 1999; Zhou \& Golledge, 2000).

Fifth, and most problematic, GPS tracking devices may fundamentally alter a person's driving behavior because they know that they are being monitored. When people 
know or are aware of being observed, they may diverge from their normal behavioral patterns and act in a more atypical manner. Research on the impact of other electronic devices such as video cameras and audio recorders on participant behavior has been examined. Some research on videotaping in clinical settings has found that awareness of being recorded has a significant impact on the patients' behavior during the office/ consultation visit (e.g., Martin \& Martin, 1984; Servant \& Matheson, 1986). Other studies have found no detrimental effect of video recording on patients (e.g., Campbell, Sullivan, \& Murray, 1995). These contradictory findings may be due in large part to the fact that the studies that found participants' "normal" behavior had been impacted by the act of video recording their behavior were conducted in the 1980s when video recording was not a common practice as it was in the 1990s where most studies found no significant impact. This change in perception may be a result to the relative differences between the prevalence and novelty of video recording in our daily lives from one decade to another. Although videotaping is more intrusive and reactive than GPS tracking devices, these findings may be applicable in research settings where GPS tracking devices are used to monitor travel behavior electronically. Despite its minor shortcomings, GPS tracking devices may significantly improve the measurement of driving behavior thereby improving the validity and scientific rigor of driving reduction interventions.

\section{Treatment Efficacy}

Based on the results of the meta-analysis, all eight studies used some form of individualized education-based travel feedback programs to reduce driving behaviors such as number of weekly trips and daily driving mileage/kilometers. One study used a 
combination of economic disincentives and travel feedback program. These educationbased travel feedback programs attempt to use education to alter attitudes about driving behavior and assume that this attitudinal change will lead to change in the target driving behavior.

The results of the interventions in the meta-analysis were modest. All eight of these studies used some form of a Travel Feedback Program to encourage driving behavior change. Overall, Cleland (2007), Garling and Marell (1992), and Jakobsson and colleagues (2002) are the only studies to report a significant reduction in number of trips taken during the study period. However, no intervention in the meta-analysis found a significant reduction in vehicles miles of travel. Eleven and the seventeen interventions (64.7\%) presented in Taniguchi and colleagues (2007) reported a car use change from $7.3 \%$ to $19.1 \%$ and an increase of public transit use from $30.0 \%$ to $68.9 \%$. However, there is no way of knowing specifically what this car use change represents because they measured change using an aggregate of the distance of trips, time duration of trips, and the frequency of trips. In both of these meta-analyses, education-based travel feedback programs appear to only have a modest impact on the number of miles traveled and trips made each day.

Fujii and Taniguchi (2006) found that interventions that asked participants to create a travel plan were more successful in changing travel behavior than those that did not require a travel plan. Again, these car use changes were modest with an $18 \%$ decrease in reported car use in interventions conducted in Japan. All eight of the interventions in this meta-analysis included some kind of travel plan or planning sessions. Consequently, 
differences could not be determined.

Contingency management interventions. Contingency management

interventions or motivational incentives are commonly used in drug abuse interventions and use basic behavioral modification techniques (operant conditioning) to increase the frequency of a target behavior using tangible positive reinforcers such as a voucher that can be exchanged for retail goods and services (e.g., Higgins et al., 1994) and prizes (e.g., Petry, Pierce et al., 2005). Other studies have given participants money (e.g., Shaner et al., 1997), changes in drug doses (e.g., Stitzer, Bickel, Bigelow, \& Liebson, 1986), and contingent take-home privileges (e.g., Stitzer, Iguchi, \& Felch, 1992). According to operant conditioning principles, behavior is maintained by environmental influences and altered by changing consequences (Griffith, Rowan-Szal, Roark, \& Simpson, 2000; Higgins \& Petry, 1999). Contingency management techniques change the environmental influences that maintain a behavior by creating a system of incentives (reinforcer) and disincentives (punishment/removal of reinforcer) that maintain and increase the probability that a more desirable target behavior will reoccur. For these reinforcers to be effective in promoting behavioral change, they must be applied consistently (schedule of reinforcement) after the demonstration of a target behavior (Griffith et al., 2000; Petry, 2000). Ultimately, the hope of contingency management plan is that the target behavior will eventually become self-reinforcing following the phased-removal of the external contingency management system (Petry, Petrakis, et al., 2001).

Contingency management interventions require three basic tenets. Petry (2000) outlined the three tenets in her review of contingency management procedures in clinical 
settings. First, the researcher arranges the treatment environment such that the target behavior is easy to detect, and objectively and frequently measured. Second, reinforcers (i.e., vouchers or money) are given to participants each time the target behavior is achieved or demonstrated. These reinforcers need to be of adequate magnitude to the patient or participant to promote the target behavior. Third, the reinforcers are withheld if the target behavior is not achieved or demonstrated.

Contingency management interventions have been found to be efficacious in promoting a wide variety of behaviors including medication compliance, clinical behaviors, drug abstinence, and treatment attendance and retention (e.g., Higgins, Alessi, \& Dantona, 2002; Lewis, 2008; Petry, 2000; Prendergast, Podus, Finney, Greenwell, \& Roll, 2006). Specifically, contingency management techniques have been found to be efficacious in treating drug dependency such as cocaine (Higgins et al., 1991, 1993, 1994; Higgins, Wong, Badger, Ogden, \& Dantona, 2000), marijuana (Budney, Higgins, Radonovich, \& Novy, 2000), alcohol (Petry, Martin, Cooney, \& Kranzler, 2000), opiods (Bickel, Amass, Higgins, Badger, \& Esch, 1997; Preston et al., 1998; Rawson et al., 2002; Silverman, Higgins, Brooner, \& Montoya, 1996), cigarettes (Reynolds, Dallery, Shroff, Patak, \& Leraas, 2008; Roll, Higgins, \& Badger, 1996; Stitzer \& Bigelow, 1982), methamphetamines (Roll et al., 2006), benzodiazepines (Stitzer et al., 1992), and multiple drug users (Piotrowski et al., 1999; Preston et al., 1999). Evidence has also been found for the long-term efficacy of these contingency management techniques in maintaining target behaviors beyond the treatment period. Specifically, Higgins, Badger, and Budney (2000), Higgins and colleagues (2003), and Higgins, Wong, and colleagues (2000) found 
drug abstinence in many participants at 1- and 2-year follow-up visits.

Contingency management techniques have also been found effective in a variety of other behaviors and settings including safety performance in open-pit mining (Fox, Hopkins, \& Anger, 1987), paper recycling (Witmer \& Geller, 1976), pedestrian safety (Boyce \& Geller, 2000), web-based carbon monoxide testing for adolescent smoking abstinence (Reynolds et al., 2008), attendance in group therapy (Alessi, Hanson, Wieners, \& Petry, 2007), and vocational rehabilitation of military veterans with comorbid psychosocial disorders (Drebing et al., 2007).

Despite strong evidence for the efficacy of contingency management techniques, there have yet to be adopted widely in scientific community and incorporated into community-based interventions. Some of the reasons that contingency management systems have not been used more frequent include the perceived high monetary costs, time-intensive nature of managing the system (i.e., monitoring target behavior and delivery of reward), the perceived lack of applicability in large-scale community-based settings, and the notion that the effects of the intervention may dissipate following the removal of the contingency system (Amass \& Kamien, 2004; Kirby, Benishek, Dugosh, \& Kerwin, 2006; Petry, 2000; Petry \& Simcic, 2002). In addition, the magnitude of the reinforcer may be too great, making it more difficult to transfer the learned behavior to natural contingency. For example, the studies conducted by Higgins and colleagues provided patients with the opportunity to earn vouchers that could be exchanged for over a $\$ 1,000$ worth of retail goods and services with most earning about $\$ 450$ to $\$ 600$ worth of prizes or services. Similarly, Olmstead, Sindelar, and Petry (2007) compared the cost- 
effectiveness of contingency management in eight clinics in the National Institute on Drug abuse Clinical Trials Network MIEDAR trial to usual care. They found that the contingency management interventions cost an additional $\$ 306$ to $\$ 582$ above the cost of usual care per patient. Clearly, most clinics and community-based organizations would have difficulty generating the funding needed to support a voucher-based program. However, some low value voucher-based contingency management interventions have been found to be effective (e.g., Carroll, Sinha, Nich, Babuscio, \& Rounsaville, 2002; Chutuape, Silverman, \& Stitzer, 1999; Iguchi, Stitzer, Bigelow, \& Liebson, 1988; Lawental \& Eshkol, 2006; Rawson, McCann, Hasson, \& Ling, 1994; Schmitz et al., 1998; Silverman et al., 1996; Stitzer et al., 1992). However, some contingency management techniques lose effectiveness if the magnitude of the reinforcer is not salient enough (Silverman, Chutuape, Bigelow, \& Stitzer, 1999; Stitzer \& Bigelow, 1982, 1983).

To combat this high monetary cost, other more cost efficient contingency management systems have been developed. Most notable is the "ishbowl technique developed by Petry and colleagues. The fishbowl technique provides the patient or participant with chances to win prizes rather than vouchers (e.g., Petry, 2000, 2006a, 2006b; Petry, Alessi, Tedford, Austin, \& Tardiff, 2005; Petry \& Martin, 2002; Petry et al., 2000; Petry, Martin, \& Simcic, 2005; Petry et al., 2004). This technique relies on an intermittent reinforcement system (Ferster, 1958) where patients earn an opportunity to draw a slip of paper from a bowl that contains approximately 250 slips. Of the 250 slips, 125 typically say something like "Sorry, try again," or “Great Job, try again," 109 are redeemable for low-value items such as $\$ 1$ gift certificates to various local business, 15 
are redeemable for larger prizes worth approximately $\$ 20$ such gift certificates to restaurants, and 1 is redeemable for a jumbo prize worth $\$ 100$ dollars such as DVD player or microwave.

Typically, maximal earnings for prize-based contingency management interventions (i.e., fishbowl) are around \$250-400 and much less expensive than the $\$ 1,000$ in more traditional voucher-based contingency management interventions (e.g., Petry et al., 2000, 2005). Petry and colleagues (2004) conducted a study to test the efficacy of a community-based, low-cost, prize-based contingency management intervention designed to reduce cocaine dependence. One hundred twelve cocaineabusing patients were randomly assigned to one of three 12-week experimental conditions: (a) standard treatment, (b) standard treatment plus a prize-based contingency management procedure with a maximum expected value of reinforcement of $\$ 80$, or (c) standard treatment plus a prize-based contingency management procedure with a maximum expected value of the prizes of $\$ 240$. Patients in the experimental condition with standard treatment plus contingency management with the maximum expected value of the prizes of $\$ 240$ achieved more abstinence than those in the other two conditions. The patients in this condition earned on average $\$ 68$ worth of prizes. The patients in the standard treatment plus contingency management with the maximum expected value of $\$ 80$ earned an average of \$36. Sindelar, Elbel, and Petry (2007) found that higher magnitude (\$240) contingency management procedure in this intervention produced lower per unit cost than the lower $(\$ 80)$ magnitude procedure. Clearly, the magnitude of the maximum expected value of the prize must be considered. 
The prize-based contingency management systems may be equally effective in promoting drug abstinence or clinical behaviors as voucher-based contingency management systems. Research on prized-based contingency management systems has found it to be effective in both treating and retaining patients in community-based treatment programs including psychosocial (Petry, Alessi, et al., 2005; Petry et al., 2000; Petry, Martin, \& Simcic, 2005; Petry, Pierce et al., 2005), HIV group treatment (Petry, Martin, \& Finocche, 2001) and methadone programs (Peirce et al., 2006; Petry \& Martin, 2002; Petry, Martin, Simcic, 2005). Petry, Alessi, and colleagues (2005) conducted a study to compare the efficacy of prize-based contingency management system with a voucher-based system in community settings. Using a group of 142 cocaine and heroin addicts, they randomly assigned them to three different conditions: (a) standard treatment (ST), (b) ST plus vouchers, and (c) ST plus prizes. The intervention lasted 12 weeks with two follow-up visits at 6 and 9 months. They found that both the prize- and voucherbased contingency management systems were equally effective in promoting longduration drug abstinence. Olmstead and Petry (2009) compared the cost-effectiveness of these two systems in this study using incremental cost-effectiveness ratios and acceptability curves and their calculation demonstrated that prized-based contingency management was more cost-effective compared to the voucher-based system.

To reduce the cost further, Amass and Kamien (2004) solicited prizes through community donations (goods and services) to finance their voucher programs for pregnant, postpartum, and parenting drug users in Toronto and Los Angeles. They solicited prizes through two direct mail campaigns. In Toronto, over $\$ 8,000(\$ 4,000$ per 
month) worth of donations were made by just $19 \%$ of those that received mail solicitation. In Los Angeles, approximately $26 \%$ of those that received a solicitation letter donated $\$ 161,000$ (\$4,472 per month) worth of goods and services over a 34-month period of time. These results show that a prize-based contingency management system that relies on donations is both feasible and sustainable over long periods of time. These donations can also significantly reduce the cost of implementing these treatment techniques on community organizations and clinics.

Overall, prize-based contingency management systems with donations are an effective, lower cost alternative to more traditional voucher-based systems (Lewis, 2008; Petry, 2000). Also, prize-based contingency management systems that rely on donations have been shown to be feasible and useful in promoting behavioral change in a variety of settings and sustainable for long periods of time at the community level (Amass \& Kamien, 2004). For these reasons, these prize-based contingency management systems show promise and will be tested as part of the proposed community-based driving reduction intervention.

Treatment dosage/length. According to the meta-analysis, no driving reduction intervention studies lasted longer than 8 weeks with most averaging about 1 or 2 weeks in duration. A week may be too short to evaluate the efficacy of an intervention and subtle changes in vehicle miles of travel or trip totals over time. In an effort to improve upon this intervention length, the proposed project will be 14 weeks in length and include a pre- and post- intervention-monitoring period.

Control group/baseline data. In this meta-analysis, seven of the eight 
interventions (87.5\%) included a control group. Taniguchi and colleagues (2007) found that 12 of the 17 interventions (70.6\%) in their meta-analysis included a control group. A control group or baseline data collection period for the target behavior needs to be included for comparison purposes and to determine treatment effects. A-B-A withdrawal design is often a method of choice in single-subject intervention research and is used to compare behavioral patterns at baseline (pre- and posttreatment) with treatment behavioral patterns to determine treatment effects (Hersen \& Barlow, 1976). The researcher first establishes baseline for the target behavior without experimental manipulation. Data are collected over time and graphically represented to determine when baseline (i.e., behavioral stability) has been achieved for the target behavior. Once baseline is established, the researcher systematically applies an experimental or treatment variable to the target behavior. This procedure is repeated for each target behavior under investigation. Finally, the researcher removes (withdrawal) the treatment condition(s) to return to baseline in an effort to determine the lasting (or long-term) impact of the treatment conditions on the target behavior(s) or determine which treatment was most potent as a reinforcer, punishment, or neutral in behavioral change. Using an A-B-A withdrawal research design will provide 3 weeks of pre- and postbaseline data that can be used to compare with mileage data during the 8-week intervention to determine the treatment effect.

Effect size. According to the meta-analysis, Garling and Marell (1992), and Cleland (2007) were the only two studies (25\%) that had an effect size greater than .50 . These studies found a difference in the number of trips made during the study period 
between the control and experimental groups. In each case, the experimental group made fewer trips with their personal vehicle. However, a treatment effect was not found on the number of miles or kilometers driven. Effect sizes were not reported in Taniguchi and colleagues (2007).

\section{Summary of Meta-Analysis}

Overall, the driving reduction interventions presented in this meta-analysis could be strengthened. On average, these interventions short in length, employed an educationbased travel feedback program, and relied too heavily on self-report measures of driving behavior. The driving reduction intervention presented in this paper, addressed these methodological and measurement problems. This intervention lasted 14-weeks and used prize-based contingency management techniques to positively reinforce reductions in vehicle miles of travel. This intervention employed a single-subject, A-B-A withdrawal research design. Pre- and postintervention driving data will be presented to demonstrate changes in vehicle mile of travel.

\section{Research Questions}

The proposed intervention is designed to answer the following research questions.

1. Are vehicle miles of travel sensitive to a prize-based contingency management intervention to reduce mileage?

2. As a result of the prize-based contingency management intervention, does the average vehicle miles of travel increase, decrease, or remain the same when compared to average vehicle miles of travel collected during the baseline data collection period? 
3. Is there an interaction effect between the prize-based contingency management system and the "Choose Clean Air" social marketing campaign on driving reductions? 
CHAPTER III

METHODS

\section{Design}

A contingency management intervention using a prize-based "fishbowl" method of reinforcer delivery (designed by Petry, 2000) was used. This intervention was a multistaged, single-subject A-B-A withdrawal research design (baseline-intervention-return to baseline).

\section{Study Location}

Cache Valley provides an ideal setting to conduct an intervention to reduce personal vehicle miles of travel. Cache Valley is located in northern Utah and encompasses a small portion of southern Idaho. The valley is surrounded by three mountain ranges (Bear River, Malad, and Wellsville Mountains) that have peaks that exceed elevations of 2,500 meters or greater. Because of its bowl-shape, Cache Valley is susceptible to a climatic phenomenon known as an inversion during the winter months (November to March). An inversion creates a pocket of stagnant air along the top of the mountain ranges that traps particulate matter ( $\mathrm{smog}$ ) and promotes the formation of ammonium nitrate-based particulate matter $\left(P M_{2.5}\right)$. Particulate matter of this size is has been linked to a number of negative health outcomes including heart and lung disease, asthma, and prolonged exposure can lead to premature death (EPA, 2009a; Holgate et al., 1999). In January of 2004, Cache Valley experienced the worst episodes (high 
concentrations of $P M_{2.5}$ ) air pollution in the United States (Malek, Davis, Martin, \& Silva, 2006). In an effort to minimize the impact of personal vehicle emission on air pollution in the Cache Valley, the local health department has implemented a social marketing campaign called "Choose Clean Air" that encourages people to engage in a number of air pollution-reducing behaviors (e.g., reducing the number of vehicles miles of travel) to minimize their contribution to air pollution and to avert exposure to air pollution.

\section{Participants}

Participants for the study were solicited using advertisements in local newspapers (i.e., Herald Journal and the Utah Statesman), the Internet (i.e., Craig's List and cachevalleydaily.com), and on Utah State University's Events Calendar (see Appendix A for a copy of the advertisement). All of the people that participated in this study were currently living in Cache County, Utah. Cache County has an estimated 108,887 residents (U.S. Census Bureau, 2009).

A preintervention questionnaire was used as a selection and inclusion tool. Inclusion criteria included: (a) ownership or lease of one vehicle, (b) use their personal vehicle as their primary source of transportation, (c) they have a current and valid driver's license, (d) between 18 to 65 years of age, (e) fluent in English, (f) have a moderate environmental orientation as measured by the preintervention questionnaire's environmental perception questions, and (g) are of average sociodemographic (i.e., SES) description in Cache County (based on U.S. Census Data). 
To determine participants' environmental orientation, the responses on the environmental questionnaire items from the preintervention question (see Appendix B for a copy of the questionnaire) were compiled and added for each participant. These totals were then plotted on a histogram to determine normality. The outliers (two standard deviations below or above the mean) were removed from the pool of possible participants. Only one potential participant's environmental orientation score was greater than two standard deviations. From the remaining 33 questionnaire participants who met all of the inclusion, 10 people were randomly selected using a random number generator in an Excel file. These 10 participants were approached by Joshua Marquit and asked to participate in a multi-staged driving reduction intervention. All 10 participants agreed to take part in all three of the remaining stages $\left(2^{\text {nd }}\right.$ Baseline, $3^{\text {rd }}$ Intervention, $4^{\text {th }}$ Return-tobaseline, and $5^{\text {th }}$ Exit Questionnaire).

\section{Materials}

\section{Preintervention Questionnaire}

A preintervention questionnaire was developed and administered to participants that answered an advertisement in various newspapers and Internet websites. The questionnaire included both closed- and open-ended questions. All items on the questionnaire were self-report measures. Questionnaire items were used to collect data on personal vehicle usage (i.e., average miles driven per day/week and types of trips made), environmental orientation, and sociodemographic variables (i.e., age and sex). See Appendix B for a copy of the preintervention questionnaire. 


\section{Electronic on Board Recorder Device}

Ten CT (Control Trac) 630 Electronic on board recorder GPS devices that were designed by Dyacon, Inc. in Logan, Utah, were secured and placed in each participant's personal vehicle (see Appendix $\mathrm{C}$ for a picture of the device and the technical specifications provided by Dyacon, Inc.). Dyacon, Inc. loaned these devices and software for use in this intervention in exchange for recognition (see Appendix D for the hardware/software contract with Dyacon, Inc.). These GPS devices were designed to accurately track daily vehicle mileage traveled (VMT). These devices operate on a Linux Operating System and $\mathrm{C}++$ programming software and are programmed to remain on while the car is running or not running. Using geo-fencing, only driving mileage in Cache County was recorded.

The mileage data were saved to an internal memory system either every 2 minutes or when the car made a turn greater than 30 degrees in any direction. Data were transmitted and stored in real-time through a mobile phone (SIM card) in the GPS device to a secure server that was housed at Dyacon, Inc. Using a secure web account (password required) on Dyacon.net, the principle investigator was able to view a map of each participant's driving patterns and calculate their driving mileage using latitudinal and longitudinal. In this way, the participants were not required to manually retrieve and send the data from the GPS devices to the principal investigator. The GPS device was secured under the driver's seat and was powered by the vehicle's battery through internal wiring. A GPS antenna was also attached to the device and mounted on the bottom left corner of the vehicle's windshield. This antenna would send a signal from the GPS device to the 
GPS satellite constellation to determine location of the vehicle.

\section{Behavioral Contract}

The behavioral contract specifically outlined the behavior to be monitored (vehicle miles of travel; VMT), when and how VMT was monitored, the purpose of the intervention, and the voucher/prize contingency management system. By signing the behavioral contract, the participant declared their understanding of their role in the intervention, the purpose of the intervention, and personally committed to reducing their VMT below their baseline average each day of the intervention. Additionally, the participants also committed to attend a prize-slip drawing held weekly at the Bear River Health Department on each Wednesday evenings on the Intervention stage of the study. See Appendix E for a copy of the Behavioral Contract.

\section{Informed Consent Forms}

Two different informed consent forms were given to and signed by each of the ten participants of the Baseline (see Appendix F) and Intervention Stages (see Appendix G). The informed consent forms contained information concerning the purpose of the intervention, their role in the intervention, possible risks and benefits associated with participating in the study, how the VMT data was going to be used by the principal investigator, and the principal investigator's contact information.

\section{Suggestion List to Reduce Vehicle Miles of Travel}

Each participant in the intervention was given a list of ways to reduce their 
vehicle miles of travel (see Appendix H for a copy of this suggestion list). The list includes such suggestions as carpooling, using public transit, trip planning, and telecommuting.

\section{Vouchers}

Vouchers (or opportunity to draw from fishbowl) were awarded each morning before noon for those that were able to reduce their vehicle miles of travel below their baseline average during the previous day. Each morning the participants were sent information via an email on their VMT from the previous day, their baseline average for that day (e.g., Weekday, Saturday, and Sunday), whether or not they earned a voucher for that day, and how many total vouchers they had earned for that week.

An example of an email from a successful reduction reads:

"Congratulations. You have earned one voucher.

Driving Day 10 Mileage: 10.42 miles

Your Weekday Baseline Average: 21.7miles

You have earned two vouchers for next week's drawing."

An example of an email from an unsuccessful reduction reads:

"Unfortunately, you were not able to reduce your driving below your baseline. You did not earn a voucher for Day 50.

Driving Day 50 Mileage: 14.68 miles

Your Sunday Baseline Average: 14.5 miles

You have 3 earned vouchers for this week's drawing."

On Wednesday evenings during the intervention, participants were able to exchange their vouchers for an opportunity to pull a slip from the prize bowl.

\section{Prizes}

All of the prizes were either donated items from local businesses in Cache 
County, Utah, or purchased items from the principal investigator. The prizes varied in retail value from .75 cents to $\$ 250$. The principal investigator (Joshua D. Marquit) secured prizes from local businesses using a flyer and brief conversation with each business owner. See Appendix I for a copy of the flyer that was given directly to local businesses.

Thirty-one businesses were approached about donating prizes. Of these, 17 (55\%) businesses donated approximately $\$ 1,538$ worth of prizes and gift certificates. An additional $\$ 3,420$ worth of prizes were purchased by the principal investigator and included in the prize bowl. There were 910 prizes in the bowl that had an approximately retail value of $\$ 4,958$. The prizes were stored at the Bear River Health Department (BRHD) for security and safety reasons. Table 2 provides a list of the prize dollar ranges, the number of prizes in the fishbowl from these price ranges, and the percentage of prizes from these price ranges relative to the total prizes in the fishbowl. The participants were not told the exact number or value of prizes that were contained in the bowl. However, they were told the value range of prizes ( $\$ 1$ to $\$ 250)$. The prize-slips that were drawn were not returned to the bowl.

\section{Fishbowl}

A fishbowl was purchased from a local retailer. It held the 910 prize slips. The fishbowl was also located at the BRHD for security and safety reasons.

\section{Exit Questionnaire}

Upon completion of the project, participants were asked to complete an exit 
Table 2

Summary of the Prizes for the 8-Week Intervention

\begin{tabular}{ccc}
\hline Prize retail value & Number of prizes in fishbowl & Percent of total \\
\hline$\$ .75-\$ 1.99$ & 504 & 55.39 \\
$\$ 2.00-\$ 2.99$ & 90 & 9.89 \\
$\$ 3.00-\$ 3.99$ & 56 & 6.15 \\
$\$ 4.00-\$ 9.99$ & 109 & 11.98 \\
$\$ 10.00-\$ 14.99$ & 67 & 7.36 \\
$\$ 15.00-\$ 19.99$ & 34 & 3.74 \\
$\$ 20.00-\$ 24.99$ & 17 & 1.87 \\
$\$ 25.00-\$ 29.99$ & 15 & 1.65 \\
$\$ 30.00-\$ 34.99$ & 4 & .04 \\
$\$ 35.00-\$ 39.99$ & 1 & .01 \\
$\$ 40.00$ & 2 & .02 \\
$\$ 50.00$ & 3 & .03 \\
$\$ 70.00$ & 1 & .01 \\
$\$ 95.00$ & 1 & .01 \\
$\$ 125.00$ & 1 & .01 \\
$\$ 150.00$ & 4 & .04 \\
$\$ 250.00$ & 1 & .01 \\
\hline
\end{tabular}

questionnaire. The exit questionnaire included both closed- and open-ended self-report questions related to the participant's perception of the efficacy of the intervention in helping them reduce their VMT during the study and what participants did to reduce their VMT (see Appendix J for copy of Exit Questionnaire).

\section{Procedure}

This intervention included multiple stages. The first stage of the project was participant recruitment through a number of advertisements in local newspapers and Internet websites. Participant recruitment occurred in September and October of 2009. Each person who responded to an advertisement was asked to complete the 
preintervention questionnaire in my office/cubicle and received $\$ 2$ in cash as compensation. From those that met the inclusion criteria $(n=33), 12$ participants were randomly selected and contacted by phone to determine their willingness to participate in the study. Ten were willing to participate in the second stage of the study (Baseline). The two other people that were randomly selected initial agreed to participate but later decide not to participate.

During the baseline stage, participants were asked take part in a GPS study in which a GPS device would be placed in their personal vehicle to test the functionality of GPS in tracking their driving patterns for 3 weeks and determine the average vehicle miles of travel of residents of Cache County. Upon acceptance of this solicitation, participants completed an informed consent form. Following the completion of the informed consent form, an in-car electronic GPS device was installed in their personal vehicles by Dyacon, Inc., and their vehicle miles of travel were collected each day. The data collection occurred in 3-week intervals between November 2009 and December 2009. During the baseline stage, participants were split into two groups because there were only six in-car GPS devices available for use at this time. The first group included six participants (five students and a resident of Logan) who were mostly students from Utah State University because many were going to leave Logan for the Christmas holiday. Their VMT data was retrieved from November 6 until December 4, 2010. Thanksgiving vacation was excluded from the data collection period. The second group included four participants (three residents of Logan and a student who was not leaving for Christmas). Their VMT data were retrieved from December 5 until December 31, 2010. 
Christmas Eve and Christmas day were excluded from the data collection period. At the end of the baseline stage, each participant was given a $\$ 20$ check and asked to participate in an intervention that focused on reducing their daily vehicle miles of travel. All 10 people in the second stage agreed to participate in the intervention and were paid an additional $\$ 10$ at this time.

The third or intervention stage lasted 8-weeks. All participants began the intervention on January 10, 2010, and ended on the March 6, 2010. During the intervention stage, their vehicle miles of travel were again collected daily. The participants received an email each day before noon that contained their previous day's VMT, their baseline (weekday, Sunday, or Saturday) average, whether they successfully earned a voucher, their total vouchers earned that week, and the baseline average for that day and following day (if it was different). Each Wednesday evening, a fishbowl prize drawing was held at the Bear River Health Department between 5 and 7 pm. In an effort to prevent artificially inflating their vehicle miles of travel on this day, the principal investigator subtracted their trip to the BRHD from their daily mileage total.

The order in which each participant drew prizes was determined by drawing a number ranging from 1 to 10 from a small bag. The number on the slip corresponded to the position in which they would draw prize slips from the fishbowl. For example, the participant who drew the " 1 " slip, drew from the prize-bowl first. During the prize drawings, participants drew a prize number slip from the fishbowl and selected a prize from a list of prizes that were grouped by dollar ranges (e.g., Prize 1 prizes were those that ranged in value from 75 cents to $\$ 2$ ). The next participant did not select their prize 
until the previous participant finished his/her selection. All prizes were given to participants upon the completion of all of their turns.

The fourth or return-to-baseline stage of the study lasted approximately 3 weeks. All participants began this stage on March 7, 2010, and ended on April 3, 2010. The spring break (March 14 to March 20) at Utah State University was excluded from the data collection period. During this stage, participants driving mileage data were recorded and collected but no emails (feedback) were sent to participants about their driving mileage, no prize vouchers were earned, and no prizes were rewarded.

At the end of the fourth stage, a final "thank you" buffet dinner and prize drawing was held at the Environmental Health Department in Logan, Utah. Participants were not told prior to or during the return-to-baseline stage that there would be a dinner and final drawing. The dinner/drawing announcement occurred following the return-to-baseline stage data collection period was finished. At this dinner, each participant was thanked for their participant, received a $\$ 20$ check, completed an exit questionnaire, and had the GPS device removed from their personal vehicle by Dyacon, Inc.

\section{Study Period}

This dissertation study included multiple stages. The first stage of the study involved the recruitment of participants for the intervention and was conducted in September and October of 2009. The timeline for the second, third, and fourth stages are summarized in Table 3. The fifth and final stage was the exit questionnaire and final dinner was held on April 6, 2010. 
Table 3

Summary of the Community Driving Intervention with Prize-Based Contingency

Management and $A-B-A$ Withdrawal Design

\begin{tabular}{|c|c|c|c|}
\hline Description & Stage 2: Baseline & $\begin{array}{l}\text { Stage 3: Community } \\
\text { intervention }\end{array}$ & $\begin{array}{l}\text { Stage 4: Return-to- } \\
\text { baseline }\end{array}$ \\
\hline Experimental condition & GPS monitoring & $\begin{array}{l}\text { GPS monitoring + prize- } \\
\text { based CM }\end{array}$ & GPS monitoring \\
\hline Duration & 3-weeks & 8-weeks & 3-weeks \\
\hline Date & $\begin{array}{l}\text { November } 2009 \text { to } \\
\text { December, } 2009\end{array}$ & $\begin{array}{l}\text { January } 10,2010 \text { to } \\
\text { March 6, } 2010\end{array}$ & $\begin{array}{l}\text { March 7, } 2010 \text { to } \\
\text { April 3, } 2010\end{array}$ \\
\hline
\end{tabular}

\section{Human Subjects Approval}

This dissertation project was approved by the Institutional Review Board at Utah State University on September 29, 2009. The assigned protocol number for this study was \#2419.

\section{Missing Data}

Some of the daily server-based VMT totals for each participant were incomplete because of missing data points. Missing data points were a direct result of software and hardware issues with onboard electronic GPS device. Specifically, the SIM cards used in the onboard GPS devices to transmit the VMT data points would occasionally fail to connect to the server at Dyacon, Inc., resulting in lost or missing data. When data were not received on the first transmission, the onboard GPS device was not programmed to continue trying to send the data until it was transmitted. To prevent data loss, the onboard GPS devices were programmed, however, to store the data that was not successfully 
transmitted. These data were retrieved manually at two different points in during the study (week 4 of the intervention stage and week 14 at the end of the return-to-baseline stage). Unfortunately, because of limited storage space the onboard GPS device would overwrite some of the previously saved VMT data points when the memory space was full.

Following all data collection, a thorough and systematic inspection of both the VMT data on the server housed at Dyacon, Inc., and the onboard GPS device revealed that VMT data stored on the off-site server was incomplete. Of the 980 possible days of observations, only 957 days of data were recorded on the server and 570 days of date on the onboard GPS device were recoverable. When compared to the data from the onboard GPS devices, the server data had a number of missing data points. However, not all of the points recorded by the onboard GPS device were points that contributed to the total daily VMT. Specifically, many of the points were random errors, hourly check-in points, or data points outside of the Cache Valley. Table 4 shows the total number of days and data points (including points that did not contribute to total VMT) that were recorded by the GPS device and server for each participant and provides the percentage of the total recorded GPS device data points that were also recorded by on the off-site server.

To determine the differences between VMT totals for the GPS (GPS-based VMT) and server (server-based VMT), a paired-samples $t$ test was conducted. Results suggested that the average GPS-based VMT $(M=12.14, S D=11.35)$ was significantly larger than the average server-based VMT $(M=8.66, S D=11.35), t(569)=-11.83, p<.001$. Because the server-based VMT data is incomplete and statistically different than GPS- 
Table 4

Summary GPS- and Server-Based Data Points

\begin{tabular}{cccc}
\hline $\begin{array}{c}\text { Participant } \\
\text { ID }\end{array}$ & GPS data points & Server data points & $\begin{array}{c}\text { Percentage of total GPS } \\
\text { data points recorded on } \\
\text { the server }\end{array}$ \\
\hline 1 & 2,592 & 1,771 & 68 \\
2 & 2,089 & 1,348 & 65 \\
3 & 4,463 & 1,905 & 43 \\
4 & 4,717 & 2,228 & 47 \\
5 & 4,701 & 2,246 & 48 \\
6 & 4,507 & 2,539 & 56 \\
7 & 7,573 & 3,170 & 42 \\
8 & 6,599 & 4,146 & 63 \\
9 & 2,026 & 944 & 47 \\
10 & 3,225 & 1,677 & 52 \\
Total & 42,492 & 21,974 & 52 \\
\hline
\end{tabular}

based VMT data, the data were split into two separate data files for the data analysis: (a) GPS-based VMT and (b) server-based VMT. The GPS-based VMT were the VMT data that were recorded and saved on the onboard GPS device. The server-based VMT data were the VMT data that were recorded by the onboard GPS device on the offsite server.

The missing data issue was particular problematic with the baseline stage data. All but one onboard GPS device overwrote over the baseline stage data during the intervention stage data collection period. Consequently, there is no way to compare server-based VMT with GPS-based VMT data for the baseline stage to determine the amount of VMT data is missing. Based on the analysis of the intervention and return-tobaseline VMT data on both the server and GPS, it is safe to assume that some data lose occurred during the baseline stage but there is no way verifying this. Consequently, the 
server-based VMT averages may be underestimates of the participant's true daily VMT averages. Caution must be used interpreting the results of this study.

\section{Data Analysis}

\section{Study Variables}

Dependent variables. The primary outcome variable was vehicle miles of travel.

VMT was defined as the number of miles that the person drives during a specified period of time with their personal vehicle. VMT is the most commonly studied driving behavior in driving reduction research.

Independent variables. The primary independent variable was the delivery of prizes within the prize-based contingency management system (intermediate schedule of reinforcement). Each participant had the opportunity to win prizes (from $\$ 1$ to $\$ 250$ in value) from the prize bowl on daily basis.

Other measured variables. Other variables that were measured include the participants' past driving behavior, sociodemographic descriptors, environmental perceptions, daily average gas price, the current weather conditions (e.g., snowing), temperature, daily atmospheric particulate matter levels (PM 2.5), fishbowl drawing date, and color-coded alert on poor air days.

Demographic characteristics of sample. The data from the pre- and postintervention questionnaires and in-car GPS tracking device were entered into Excel. The preintervention questionnaire data were used to determine eligibility in baseline stage of this research project. Descriptive statistics were first calculated for demographic 
characteristics and political affiliation variables for both the preintervention questionnaire participants and for the ten participants in the final enrolled sample. The average serverbased, GPS-based, and adjusted VMT from the baseline, intervention, and return-tobaseline stage of the project are represented graphically for each of the 10 participants in Figures 1-22. The data analytic strategy for each research question is described below.

\section{Analysis Procedures for the Research Questions}

1. Are vehicle miles of travel sensitive to a prize-based contingency management intervention to reduce mileage?

Average server-based VMT for the baseline period (weeks 1 to 3) was compared to average server-based VMT during the 8-week intervention (weeks 4 to 11 ) and the 3week return-to-baseline periods (weeks 12 to 14) using a repeated-measures ANOVA. Paired-samples $t$ tests were used to follow-up significant main effects for each study period comparison. Due to lack of reliable and consistent data from the Baseline stage of GPS-based VMT recordings, a paired-samples $t$ test was conducted to compare average GPS-based VMT between the 8-week intervention (weeks 4 to 11) and the 3-week return-to-baseline periods (weeks 12 to 14 ) only.

2. As a result of the prize-based contingency management intervention, does the average vehicle miles of travel increase, decrease, or remain the same when compared to average vehicle miles of travel collected during the baseline data collection period?

Line plots of both weekly and stage (baseline, intervention, return-to-baseline) means and medians were created to visualize the direction of change for each participant. 
3. Is there an interaction effect between the prize-based contingency management system and the 'Choose Clean Air' social marketing campaign on driving reductions?

A series of multilevel models (mixed-effect models) were computed with serverand GPS-based VMT as the repeated-measures outcomes and each of the following five environmental or contextual variables as repeated-measures predictors: PM 2.5 concentration level, color of the air alert, weather (e.g., sunny, cloudy, rainy, foggy, snow), gasoline prices, temperature. Data from each stage of the 14-week study were used in these analyses to capture the day-to-day variation in both driving behavior and the environmental and contextual variables. This analysis strategy was selected to account for repeated-measurements of both outcomes and predictors within participants. To determine the best-fitting, most parsimonious statistical models, several test models were conducted, compared, and evaluated. A visual inspection (line plots) of the average VMT for each stage was also conducted. 


\section{CHAPTER IV}

\section{RESULTS}

\section{Sample Demographics}

\section{Preintervention Questionnaire}

Table 5 includes the demographic information for all of the participants of the preintervention questionnaire (driving behavior) and the 10 screened intervention participants. Age was measured as a continuous variable and was not included in the table. The mean age for the questionnaire participants, $M=32.98(S D=14.84$; range: 18 to 73$)$ and the screened participants, $M=32.10(S D=14.49$; range: 20 to 55$)$. All participants reported fluency in the English language. Table 6 includes the political information for the all of the questionnaire and screened participants.

The Preintervention Questionnaire also included vehicle miles travel estimations and other vehicle-related items. All 56 participants owned a valid driver's license. Fortyseven of 56 participants reported using their personal vehicle as their primary source of transportation with five others using some combination of their personal vehicle and another mode of transportation, and four others who reported walking as their primary mode. Of the screened participants, 9 of the 10 reported using their personal vehicle as their primary mode of transportations. The last screened participant reported using a combination of personal vehicle and bicycle as their primary modes of transit. Fifty-one of the participants reported owning or leasing a car. Only four participants reported not owning a personal vehicle. All 10 screened participants reported owning a vehicle. 
Table 5

Demographic Information for Preintervention Questionnaire and Screened Sample

\begin{tabular}{|c|c|c|c|c|c|}
\hline \multirow[b]{2}{*}{ Demographics } & \multirow[b]{2}{*}{ Response } & \multicolumn{2}{|c|}{ All participants } & \multicolumn{2}{|c|}{ Screened } \\
\hline & & $n$ & $\%$ & $n$ & $\%$ \\
\hline \multicolumn{6}{|l|}{ Sex } \\
\hline & Male & 28 & 50.00 & 6 & 60.00 \\
\hline & Female & 28 & 50.00 & 4 & 30.00 \\
\hline \multicolumn{6}{|c|}{$\begin{array}{l}\text { Permanent resident of } \\
\text { cache county }\end{array}$} \\
\hline & Yes & 40 & 71.00 & 5 & 50.00 \\
\hline & No & 16 & 29.00 & 5 & 50.00 \\
\hline \multicolumn{6}{|l|}{ Marital status } \\
\hline & Married & 29 & 51.79 & 5 & 50.00 \\
\hline & Single & 23 & 41.07 & 3 & 30.00 \\
\hline & Divorced & 4 & 7.14 & 2 & 20.00 \\
\hline & Widowed & 0 & 0.00 & 0 & 0.00 \\
\hline \multicolumn{6}{|c|}{ Own or rent home } \\
\hline & Own & 21 & 37.50 & 5 & 50 \\
\hline & Rent & 34 & 60.71 & 5 & 50 \\
\hline & No response given & 1 & 1.79 & 0 & 0 \\
\hline \multicolumn{6}{|c|}{ Household income range } \\
\hline & Under $\$ 10,000$ & 18 & 32.14 & 0 & 0.00 \\
\hline & $\$ 10,001$ to $\$ 20,000$ & 9 & 16.07 & 2 & 20.00 \\
\hline & $\$ 20,001$ to $\$ 30,000$ & 10 & 17.86 & 5 & 50.00 \\
\hline & $\$ 30,001$ to $\$ 40,000$ & 1 & 1.79 & 2 & 20.00 \\
\hline & $\$ 40,001$ to $\$ 50,000$ & 2 & 3.57 & 0 & 0.00 \\
\hline & $\$ 50,001$ to $\$ 60,000$ & 5 & 8.93 & 0 & 0.00 \\
\hline & $\$ 60,001$ to $\$ 70,000$ & 4 & 7.14 & 0 & 0.00 \\
\hline & $\$ 70,001$ to $\$ 80,000$ & 5 & 8.93 & 1 & 10.00 \\
\hline & $\$ 80,001$ to $\$ 90,000$ & 0 & 0.00 & 0 & 0.00 \\
\hline & $\$ 90,001$ to $\$ 100,000$ & 1 & 1.79 & 0 & 0.00 \\
\hline & Over $\$ 100,001 \$ 110,000$ & 0 & 0.00 & 0 & 0.00 \\
\hline & No response given & 1 & 1.79 & 0 & 0.00 \\
\hline
\end{tabular}


Table 6

Political Summary for Preintervention Questionnaire and Screened Sample

\begin{tabular}{|c|c|c|c|c|c|}
\hline \multirow[b]{2}{*}{ Demographic } & \multirow[b]{2}{*}{ Response } & \multicolumn{2}{|c|}{ All participants } & \multicolumn{2}{|c|}{ Screened } \\
\hline & & $n$ & $\%$ & $n$ & $\%$ \\
\hline \multicolumn{6}{|c|}{ Political orientation } \\
\hline & Republican & 25 & 44.64 & 3 & 30.00 \\
\hline & Democrat & 9 & 16.07 & 1 & 10.00 \\
\hline & Independent & 10 & 17.86 & 3 & 30.00 \\
\hline & Other & 11 & 19.64 & 2 & 20.00 \\
\hline & No response given & 1 & 1.79 & 1 & 10.00 \\
\hline \multicolumn{6}{|l|}{ Political views } \\
\hline & Conservative & 27 & 48.21 & 5 & 50.00 \\
\hline & Moderate & 18 & 32.14 & 4 & 40.00 \\
\hline & Liberal & 7 & 12.50 & 1 & 10.00 \\
\hline & Other & 4 & 7.14 & 0 & 0.00 \\
\hline
\end{tabular}

Thirty-three people reported owning one vehicle, 13 with two vehicles, 3 with three vehicles, 2 with four vehicles, 1 with no vehicles, and 3 participants did not respond to the question. All 10 screened participants reported owning just one vehicle.

Participants of the Preintervention Questionnaire were also asked to estimate their daily vehicle miles of travel. Table 7 includes the descriptive data for their VMT estimates.

A repeated-measures ANOVA was conducted on the miles a day, miles on Saturday, and miles on Sunday data to determine differences. The assumption of sphericity was violated, Mauchley's Test: $\chi^{2}(2)=12.66, p<.01$. Consequently, the degrees of freedom were corrected using Greenhouse-Geisser estimates of sphericity 
Table 7

VMT Estimates for Preintervention Questionnaire and Screened Sample

\begin{tabular}{lrrrrrrrr}
\hline & \multicolumn{3}{c}{ All participants } & & \multicolumn{3}{c}{ Screened } \\
\cline { 2 - 4 } \cline { 6 - 8 } Source & $n$ & \multicolumn{1}{c}{$M$} & \multicolumn{1}{c}{$S D$} & & $n$ & \multicolumn{1}{c}{$M$} & \multicolumn{1}{c}{$S D$} \\
\hline Commute & 52 & 11.58 & 22.71 & & 10 & 8.75 & 6.42 \\
Miles a day & 56 & 14.83 & 13.57 & & 10 & 12.10 & 9.51 \\
Miles a week & 56 & 105.89 & 88.68 & & 10 & 94.85 & 71.24 \\
Miles a year & 53 & 9883.40 & 6577.23 & & 10 & 11600.00 & 5394.44 \\
Miles on Saturday & 56 & 32.05 & 44.84 & & 10 & 60.70 & 89.10 \\
Miles on Sunday & 55 & 16.75 & 28.27 & & 10 & 14.60 & 18.13 \\
\hline
\end{tabular}

$(\varepsilon=.83)$. The results of the repeated-measures ANOVA indicate that the estimated vehicle miles travel differs by day of the week, $F(1.65,89.07)=5.57, p<.01$. Pairedsamples $t$ tests were also conducted and suggest that the participants' Saturday VMT is significantly larger than both their Sunday VMT, $t(54)=-2.38, p<.05$; and weekday VMT, $t(55)=2.77, p<.01$. Sunday VMT was not significantly larger than weekday VMT, $t(54)=.52, p=.607$.

Environmental perception questionnaire items. Descriptive statistics were calculated for each questionnaire item in the Environmental Perception portion of the Pre-intervention questionnaire. Participants were asked to indicate the extent to which they agreed or disagreed with a number of environmental statements using a scale that ranged from, 1- Strongly Disagree to 9 -Strongly Agree. Table 8 includes a summary of the descriptive statistic for the Environmental Perception questionnaire items. The environmental statements with the highest levels of agreement were "Reducing the mileage of our personal vehicles will improve air quality in Cache Valley" $(M=7.04)$, 
Table 8

Descriptive Statistics for the Environmental Perception Questionnaire Items for the

Preintervention Questionnaire and Screened Sample

\begin{tabular}{|c|c|c|c|c|c|c|}
\hline \multirow[b]{2}{*}{ Statement } & \multicolumn{3}{|c|}{ All participants } & \multicolumn{3}{|c|}{ Screened } \\
\hline & $n$ & $M$ & $S D$ & $n$ & $M$ & $S D$ \\
\hline Air pollution is a problem in Cache Valley. & 56 & 6.50 & 1.94 & 10 & 7.30 & 1.57 \\
\hline $\begin{array}{l}\text { Air pollution is only a problem in Cache Valley during the } \\
\text { winter. }\end{array}$ & 56 & 5.21 & 2.15 & 10 & 3.50 & 1.78 \\
\hline I am doing my part to reduce air pollution in Cache Valley. & 56 & 5.64 & 1.81 & 10 & 6.20 & 1.48 \\
\hline $\begin{array}{l}\text { Personal vehicles are the main cause of air pollution in } \\
\text { Cache Valley. }\end{array}$ & 56 & 5.93 & 1.55 & 10 & 5.70 & 1.70 \\
\hline $\begin{array}{l}\text { Reducing the mileage of our personal vehicles will improve } \\
\text { air quality in Cache Valley. }\end{array}$ & 56 & 7.04 & 1.63 & 10 & 7.80 & 1.40 \\
\hline $\begin{array}{l}\text { I try to reduce my driving during the winter inversion in } \\
\text { Cache Valley to improve air quality. }\end{array}$ & 56 & 5.77 & 2.06 & 10 & 5.90 & 2.42 \\
\hline I use public transit often & 56 & 3.02 & 1.98 & 10 & 3.60 & 2.22 \\
\hline I consider myself an environmentally concerned individual. & 56 & 6.00 & 1.69 & 10 & 6.10 & 1.91 \\
\hline
\end{tabular}

"Air pollution is a problem in Cache Valley" $(M=6.50)$, and "I consider myself an environmentally concerned individual" $(M=6.00)$. The environmental statement with the lowest levels of agreement was "I use public transit often" $(M=3.02)$.

In effort to determine eligibility in the baseline stage of this research project, an overall environmental perception score was calculated. To determine the questionnaire participants' overall environmental perception score, the response values from each of the eight environmental statements were totaled for each participant. Because all of the environmental statements represented positive environmental attitudes and perceptions, a high overall environmental perception score meant that the participants viewed themselves as environmentally conscious person. A low overall environmental perception score may mean the opposite. The participant's overall environmental perception scores 
were totaled. The average environmental score was 45.11 with a standard deviation of 7.75. Only one participant was excluded from the pool of participants eligible for the Baseline stage of the project because their overall environmental perception score did not fall within -2 to 2 standard deviations from the mean.

\section{Results from the Research Question 1 and 2}

1. Are vehicle miles of travel sensitive to a prize-based contingency management intervention to reduce mileage?

2. As a result of the prize-based contingency management intervention, does the average vehicle miles of travel increase, decrease, or remain the same when compared to average vehicle miles of travel collected during the baseline data collection period?

The descriptive statistics were conducted for each stage of intervention for both the server-based, GPS-based, and adjusted vehicle miles of travel and listed in Table 9. Table 10 includes the weekly VMT data. The adjusted VMT stage estimates were

Table 9

Descriptive Statistics for the Server-and GPS-Based Vehicle Miles of Travel by the Stage of the Intervention for Screened Sample

\begin{tabular}{lllrrrc}
\hline Source & \multicolumn{1}{c}{ Stage } & Weeks & \multicolumn{1}{c}{$n$} & VMT Mean & VMT Median & $S D$ \\
\hline Server & Baseline & 1 to 3 & 210 & 15.66 & 12.97 & 12.55 \\
& Intervention & 4 to 11 & 539 & 8.19 & 5.35 & 10.27 \\
& Return-to-baseline & 12 to 14 & 208 & 9.77 & 6.86 & 11.25 \\
GPS & Baseline & 1 to 3 & 17 & 19.72 & 18.83 & 16.31 \\
& Intervention & 4 to 11 & 359 & 10.78 & 7.98 & 11.79 \\
& Return-to-baseline & 12 to 14 & 194 & 13.99 & 10.71 & 12.77 \\
Adjusted & Baseline & 1 to 3 & N/A & 19.18 & N/A & N/A \\
& Intervention & 4 to 11 & N/A & 11.71 & N/A & N/A \\
& Return-to-baseline & 12 to 14 & N/A & 13.29 & N/A & N/A \\
\hline
\end{tabular}


Table 10

Descriptive Statistics for the Server-Based, GPS-Based, and Adjusted VMT by Week of the Intervention for Screened Sample

\begin{tabular}{|c|c|c|c|c|c|c|}
\hline Source & Stage & Week & $n$ & VMT Mean & VMT Median & $S D$ \\
\hline Server & Baseline & 1 & 70 & 14.29 & 12.67 & 10.03 \\
\hline Server & Baseline & 2 & 70 & 15.45 & 11.82 & 13.62 \\
\hline Server & Baseline & 3 & 70 & 17.23 & 16.41 & 13.65 \\
\hline Server & Intervention & 4 & 65 & 8.56 & 4.15 & 12.08 \\
\hline Server & Intervention & 5 & 63 & 7.66 & 2.95 & 11.42 \\
\hline Server & Intervention & 6 & 70 & 7.79 & 6.59 & 8.66 \\
\hline Server & Intervention & 7 & 70 & 8.63 & 8.55 & 7.23 \\
\hline Server & Intervention & 8 & 66 & 10.29 & 8.03 & 11.30 \\
\hline Server & Intervention & 9 & 65 & 7.43 & 3.55 & 9.81 \\
\hline Server & Intervention & 10 & 70 & 7.68 & 5.75 & 8.98 \\
\hline Server & Intervention & 11 & 70 & 7.52 & 3.41 & 12.08 \\
\hline Server & Return-to-baseline & 12 & 70 & 9.75 & 4.70 & 13.43 \\
\hline Server & Return-to-baseline & 13 & 70 & 10.14 & 9.73 & 10.31 \\
\hline Server & Return-to-baseline & 14 & 68 & 9.39 & 6.32 & 9.78 \\
\hline GPS & Baseline & 1 & 3 & 15.70 & 18.83 & 7.26 \\
\hline GPS & Baseline & 2 & 7 & 19.20 & 17.00 & 19.89 \\
\hline GPS & Baseline & 3 & 7 & 21.95 & 21.03 & 16.81 \\
\hline GPS & Intervention & 4 & 41 & 13.26 & 8.64 & 15.91 \\
\hline GPS & Intervention & 5 & 48 & 11.67 & 6.28 & 15.67 \\
\hline GPS & Intervention & 6 & 49 & 9.04 & 8.34 & 6.82 \\
\hline GPS & Intervention & 7 & 53 & 9.76 & 8.27 & 7.69 \\
\hline GPS & Intervention & 8 & 39 & 12.01 & 8.49 & 12.62 \\
\hline GPS & Intervention & 9 & 30 & 9.55 & 5.16 & 12.04 \\
\hline GPS & Intervention & 10 & 47 & 9.76 & 8.09 & 8.93 \\
\hline GPS & Intervention & 11 & 52 & 11.37 & 7.67 & 12.69 \\
\hline GPS & Return-to-baseline & 12 & 63 & 12.14 & 7.75 & 13.85 \\
\hline GPS & Return-to-baseline & 13 & 63 & 15.45 & 13.65 & 13.10 \\
\hline GPS & Return-to-baseline & 14 & 68 & 14.35 & 11.48 & 11.30 \\
\hline Adjusted & Baseline & 1 & N/A & 17.81 & N/A & N/A \\
\hline Adjusted & Baseline & 2 & N/A & 18.97 & N/A & N/A \\
\hline
\end{tabular}




\begin{tabular}{llccccc}
\hline Source & \multicolumn{1}{c}{ Stage } & Week & $n$ & VMT Mean & VMT Median & SD \\
\hline Adjusted & Baseline & 3 & N/A & 20.75 & N/A & N/A \\
Adjusted & Intervention & 4 & N/A & 12.08 & N/A & N/A \\
Adjusted & Intervention & 5 & N/A & 11.18 & N/A & N/A \\
Adjusted & Intervention & 6 & N/A & 11.31 & N/A & N/A \\
Adjusted & Intervention & 7 & N/A & 12.15 & N/A & N/A \\
Adjusted & Intervention & 8 & N/A & 13.81 & N/A & N/A \\
Adjusted & Intervention & 9 & N/A & 10.95 & N/A & N/A \\
Adjusted & Intervention & 10 & N/A & 11.20 & N/A & N/A \\
Adjusted & Intervention & 11 & N/A & 11.04 & N/A & N/A \\
Adjusted & Return-to-baseline & 12 & N/A & 13.27 & N/A & N/A \\
Adjusted & Return-to-baseline & 13 & N/A & 13.66 & N/A & N/A \\
Adjusted & Return-to-baseline & 14 & N/A & 12.91 & N/A & N/A \\
\hline
\end{tabular}

calculated to account for the differences between the server-based and GPS-based VMT. The average stage VMT for the adjusted estimate was calculated by conducting a pairedsample $t$ test. The baseline stage did not have an adequate number of matched pairs so it was not included in the adjustment procedure. The results indicate that the average VMT for the GPS-based VMT data were significantly larger than server-based VMT in both the intervention stage, $t(358)=-9.33, p<.001$; server-based VMT average $=7.84$ and GPS-based VMT average $=10.78$; difference: 2.94 , and return-to-baseline stage, $t(193)$ $=-6.83, p<.001 ;$ server-based VMT average $=9.80$ and GPS-based VMT average $=$ 13.99; difference: 4.10. To calculate the adjusted average stage VMT, the differences between the server-based and GPS-based VMT from both the intervention and return-tobaseline stages were added $(2.94+4.10=7.04)$ and divided by two $(7.04 / 2=3.52)$ then added to the server-based VMT totals for each stage. This process was repeated for the weekly averages. Additionally, line plots have been included for each the server-based, GPS-based, and the adjusted VMT data (see Figures 1 and 2). 


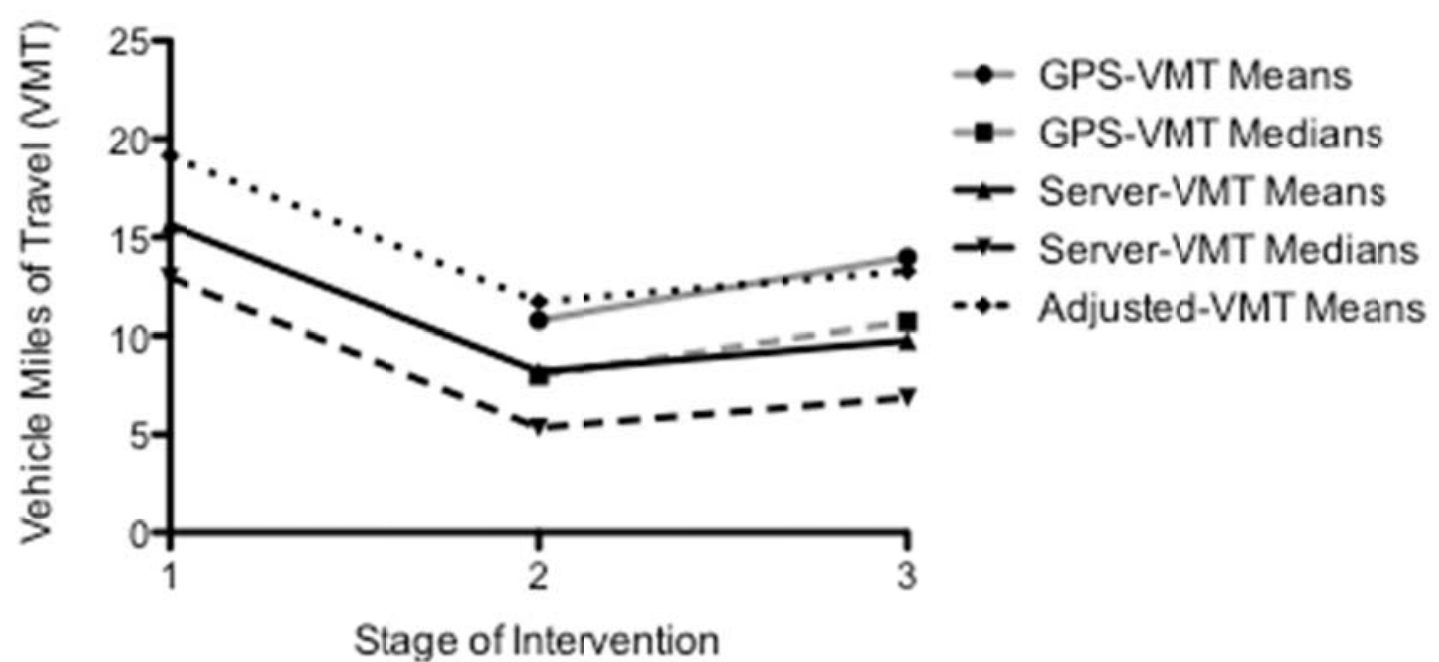

Figure 1. Stage VMT means and medians for the screened participants.

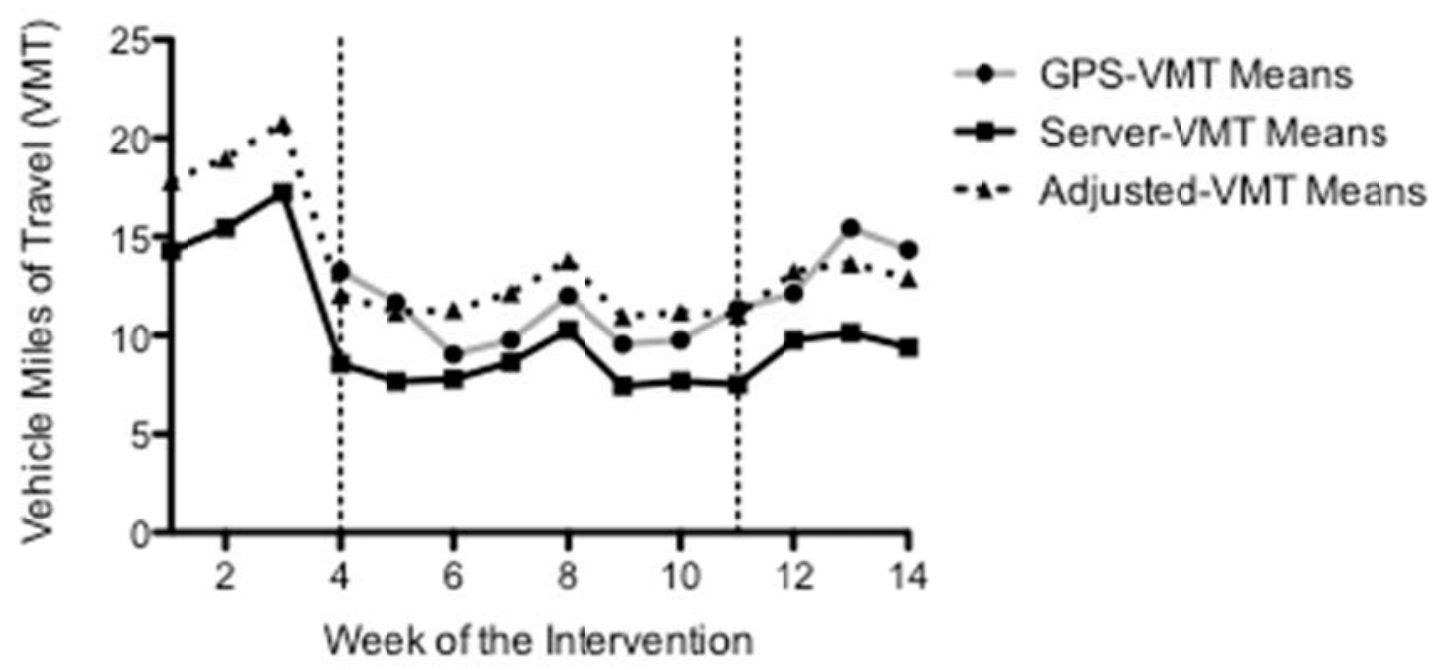

Figure 2. Weekly VMT means and medians for the screened participants. 
A repeated-measures ANOVA was conducted to determine differences between average server-based VMT during the baseline, intervention, and return-to-baseline stages of the study. The Mauchly's test of sphericity indicated that the assumption sphericity had not been violated, $\chi^{2}(2)=2.40, p=.301$. Results indicate a treatment effect, the average server-based VMT significantly differed at each stage of the intervention: $F(2,414)=41, p<.001, \eta=.165$. Paired-samples $t$ tests were conducted to follow-up on this significant main effect. It was found that the average server-based VMT for the baseline stage $(M=15.66)$ was significantly larger than both the intervention stage $(M=8.19): t(209)=8.96, p<.001$ and return-to-baseline stage $(M=9.77): t(207)=$ $5.38, p<.001$, respectively. The average server-based VMT for the intervention stage was significantly different from the average server-based VMT for the return-to-baseline stage: $t(207)=-3.48, p<.001$. The effect sizes were calculated using Cohen's $d$ for the Baseline and Intervention stages, $d=.66$ and the Baseline and Return-to-baseline stages, $d=.52$.

A paired-samples $t$ test was conducted on the average GPS-based VMT for the intervention and return-to-baseline stage. It was found that GPS-based VMT for the intervention stage was significantly smaller than the average GPS-based VMT for the return-to-baseline stage, $t(132)=-5.78, p<.001$.

For each participant, a repeated-measures ANOVA was conducted to determine the differences between average server-based VMT during the baseline, intervention, and return-to-baseline stages of the study. Paired-samples $t$ tests were used to follow-up significant main effects for study period. When possible, paired-samples $t$ tests were also 
conducted on the average GPS-based VMT for the baseline, intervention, and return-tobaseline stages.

\section{Baseline Stage}

An additional analysis was conducted on the server-based VMT data to determine possible differences between to two groups. Group 1 included the daily VMT data for the

6 participants that had their data baseline data recorded from November 6 to December 4 , 2010. Group 2 included the daily VMT data for the 4 participants that had their baseline data recorded from December 5 to December 31, 2010. The mean for Group 1 was 15.33 with standard deviation of 11.30. The mean for Group 2 was 16.14 with a standard deviation of 14.27. An independent-sample $t$ test was conducted and revealed that the daily VMT means for Group 1 and Group 2 were not statistically different from each other, $t(208)=-.454, p=.650$.

\section{Participant 1}

For Participant 1, the results of the repeated-measures ANOVA indicate that the average server-based VMT differed by stage, $F(2,40)=15.61, p<.001, \eta=.438$; Mauchly's test of sphericity: $\chi^{2}(2)=.96, p=.618$. Paired-samples $t$ tests were conducted to follow-up on this significant main effect. It was found that the average server-based VMT for the baseline stage $(M=19.57, S D=7.59)$ was significantly larger than both the intervention stage, $M=9.52, S D=6.85): t(20)=4.48, p<.001$, and return-to-baseline stage, $M=6.80, S D=7.06): t(20)=4.80, p<.001$, respectively. The average serverbased VMT for the intervention was not significantly different from the average server- 
based VMT for the return-to-baseline stage: $t(20)=-1.18, p=.251$. The effect sizes were calculated using Cohen's $d$ for the server-based VMT for baseline and Intervention stage, $d=1.07$ and the baseline and return-to-baseline stages, $d=1.42$.

The paired-samples $t$ test was not conducted for the average GPS-based VMT for the intervention and return-to-baseline stages because of the lack of valid pairs. Table 11 includes the descriptive statistics for the server- and GPS-based VMT for Participant 1. Additionally, line plots of stage and weekly means and medians have been included for Participant 1 for both the server-based and GPS-based VMT data (see Figures 3 and 4).

\section{Participant 2}

For Participant 2, the results of the repeated-measures ANOVA show that the average server-based VMT did not differ by stage (baseline: $M=9.22, S D=9.32$; intervention: $M=6.57, S D=7.00$; return-to-baseline: $M=6.80, S D=7.06), F(2,40)=$ $.76, p=.473, \eta=.037$; Mauchly's test of sphericity: $\chi^{2}(2)=3.36, p=.186$. The effect sizes were calculated using Cohen's $d$ for the serve-based VMT baseline and intervention stage, $d=.38$ and the baseline and return-to-baseline stages, $d=.32$.

\section{Table 11}

Descriptive Statistics for the Server-and GPS-Based VMT for Participant 1

\begin{tabular}{llccc}
\hline \multicolumn{1}{c}{ Source } & \multicolumn{1}{c}{ Stage } & $n$ & $M$ & $S D$ \\
\hline Server & Baseline & 21 & 19.57 & 7.59 \\
Server & Intervention & 56 & 9.93 & 8.27 \\
Server & Return-to-baseline & 21 & 6.80 & 7.06 \\
GPS & Baseline & 0 & N/A & N/A \\
GPS & Intervention & 7 & 16.93 & 8.99 \\
GPS & Return-to-baseline & 21 & 9.39 & 9.16 \\
\hline
\end{tabular}




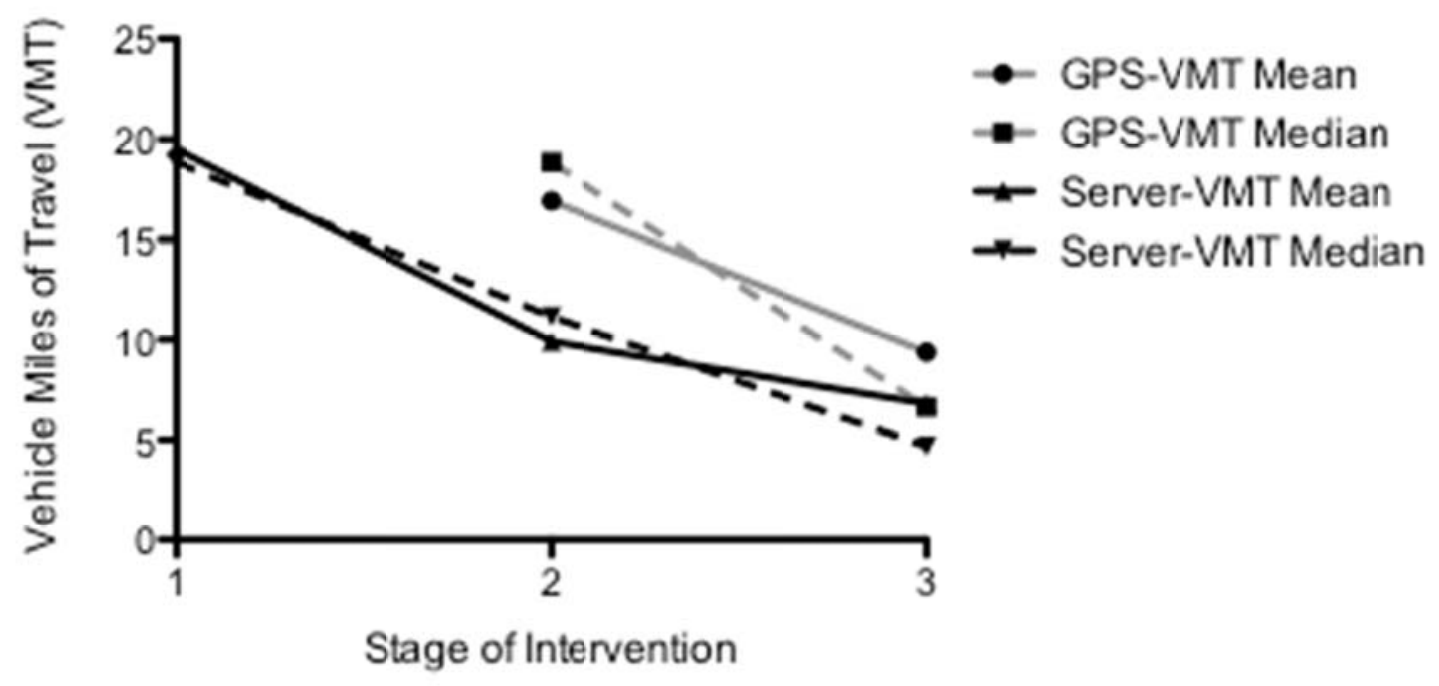

Figure 3. Stage means and medians for Participant 1.

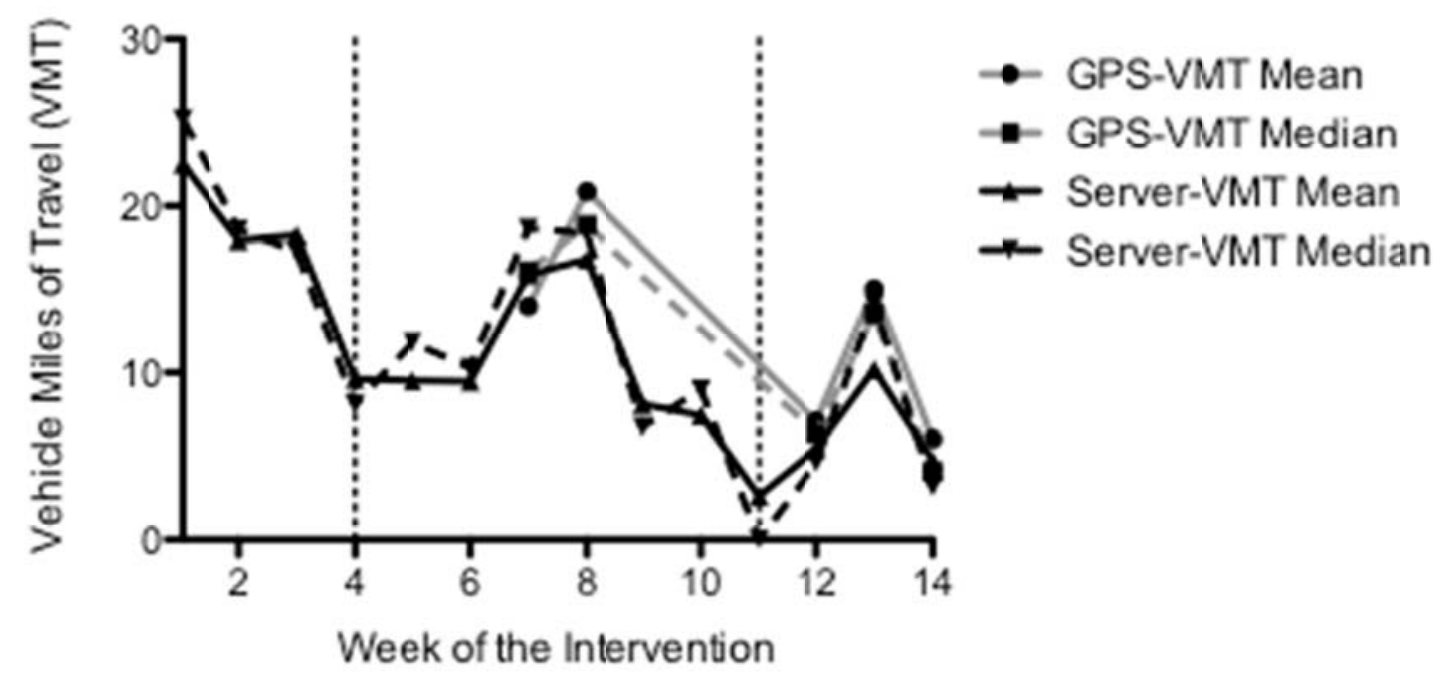

Figure 4. Weekly means and medians for Participant 1. 
A paired-samples $t$ test was conducted on the average GPS-based VMT and the results show no statistical difference between the intervention $(M=7.78, S D=7.52)$ and return-to-baseline $(M=9.39, S D=9.16)$ stages, $t(20)=.556, p=.585$. Table 12 includes the descriptive statistics for the server- and GPS-based VMT for participant 2.

Additionally, line plots of stage and weekly means and medians have been included for participant 2 for both the server-based and GPS-based VMT data (see Figure 5 and 6).

\section{Table 12}

Descriptive Statistics for the Server-and GPS-Based VMT for Participant 2

\begin{tabular}{llccc}
\hline \multicolumn{1}{c}{ Source } & \multicolumn{1}{c}{ Stage } & $n$ & $M$ & $S D$ \\
\hline Server & Baseline & 21 & 9.22 & 9.32 \\
Server & Intervention & 56 & 6.37 & 7.06 \\
Server & Return-to-baseline & 21 & 6.80 & 7.06 \\
GPS & Baseline & 0 & N/A & N/A \\
GPS & Intervention & 56 & 7.11 & 7.29 \\
GPS & Return-to-baseline & 21 & 9.39 & 9.16 \\
\hline
\end{tabular}

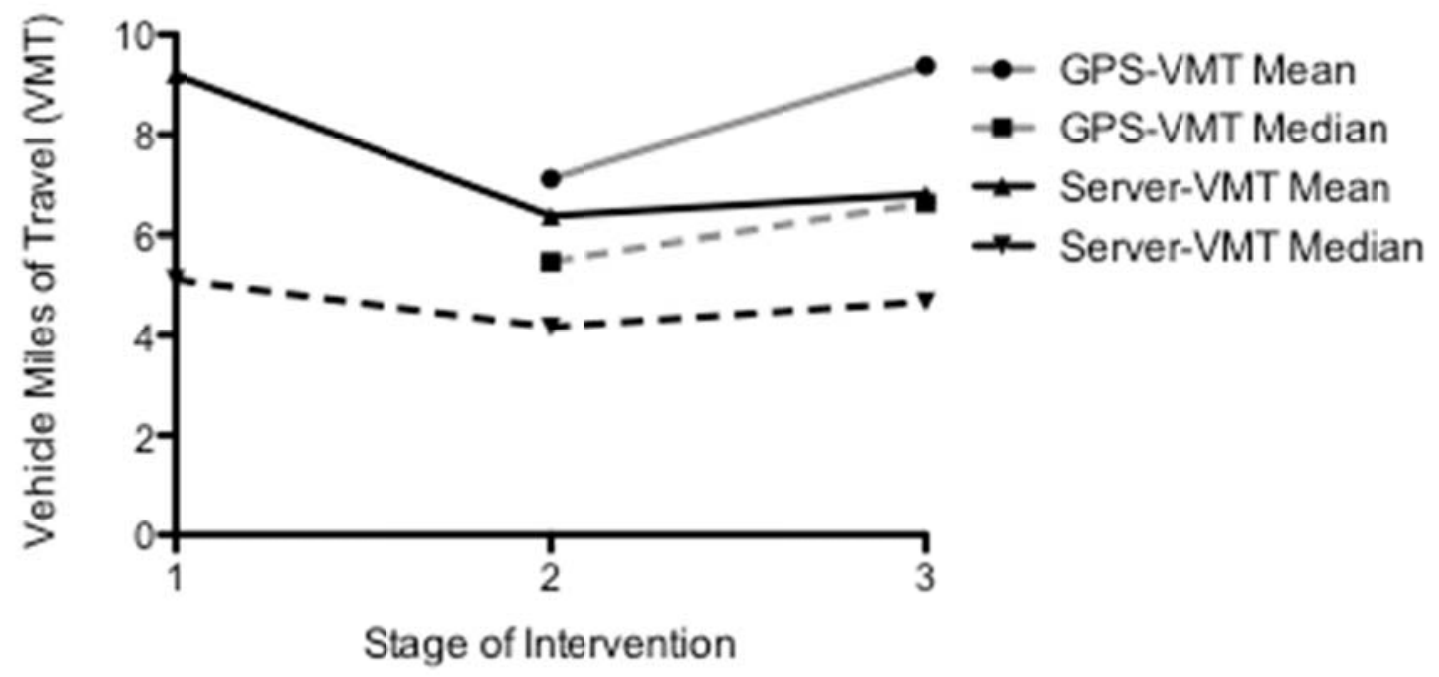

Figure 5. Stage means and medians for Participant 2. 


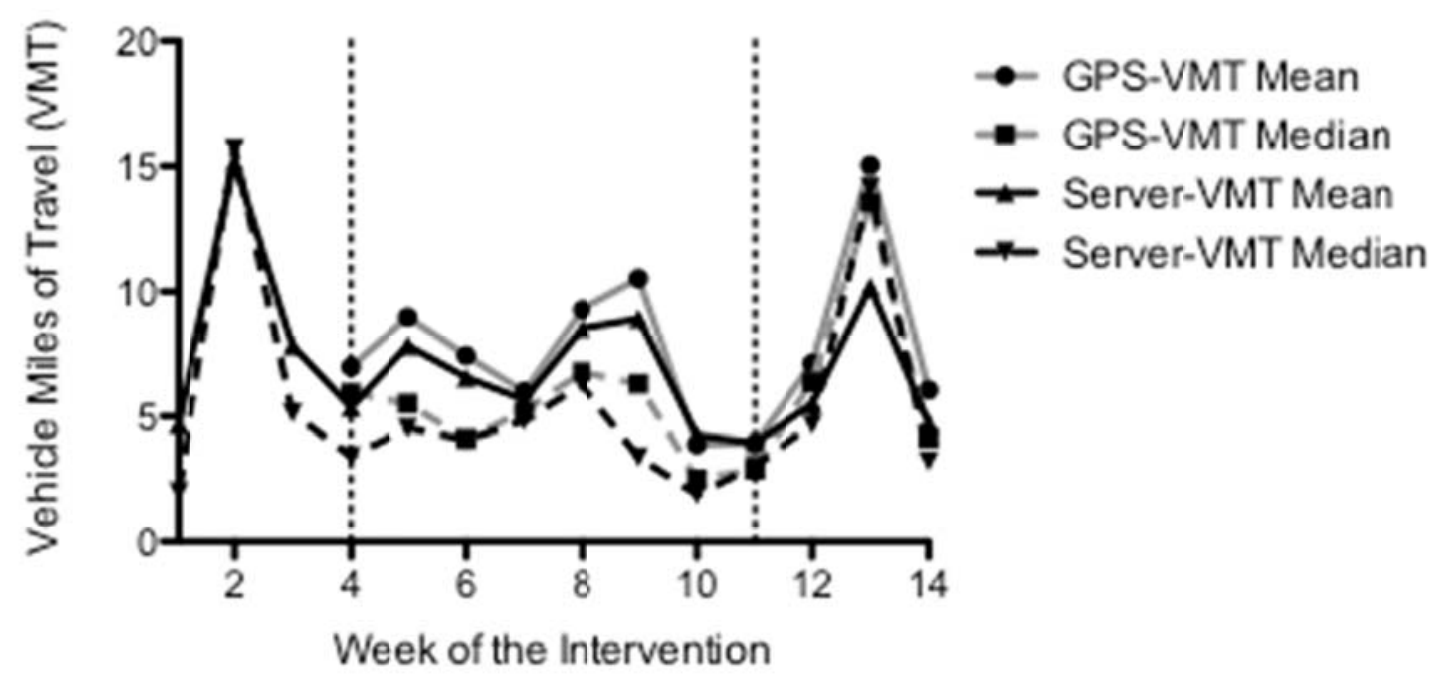

Figure 6. Weekly means and median for Participant 2.

\section{Participant 3}

For Participant 3, the results of Mauchly's test of sphericity indicated a violation of the assumption of sphericity, $\chi^{2}(2)=7.16, p=.028$. For this reason, the degrees of freedom were corrected using Greenhouse-Geisser estimates of sphericity $(\varepsilon=.76)$. The results of the repeated-measures ANOVA show that average server-based VMT differed by stage, $F(1.52,30.44)=6.30, p<.01, \eta=.240$. Paired-samples $t$ tests were conducted to follow-up on this significant main effect. The results of these tests found that the average server-based VMT for the baseline stage $(M=11.20, S D=7.54)$ was significantly larger than both the intervention stage $(M=2.59, S D=5.52): t(20)=4.52, p$ $<.001$ and return-to-baseline stage $(M=6.51, S D=10.85): t(20)=1.55, p=.136$, respectively. The average server-based VMT for the intervention was not significantly different from the average server-based VMT for the return-to-baseline stage: $t(20)$ $=-1.76, p=.094$. The effect sizes were calculated using Cohen's $d$ for the server-based 
VMT for baseline and intervention stage, $d=.79$ and the baseline and return-to-baseline stages, $d=.50$.

Additionally, the results of the paired-samples $t$ test for the average GPS-based VMT for the intervention stage $(M=3.87, S D=5.96)$ was significantly smaller than the average GPS-based VMT for the return-to-baseline stage $(M=9.84, S D=10.33), t(19)=$ 3.11, $p<.01$. Table 13 includes the descriptive statistics for the server- and GPS-based VMT for participant 3. Additionally, line plots of stage and weekly means and medians have been included for Participant 3 for both the server-based and GPS-based VMT data (see Figures 7 and 8).

\section{Participant 4}

For Participant 4, the results of the Mauchly's test of sphericity indicated a violation of the assumption of sphericity, $\chi^{2}(2)=6.78, p=.034$. Consequently, the degrees of freedom were corrected using Greenhouse-Geisser estimates of sphericity $(\varepsilon=$ .77). The results show that the average server-based VMT differed by stage, $F(1.54$,

Table 13

Descriptive Statistics for the Server-and GPS-Based VMT for Participant 3

\begin{tabular}{llrcr}
\hline \multicolumn{1}{c}{ Source } & \multicolumn{1}{c}{ Stage } & $n$ & \multicolumn{1}{c}{$M$} & \multicolumn{1}{c}{$S D$} \\
\hline Server & Baseline & 21 & 11.20 & 7.54 \\
Server & Intervention & 56 & 3.76 & 8.77 \\
Server & Return-to-baseline & 21 & 6.51 & 10.85 \\
GPS & Baseline & 0 & N/A & N/A \\
GPS & Intervention & 55 & 5.45 & 8.87 \\
GPS & Return-to-baseline & 21 & 9.37 & 10.29 \\
\hline
\end{tabular}




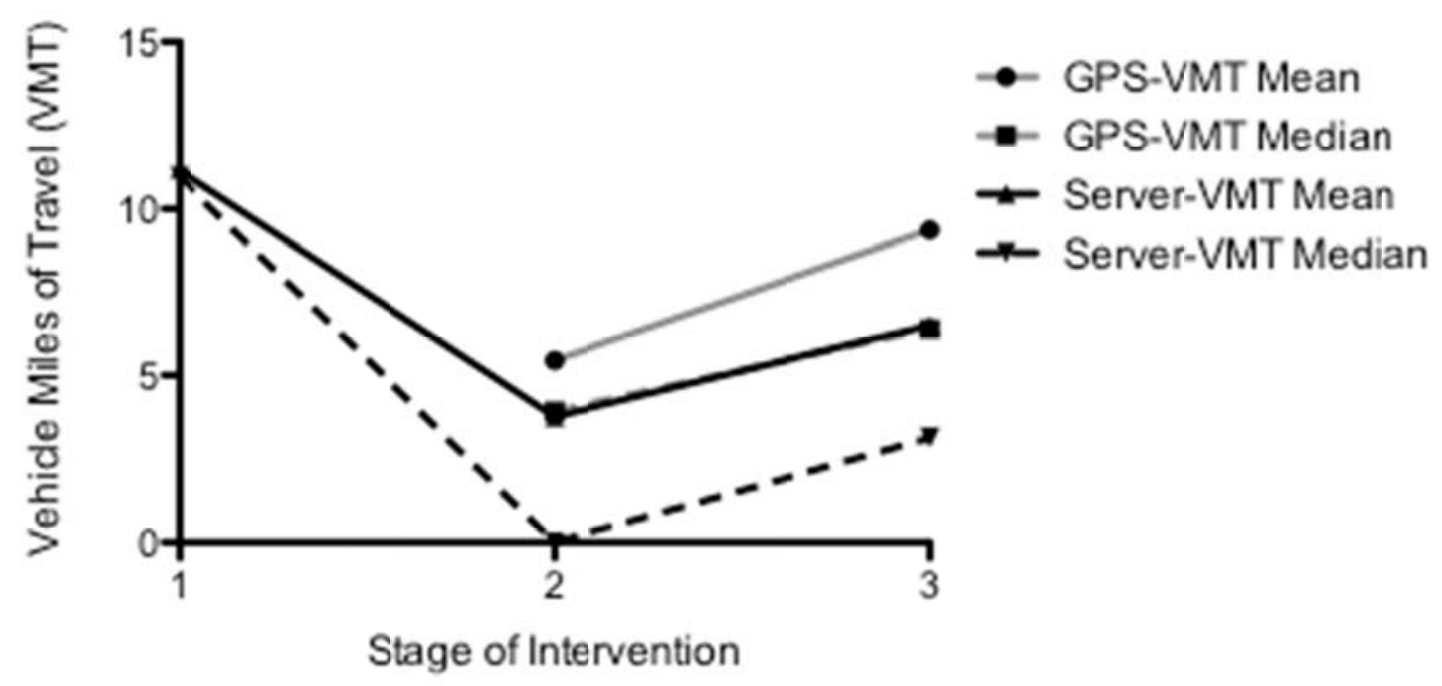

Figure 7. Stage means and medians for Participant 3.

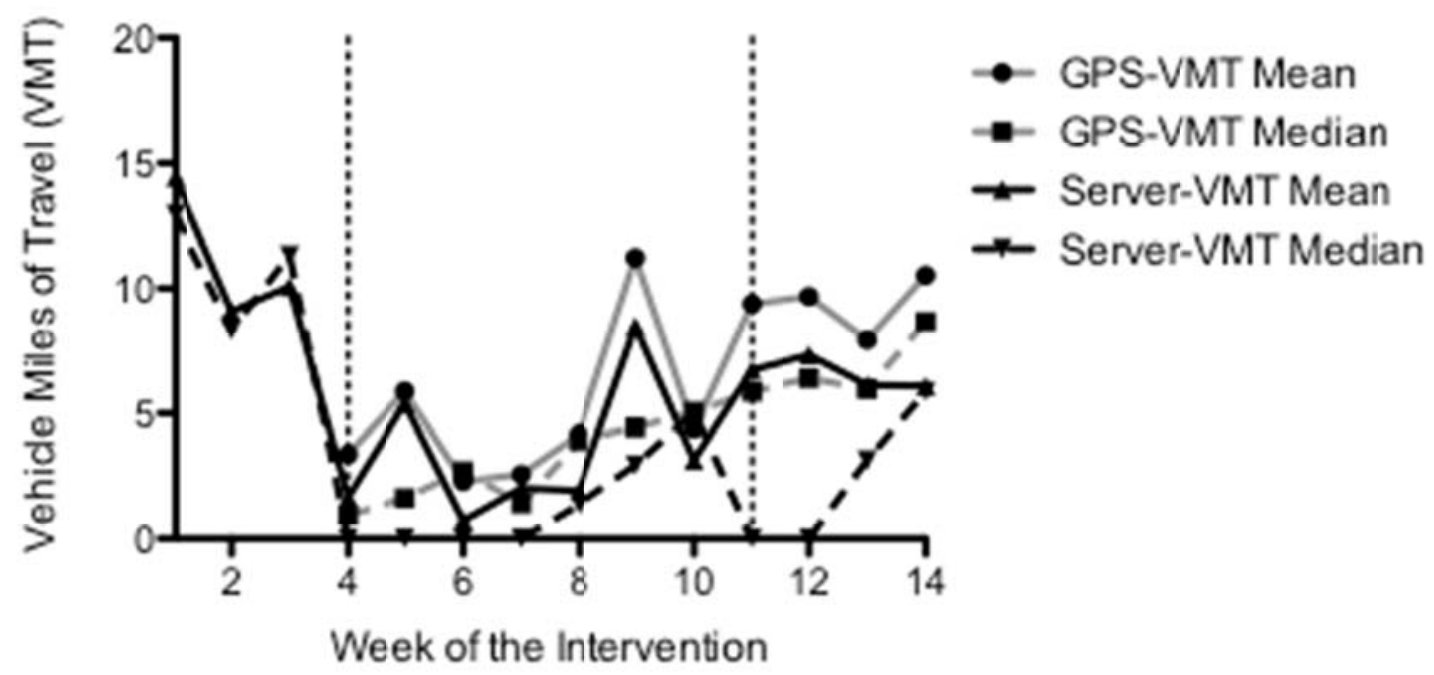

Figure 8. Weekly means and medians for Participant 3. 
$30.77)=16.58, p<.001, \eta=.453$. Paired-samples $t$ tests were conducted to follow-upon this significant main effect. It was found that the average server-based VMT for the baseline stage $(M=16.51, S D=10.40)$ was significantly larger than both the intervention stage $(M=4.69, \mathrm{SD}=6.99): t(20)=5.10, p<.001$ and return-to-baseline stage $(M=$ $7.88, S D=9.51): t(20)=3.50, p<.01$, respectively. The average server-based VMT for the intervention was significantly smaller than the average server-based VMT for the return-to-baseline stage: $t(20)=-2.21, p<.05$. The effect sizes were calculated using Cohen's $d$ for the server-based VMT for baseline and intervention stage, $d=1.29$ and the baseline and return-to-baseline stages, $d=.98$.

Using a paired-samples $t$ test, the average GPS-based VMT for the intervention $(M=8.93, S D=11.17)$ and return-to-baseline $(M=12.91, S D=8.37)$ stages were compared and no significant difference was found, $t(20)=1.81, p=.086$. Table 14 includes the descriptive statistics for the server- and GPS-based VMT for Participant 4. Additionally, line plots of stage and weekly means and medians have been included for Participant 4 for both the server-based and GPS-based VMT data (see Figures 9 and 10).

\section{Table 14}

Descriptive Statistics for the Server- and GPS-Based VMT for Participant 4

\begin{tabular}{llrrc}
\hline \multicolumn{1}{c}{ Source } & \multicolumn{1}{c}{ Stage } & $n$ & \multicolumn{1}{c}{$M$} & $S D$ \\
\hline Server & Baseline & 21 & 16.51 & 10.40 \\
Server & Intervention & 56 & 5.19 & 5.27 \\
Server & Return-to-baseline & 21 & 7.88 & 9.51 \\
GPS & Baseline & 0 & $\mathrm{~N} / \mathrm{A}$ & $\mathrm{N} / \mathrm{A}$ \\
GPS & Intervention & 44 & 8.87 & 9.72 \\
GPS & Return-to-baseline & 21 & 12.91 & 8.37 \\
\hline
\end{tabular}




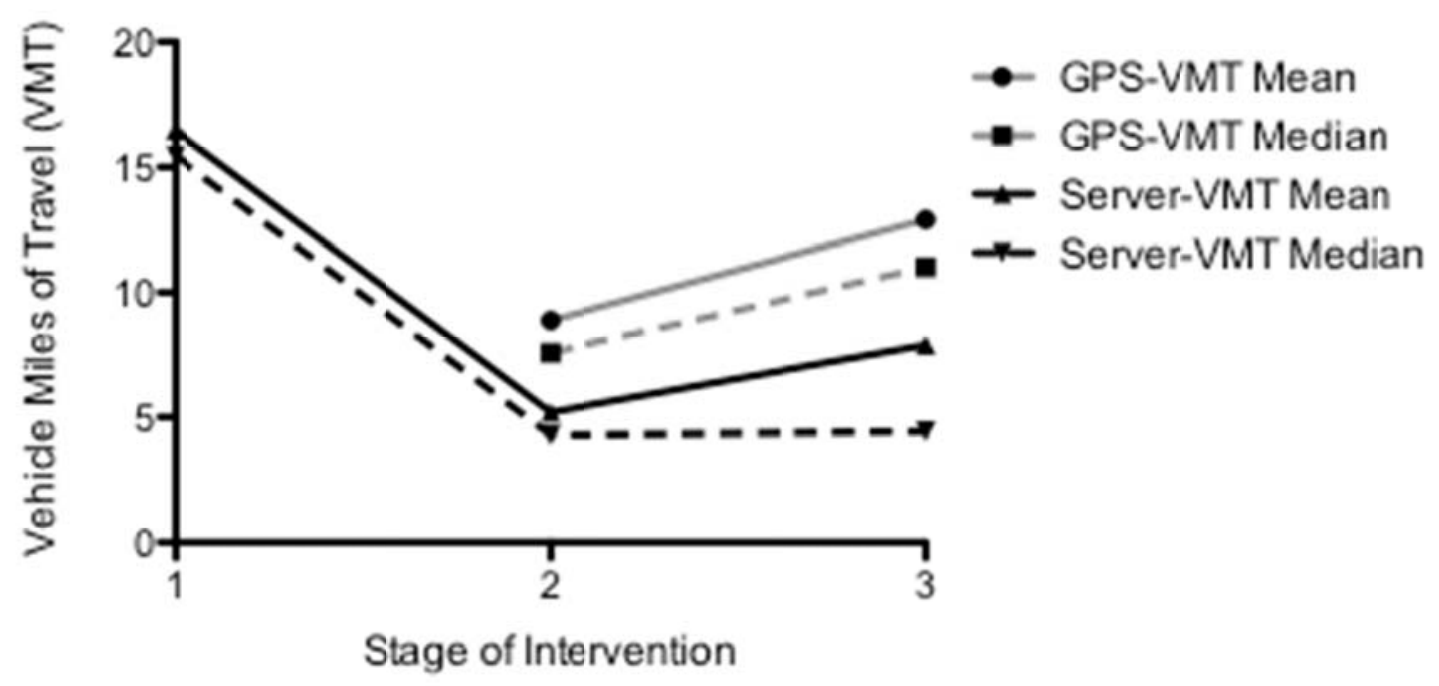

Figure 9. Stage means and medians for Participant 4.

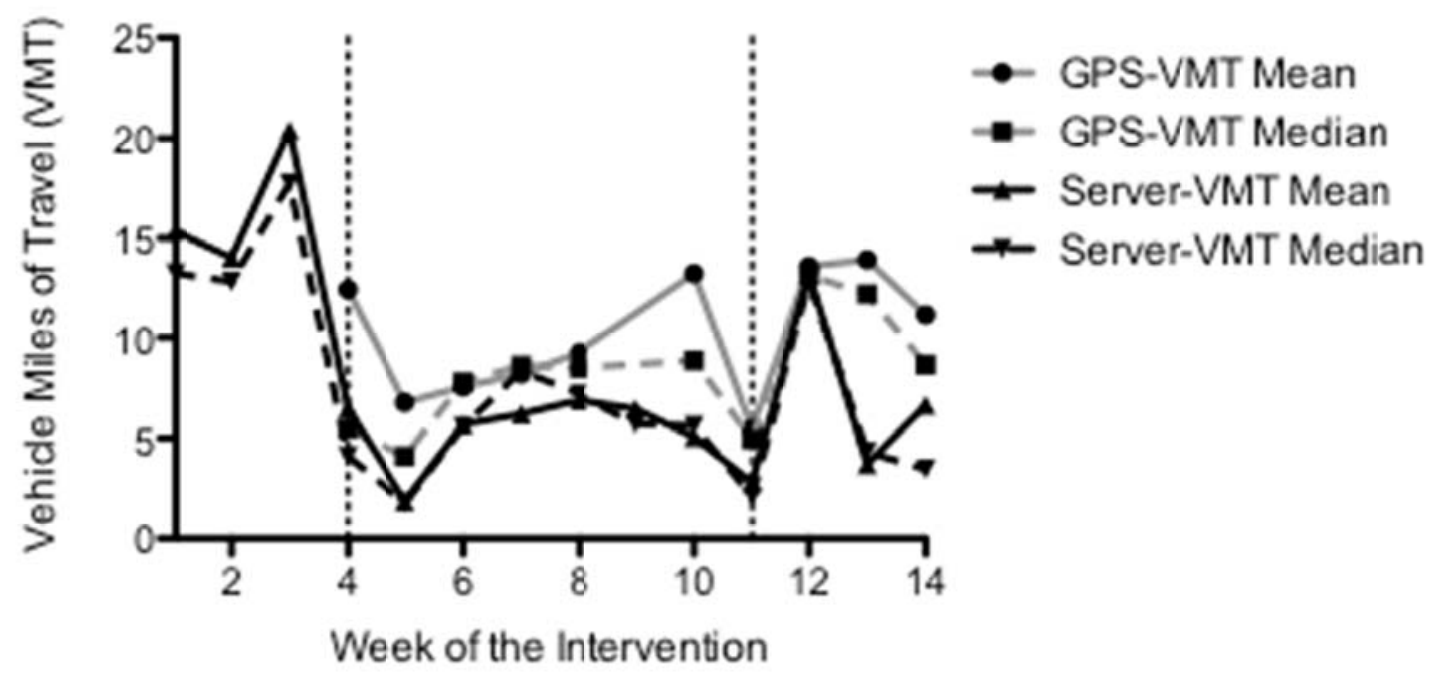

Figure 10. Weekly means and medians for Participant 4. 


\section{Participant 5}

For Participant 5, the results of the repeated-measures ANOVA found that the average server-based VMT did not differ by stage $(n=21$; baseline: $M=25.05, S D=$ 17.31; intervention: $M=19.93, S D=18.03$; return-to-baseline: $M=18.51, S D=20.25$ ), $F(2,40)=.819, p=.448, \eta=.039 ;$ Mauchly's test of sphericity: $\chi^{2}(2)=2.79, p=.248$. The effect sizes were calculated using Cohen's $d$ for the server-based VMT for baseline and intervention stage, $d=.53$ and the baseline and return-to-baseline stages, $d=.37$.

Using a paired-samples $t$ test, the average GPS-based VMT for the intervention $(M=26.50, S D=20.94)$ and return-to-baseline $(M=26.60, S D=17.91)$ stages were compared and no significant difference was found, $t(20)=-.02, p=.985$. Table 15 contains the descriptive statistics for the server- and GPS-based VMT for Participant 5. Additionally, line plots of stage and weekly means and medians have been included for Participant 5 for both the server-based and GPS-based VMT data (see Figures 11 and 12).

Table 15

Descriptive Statistics for the Server-and GPS-Based VMT for Participant 5

\begin{tabular}{llccc}
\hline \multicolumn{1}{c}{ Source } & \multicolumn{1}{c}{ Stage } & $n$ & \multicolumn{1}{c}{$M$} & \multicolumn{1}{c}{$S D$} \\
\hline Server & Baseline & 21 & 25.05 & 17.31 \\
Server & Intervention & 56 & 15.76 & 16.36 \\
Server & Return-to-baseline & 21 & 18.51 & 20.25 \\
GPS & Baseline & 0 & N/A & N/A \\
GPS & Intervention & 35 & 24.38 & 18.53 \\
GPS & Return-to-baseline & 21 & 26.60 & 17.91 \\
\hline
\end{tabular}




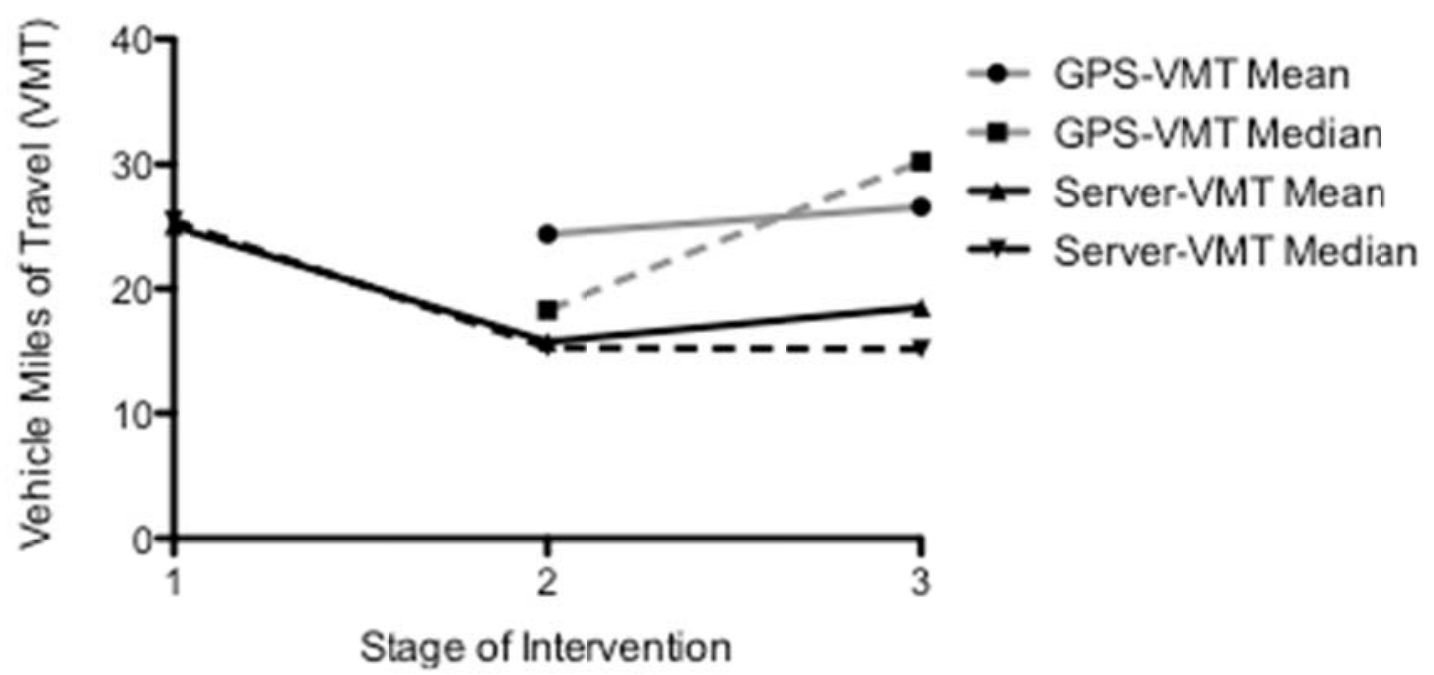

Figure 11. Stage means and medians for Participant 5.

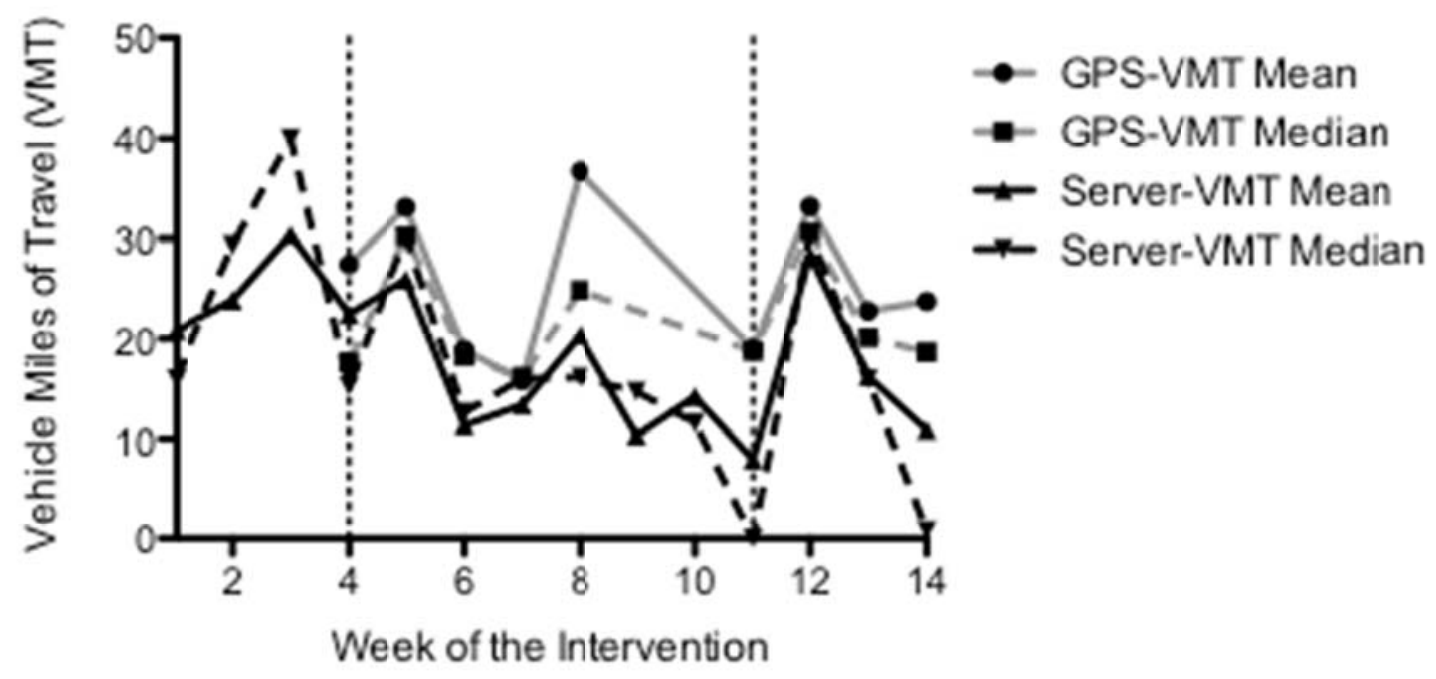

Figure 12. Weekly means and medians for Participant 5. 


\section{Participant 6}

For Participant 6, the results Mauchly's test of sphericity indicated a violation of the assumption of sphericity, $\left.\chi^{2}(2)=6.432, p<.05\right)$. Therefore, the degrees of freedom were corrected using Greenhouse-Geisser estimates of sphericity $(\varepsilon=.78)$. The resultsshow that the average server-based VMT differed by stage, $F(1.55,31.08)=7.51$, $p<.01, \eta=.273$. Paired-samples $t$ tests were conducted to follow-up on this significant main effect. It was found that the average server-based VMT for the baseline stage $(M=$ $13.51, S D=8.00)$ was significantly larger than the intervention stage $(M=5.43, S D=$ 4.47): $t(20)=4.10, p<.001$ but did not differ significantly with the average server-based VMT for the return-to-baseline stage $(M=11.52, \mathrm{SD}=8.63): t(20)=.743, p<.466$, respectively. Additionally, the average server-based VMT for the intervention was significantly smaller than the average server-based VMT for the return-to-baseline stage: $t(20)=-3.48, p<.01$. The effect sizes were calculated using Cohen's $d$ for the serverbased VMT for baseline and intervention stage, $d=.93$ and the baseline and return-tobaseline stages, $d=.24$.

The paired-samples $t$ test for the average GPS-based VMT was not conducted because of the lack of valid pairs. Table 16 contains the descriptive statistics for the server- and GPS-based VMT for Participant 6. Additionally, line plots of stage and weekly means and medians have been included for Participant 6 for both the server-based and GPS-based VMT data (see Figure 13 and 14).

\section{Participant 7}

For Participant 7, the results of the repeated-measures ANOVA found that the 
Table 16

Descriptive Statistics for the Server-and GPS-Based VMT for Participant 6

\begin{tabular}{llrrl}
\hline \multicolumn{1}{c}{ Source } & \multicolumn{1}{c}{ Stage } & $n$ & \multicolumn{1}{c}{$M$} & \multicolumn{1}{c}{$S D$} \\
\hline Server & Baseline & 21 & 13.51 & 8.00 \\
Server & Intervention & 56 & 5.93 & 6.84 \\
Server & Return-to-baseline & 21 & 11.52 & 8.63 \\
GPS & Baseline & 0 & N/A & N/A \\
GPS & Intervention & 16 & 8.81 & 3.50 \\
GPS & Return-to-baseline & 21 & 13.67 & 8.87 \\
\hline
\end{tabular}

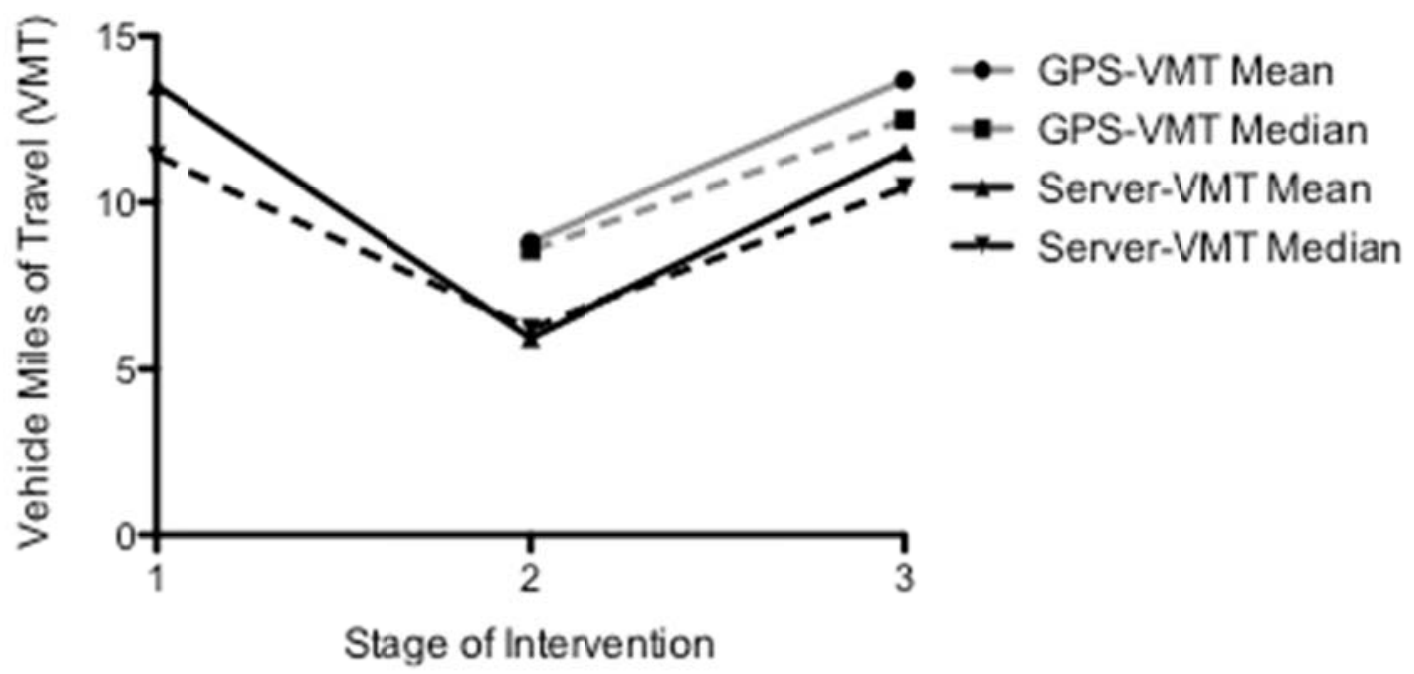

Figure 13. Stage means and medians for Participant 6.

average server-based VMT did not differed by stage $(n=21$; baseline: $M=13.41, S D=$ 16.65; intervention: $M=10.43, S D=13.96$; return-to-baseline: $M=9.77, S D=12.73$ ), $F(2,40)=.369, p=.693, \eta=.018$; Mauchly's test of sphericity: $\chi^{2}(2)=.729, p=.694$. The effect sizes were calculated using Cohen's $d$ for the server-based VMT for baseline and intervention stage, $d=.27$ and the baseline and return-to-baseline stages, $d=.27$. 


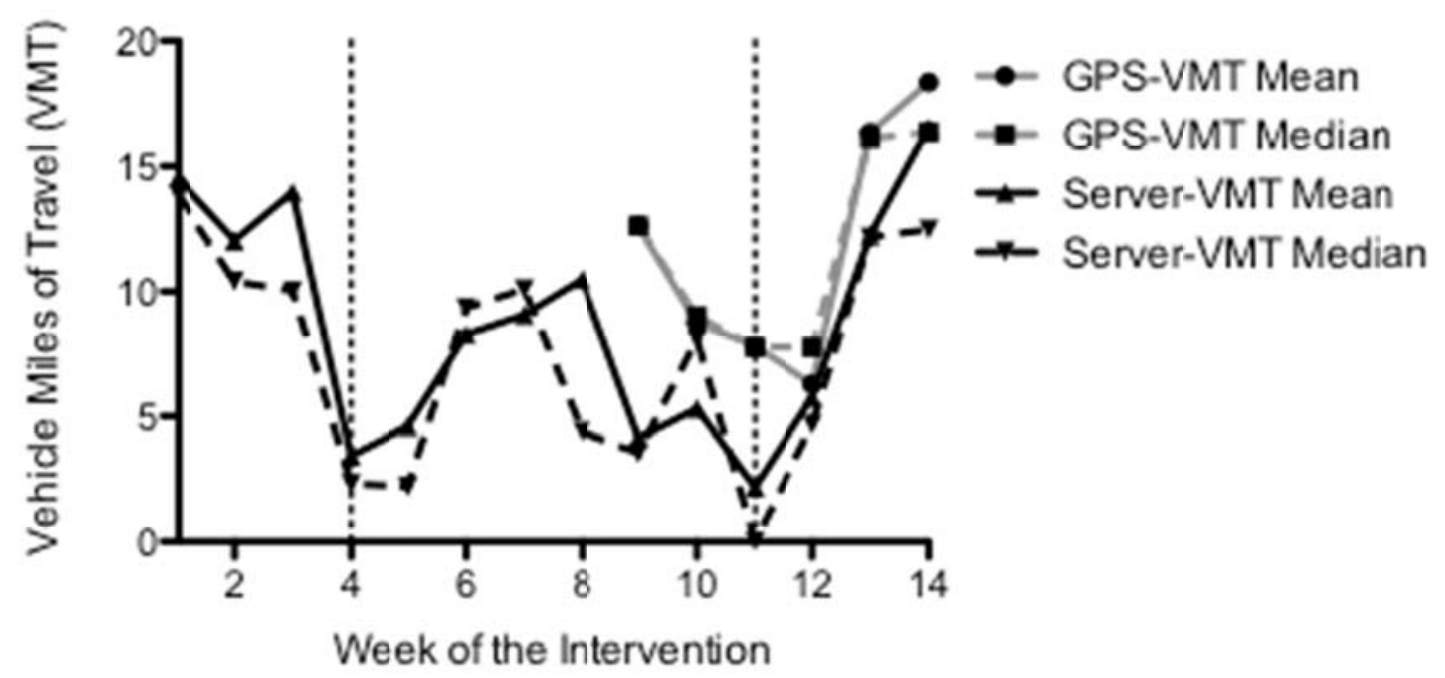

Figure 14. Weekly means and medians for Participant 6.

Additionally, the results of the repeated-measures ANOVA showed that the average GPS-based VMT did not differ by stage, $(n=17$; baseline: $M=19.72, S D=$ 16.31; intervention: $M=14.43, S D=14.08$; return-to-baseline: $M=20.25, S D=16.01$ ), $F(2,32)=.668, p=.520, \eta=.040$ (Mauchly's test of sphericity: $\left.\chi^{2}(2)=.234, p=.890\right)$. The effect sizes were calculated using Cohen's $d$ for the GPS-based VMT for baseline and intervention stage, $d=.31$ and the baseline and return-to-baseline stages, $d=.09$. Table 17 includes the descriptive statistics for the server- and GPS-based VMT for Participant 7. Additionally, line plots of stage and weekly means and medians have been included for Participant 7 for both the server-based and GPS-based VMT data (see Figures 15 and 16).

\section{Participant 8}

For Participant 8, the results of the repeated-measures ANOVA showed that the 
Table 17

Descriptive Statistics for the Server-and GPS-Based VMT for Participant 7

\begin{tabular}{lllcc}
\hline \multicolumn{1}{c}{ Source } & \multicolumn{1}{c}{ Stage } & $n$ & \multicolumn{1}{c}{$M$} & $S D$ \\
\hline Server & Baseline & 21 & 13.41 & 16.65 \\
Server & Intervention & 56 & 9.78 & 12.96 \\
Server & Return-to-baseline & 21 & 9.77 & 12.73 \\
GPS & Baseline & 17 & 19.72 & 16.32 \\
GPS & Intervention & 55 & 15.36 & 12.95 \\
GPS & Return-to-baseline & 21 & 18.42 & 15.67 \\
\hline
\end{tabular}

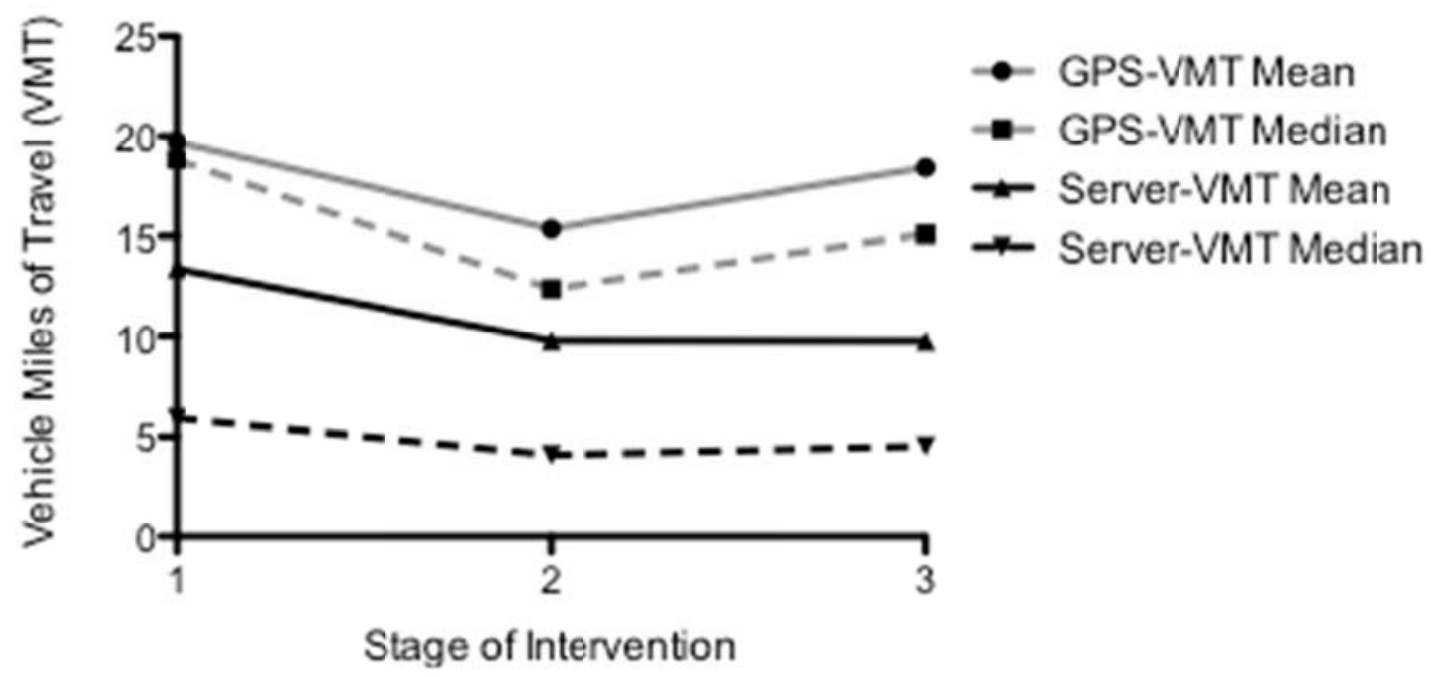

Figure 15. Stage means and medians for Participant 7.

average server-based VMT differed by stage, $F(2,36)=8.18, p<.001, \eta=.312$;

Mauchly's test of sphericity: $\chi^{2}(2)=1.062, p=.588$. Paired-samples $t$ tests were

conducted to follow-up on this significant main effect. These tests found that the average server-based VMT for the baseline stage $(M=20.82, \mathrm{SD}=11.91)$ was significantly larger than both the intervention stage $(M=7.66, \mathrm{SD}=7.08): t(20)=4.77, p<.001$ and 


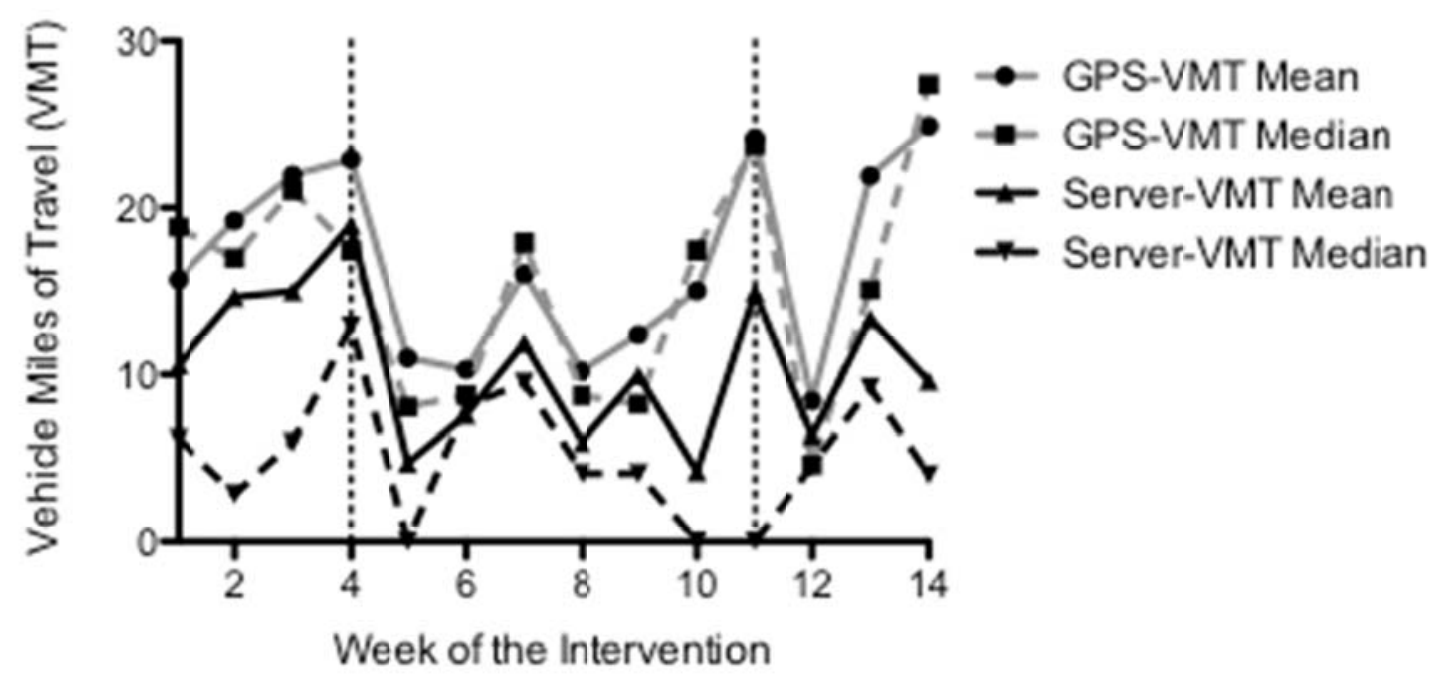

Figure 16. Weekly means and medians for Participant 7.

return-to-baseline stage $(M=11.25, S D=10.55): t(18)=2.57, p<.05$, respectively. In addition, the average server-based VMT for the intervention stage was not significantly different from the average server-based VMT for the return-to-baseline stage, $t(18)$ $=-1.10, p=.286$. The effect sizes were calculated using Cohen's $d$ for the server-based VMT for baseline and intervention stage, $d=1.10$ and the baseline and return-to-baseline stages, $d=.96$.

Additionally, the results of the paired-samples $t$ test on the average GPS-based VMT for the intervention $(M=13.92, S D=4.80)$ and return-to-baseline $(M=18.38, S D$ $=11.27$ ) stage was not significantly different, $t(4)=.827, p=.455$. Table 18 includes descriptive statistics for the server- and GPS-based VMT for Participant 8. Additionally, line plots of stage and weekly means and medians have been included for Participant 8 for both the server-based and GPS-based VMT data (see Figures 17 and 18). 
Table 18

Descriptive Statistics for the Server-and GPS-Based VMT for Participant 8

\begin{tabular}{llrrr}
\hline \multicolumn{1}{c}{ Source } & \multicolumn{1}{c}{ Stage } & $n$ & \multicolumn{1}{c}{$M$} & \multicolumn{1}{c}{$S D$} \\
\hline Server & Baseline & 21 & 20.82 & 11.91 \\
Server & Intervention & 56 & 9.89 & 7.01 \\
Server & Return-to-baseline & 19 & 11.25 & 10.55 \\
GPS & Baseline & 0 & $\mathrm{~N} / \mathrm{A}$ & $\mathrm{N} / \mathrm{A}$ \\
GPS & Intervention & 23 & 12.49 & 5.53 \\
GPS & Return-to-baseline & 5 & 18.38 & 11.27 \\
\hline
\end{tabular}

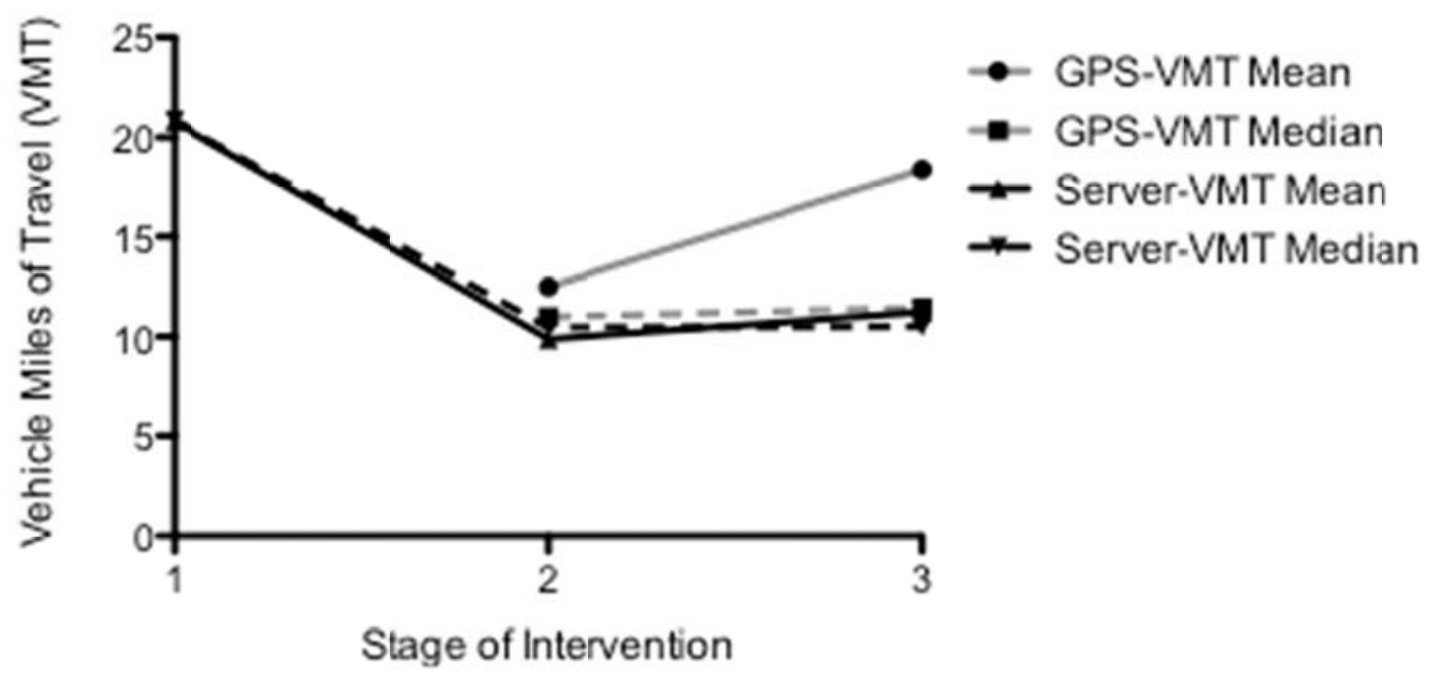

Figure 17. Stage means and medians for Participant 8.

\section{Participant 9}

For Participant 9, the Mauchly's test of sphericity indicated a violation of the assumption of sphericity, $\chi^{2}(2)=11.60, p<.01$. Therefore, the degrees of freedom were corrected using Greenhouse-Geisser estimates of sphericity $(\varepsilon=.69)$. The results of the repeated-measures ANOVA show that the average server-based VMT differed by stage, 


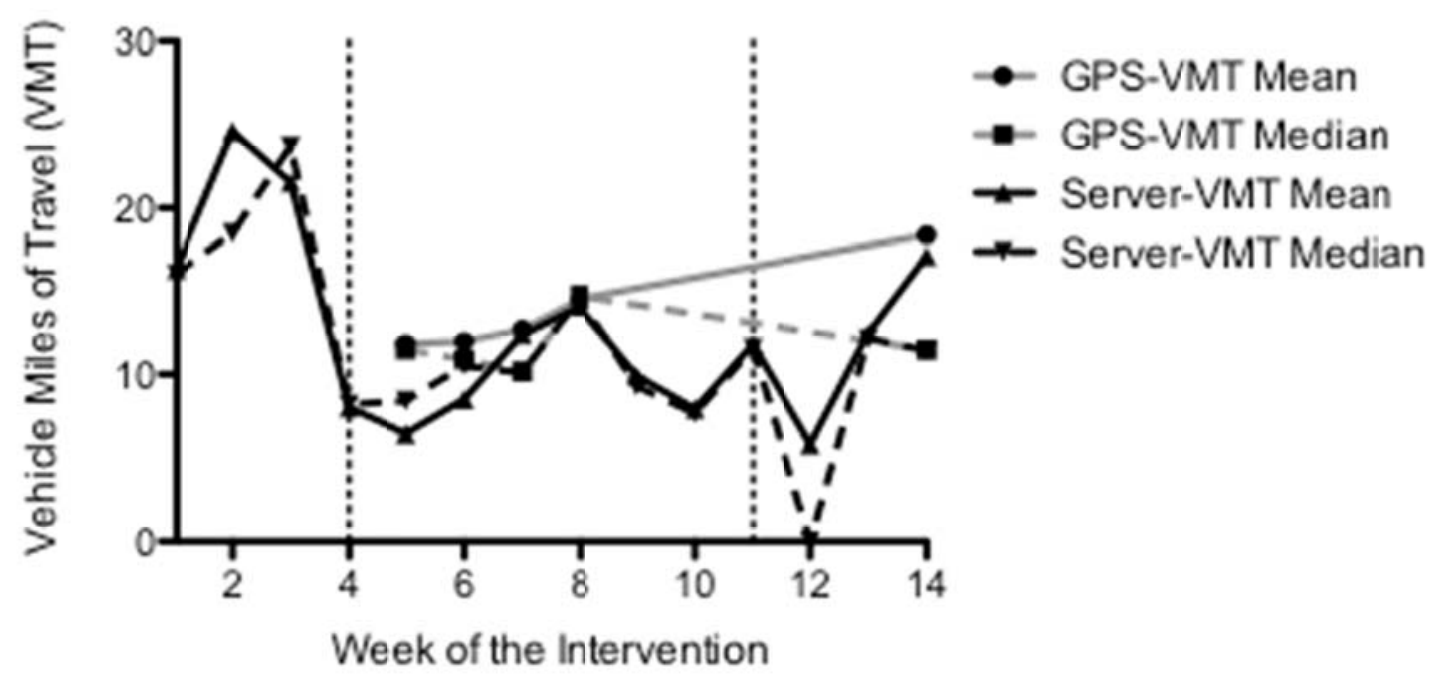

Figure 18. Weekly means and medians for Participant 8.

$F(1.373,27.458)=5.649, p<.05, \eta=.220$. Paired-samples $t$ tests were conducted to follow-up on this significant main effect. The tests found that the average server-based VMT for the baseline stage $(M=12.37, S D=15.36)$ was significantly larger than the intervention stage $(M=2.53 S D=2.65): t(20)=2.78, p<.05$ but did not differ significantly with the average server-based VMT for the return-to-baseline stage ( $M=$ $5.80, S D=7.26): t(20)=1.96, p=.064$, respectively. Additionally, the average serverbased VMT for the intervention was not significantly different than the average serverbased VMT for the return-to-baseline stage: $t(20)=1.91, p=.071$. The effect sizes were calculated using Cohen's $d$ for the server-based VMT for baseline and intervention stage, $d=.84$ and the baseline and return-to-baseline stages, $d=.69$.

In addition, the average GPS-based VMT for the intervention stage $(M=4.66, S D$ $=3.33)$ and return-to-baseline stage $(M=7.87, S D=9.76)$ did not differ significantly, $t(20)=-1.69, p=.107$. Table 19 contains descriptive statistics for the server- and GPS- 
Table 19

Descriptive Statistics for the Server-and GPS-Based VMT for Participant 9

\begin{tabular}{llrrr}
\hline \multicolumn{1}{c}{ Source } & \multicolumn{1}{c}{ Stage } & $n$ & \multicolumn{1}{c}{$M$} & \multicolumn{1}{c}{$S D$} \\
\hline Server & Baseline & 21 & 12.37 & 15.36 \\
Server & Intervention & 56 & 4.39 & 5.91 \\
Server & Return-to-baseline & 21 & 5.80 & 7.26 \\
GPS & Baseline & 0 & N/A & N/A \\
GPS & Intervention & 56 & 6.42 & 7.15 \\
GPS & Return-to-baseline & 21 & 7.87 & 9.76 \\
\hline
\end{tabular}

based VMT for Participant 9. Additionally, line plots of stage and weekly means and medians have been included for Participant 9 for both the server-based and GPS-based VMT data (see Figures 19 and 20).

\section{Participant 10}

For Participant 10, it was found that the average server-based VMT did not differ by stage ( $n=9$; baseline: $M=13.31, S D=6.14$; intervention: $M=14.18, S D=15.88$; return-to-baseline: $M=10.11, S D=5.75), F(2,16)=.441, p=.651, \eta=.052$; Mauchly’s test of sphericity: $\chi^{2}(2)=4.73, p=.094$. The effect sizes were calculated using Cohen's $d$ for the server-based VMT for baseline and intervention stage, $d=.22$ and the Baseline and Return-to-baseline stages, $d=.18$.

The paired-samples $t$ tests for the average GPS-based VMT intervention and return-to-baseline stages was not conducted because of the lack of valid pairs. Table 20 contains the descriptive statistics for the server- and GPS-based VMT for Participant 10. 


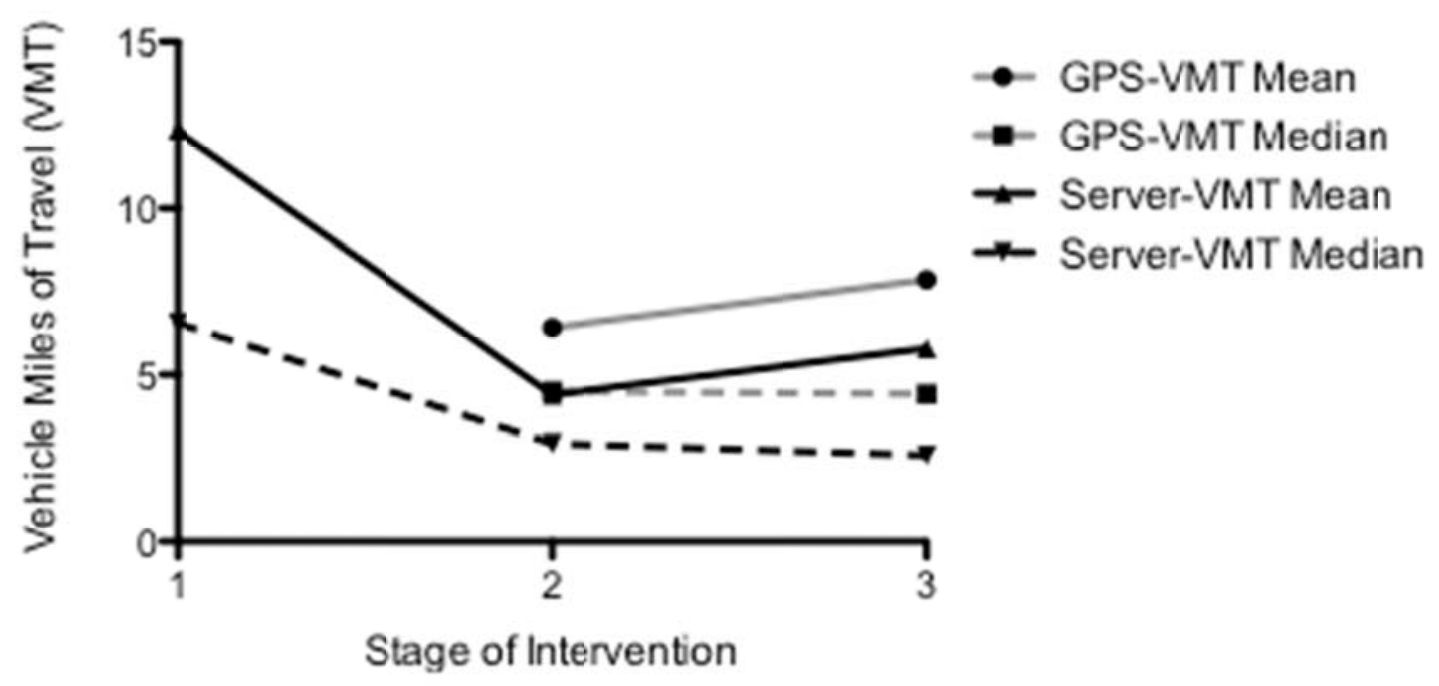

Figure 19. Stage means and medians for Participant 9.

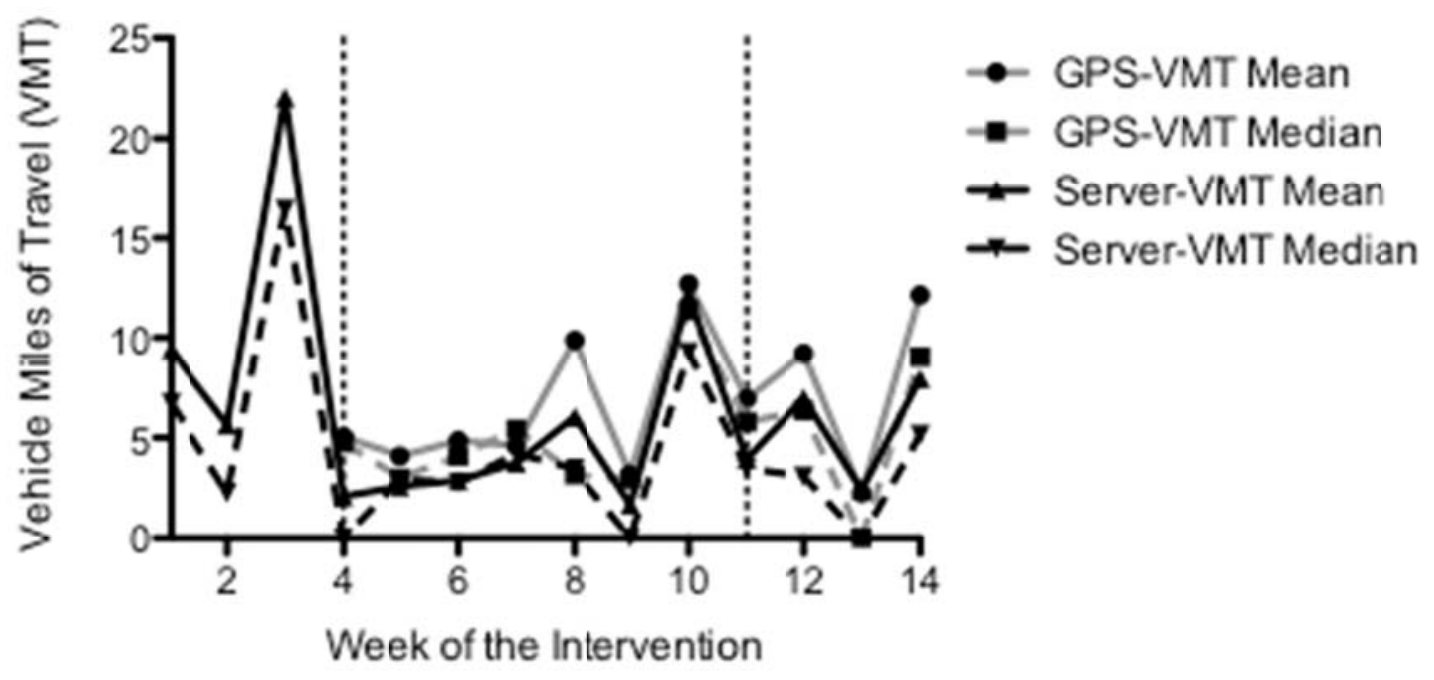

Figure 20. Weekly means and medians for Participant 9. 
Table 20

Descriptive Statistics for the Server-and GPS-based VMT for Participant 10

\begin{tabular}{llccc}
\hline \multicolumn{1}{c}{ Source } & \multicolumn{1}{c}{ Stage } & $n$ & $M$ & $S D$ \\
\hline Server & Baseline & 21 & 14.89 & 9.61 \\
Server & Intervention & 35 & 12.52 & 13.38 \\
Server & Return-to-baseline & 21 & 12.96 & 7.59 \\
GPS & Baseline & 0 & N/A & N/A \\
GPS & Intervention & 12 & 14.74 & 13.13 \\
GPS & Return-to-baseline & 21 & 17.24 & 12.36 \\
\hline
\end{tabular}

Additionally, line plots of stage and weekly means and medians have been included for Participant 10 for both the server-based and GPS-based VMT data (see Figures 21 and 22).

\section{Results from Research Question 3}

3. Is there an interaction effect between the prize-based contingency management system and the "Choose Clean Air" social marketing campaign on driving reductions?

A series of multilevel models (mixed-effect models) were computed with serverand GPS-based VMT as the repeated-measures outcomes and each of the following five environmental or contextual variables as repeated-measures predictors: PM 2.5 concentration level, color of the air alert, weather (e.g., sunny, cloudy, rainy, foggy, snow), gasoline prices, and temperature. Data from each stage of the 14-week study were used in these analyses to capture the day-to-day variation in both driving behavior and the 


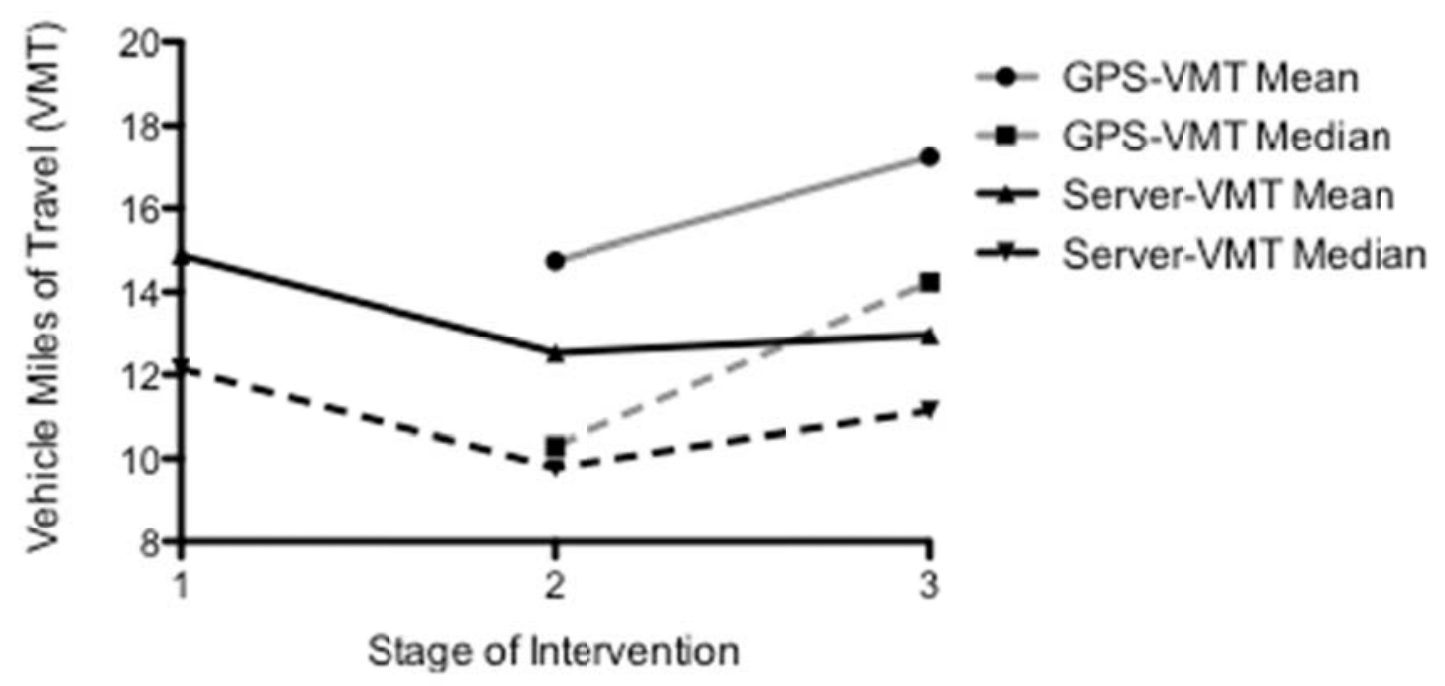

Figure 21. Stage means and medians for Participant 10.

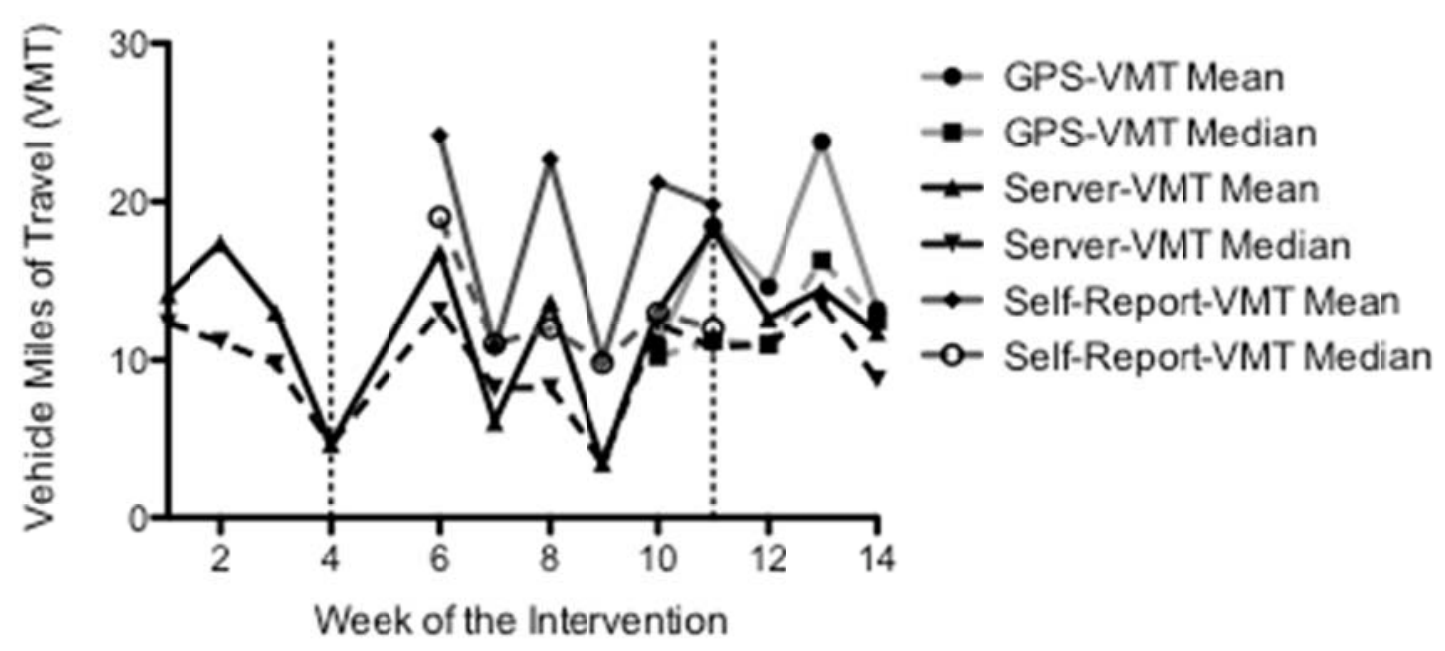

Figure 22. Weekly means and median for Participant 10.

environmental and contextual variables. This analysis strategy was selected to account for repeated-measurements of both outcomes and predictors within participants. To determine the best-fitting, most parsimonious statistical models, several test models were 
conducted, compared, and evaluated.

Table 21 includes the descriptive statistics for the variables used in the serverbased VMT mixed-effect models. Table 22 includes the descriptive statistics for variables used in the GPS-based VMT mixed-effects models.

Server-based VMT. A visual inspection of the average server-based VMT for each stage shows overall pattern of decline from the baseline to intervention stage and a slight increase from intervention to return-to-baseline stage. Due to this abrupt change in the direction of VMT over time, a segmented mixed-model was used to model the change in average vehicle miles of travel from the baseline to intervention stages (segment 1) and the intervention to the return-to-baseline stages (segment 2). This approach is also known as spline regression. These segment variables representing time were included in addition

\section{Table 21}

Descriptive Statistics for Variables Used in Server-Based VMT Mixed-Effects Model

\begin{tabular}{|c|c|c|c|c|c|c|}
\hline Variables & $M$ & $S D$ & Min & Max & $N$ & $\%$ \\
\hline \multicolumn{7}{|l|}{ Continuous variables } \\
\hline Gas prices (dollars) & 2.68 & 0.11 & 2.47 & 2.95 & & \\
\hline Temperature (Celsius) & 32.81 & 9.81 & 5.00 & 61.00 & & \\
\hline PM 2.5 levels (concentration level) & 20.91 & 19.29 & 0.80 & 102.20 & & \\
\hline \multicolumn{7}{|l|}{ Discrete variables (weather) } \\
\hline Sunny/fair/clear & & & & & 232 & 23.70 \\
\hline Cloudy/partly or mostly cloudy & & & & & 462 & 47.10 \\
\hline Windy & & & & & 4 & 0.40 \\
\hline Fog/haze & & & & & 103 & 10.50 \\
\hline Rain & & & & & 26 & 2.70 \\
\hline Light snow/snow showers & & & & & 143 & 14.60 \\
\hline Heavy snow & & & & & 10 & 1.00 \\
\hline \multicolumn{7}{|l|}{ Color-coded health alert } \\
\hline Green & & & & & 688 & 70.20 \\
\hline Yellow & & & & & 136 & 13.90 \\
\hline Red & & & & & 156 & 15.90 \\
\hline
\end{tabular}


Table 22

Descriptive Statistics for Variables Used in GPS-Based VMT Mixed-Effects Model

\begin{tabular}{|c|c|c|c|c|c|c|}
\hline Variables & $M$ & $S D$ & Min & $\operatorname{Max}$ & $N$ & $\%$ \\
\hline \multicolumn{7}{|l|}{ Continuous Variables } \\
\hline Gas prices (dollars) & 2.72 & 0.11 & 2.47 & 2.95 & & \\
\hline Temperature (Celsius) & 33.77 & 9.64 & 5.00 & 60.00 & & \\
\hline PM 2.5 levels (concentration level) & 20.20 & 19.63 & 0.80 & 102.20 & & \\
\hline \multicolumn{7}{|l|}{ Discrete variables (weather) } \\
\hline Sunny/fair/clear & & & & & 132 & 23.20 \\
\hline Cloudy/partly or mostly cloudy & & & & & 252 & 44.20 \\
\hline Windy & & & & & 0 & 0.00 \\
\hline Fog/haze & & & & & 61 & 10.70 \\
\hline Rain & & & & & 17 & 3.00 \\
\hline Light snow/snow showers & & & & & 98 & 17.20 \\
\hline Heavy snow & & & & & 10 & 1.80 \\
\hline \multicolumn{7}{|l|}{ Color-coded health alert } \\
\hline Green & & & & & 407 & 71.40 \\
\hline Yellow & & & & & 70 & 12.30 \\
\hline Red & & & & & 93 & 16.30 \\
\hline
\end{tabular}

to the covariates previously mentioned in each model. Random slopes for each segment were included in the model. Interactions between each time segment and each covariate were also tested and removed iteratively if they did not contribute to model fit.

Beginning with a linear mixed model with these five covariates included as main effects, no interaction terms were found to be statistically significant. As a result, the final model included the five covariates as main effects and random slopes for each segment. The results in the final model included three significant predictors of VMT:

Segment 1: $b=-8.16, t=-5.90, p<.001$, Weather 4 (1: Sunny/Fair/Clear versus 4: Fog /Haze): $b=-3.15, t=-2.22, p<.05$; Weather 3: (1: Sunny/Fair/Clear versus 3: Windy): $b$ $=-12.98, t=-2.49, p<.05$. The statistically significant slope for Segment 1 suggested a decrease in VMT from the baseline $(M=15.66)$ to the Intervention $(M=8.19)$ stage of 
the study. The slope for Segment 2 was not found to be statistically significant which suggests the maintenance of the treatment effect from the Intervention $(M=8.19)$ to the return-to-baseline $(M=9.77)$ stage of the study. The final fit model was also significantly different than the null model; $\chi^{2}(18)=90.51, p=.0001$. Table 23 includes the results of the linear mixed-effects model for the server-based VMT data.

GPS-based VMT. A visual inspection of the average server-based VMT for each stage shows a slight increase from intervention to return-to-baseline stage. Due to this abrupt change in the direction of VMT over time, a segmented mixed-model was used to

\section{Table 23}

Results of the Server-Based VMT Mixed-Effects Model

\begin{tabular}{|c|c|c|c|c|}
\hline \multirow[b]{2}{*}{ Name } & \multirow{2}{*}{$\begin{array}{c}\text { Random effects } \\
S D \\
\end{array}$} & \multicolumn{3}{|c|}{ Fixed effects } \\
\hline & & $\beta$ & $S E$ & $t$ value \\
\hline Intercept & 3.56 & -6.01 & 19.82 & -0.30 \\
\hline Segment 1 & 3.92 & -8.16 & 1.38 & $-5.90 * *$ \\
\hline Segment 2 & 0.06 & 0.84 & 1.48 & 0.57 \\
\hline Gas price & N/A & 6.53 & 7.42 & 0.88 \\
\hline PM 2.5 concentration level & N/A & -0.02 & 0.03 & -0.67 \\
\hline Temperature & $\mathrm{N} / \mathrm{A}$ & -0.06 & 0.05 & -1.20 \\
\hline Green versus yellow days & N/A & 0.73 & 1.15 & 0.63 \\
\hline Green versus red days & N/A & 1.45 & 1.63 & 0.89 \\
\hline $\begin{array}{l}\text { Sunny/fair/clear versus cloudy/partly or mostly } \\
\text { cloudy }\end{array}$ & $\mathrm{N} / \mathrm{A}$ & -1.47 & 0.86 & -1.72 \\
\hline Sunny/fair/clear versus windy & N/A & -12.98 & 5.35 & $-2.43 *$ \\
\hline Sunny/fair/clear versus fog/haze & $\mathrm{N} / \mathrm{A}$ & -3.15 & 1.42 & $-2.22 *$ \\
\hline Sunny/fair/clear versus rain & N/A & -3.55 & 2.18 & -1.63 \\
\hline $\begin{array}{l}\text { Sunny/fair/clear versus light snow/snow } \\
\text { showers }\end{array}$ & N/A & -0.49 & 1.13 & -0.44 \\
\hline Sunny/fair/clear versus heavy snow & N/A & -5.22 & 3.52 & -1.48 \\
\hline
\end{tabular}


model the change in average vehicle miles of travel from the intervention to the return-tobaseline stages (segment 2). These segment variables representing time were included in addition to the covariates previously mentioned in each model. Random slopes for each segment were included in the model. Interactions between each time segment and each covariate were also tested and removed iteratively if they did not contribute to model fit.

Beginning with a linear mixed model with these five covariates included as main effects, no interaction terms were found to be statistically significant. As a result, the final model included the five covariates as main effects and random slopes for each segment. The results in the final model did not include a significant predictor of VMT. The slope for segment 2; intervention $(M=10.78)$ to the return-to-baseline $(M=13.99)$ stage, of the study was not statistically significant which suggests the maintenance of the treatment effect. The final fit model was not significantly different than the null model, $\chi^{2}(13)=13.22, p=.43$. Table 24 includes the results of the linear mixed-effects model for the GPS-based VMT data.

\section{Exit Questionnaire}

Participants were asked to complete an exit questionnaire at the final dinner and drawing in April 2010. All 10 participants completed the questionnaire. The questionnaire included both closed- and open-ended questions. Table 25 includes a descriptive summary of their responses.

Participants were asked a few follow-up questions about the intervention, weekly drawings, and prizes. They were asked, "What did you like most about the intervention?" 
Table 24

Results of the GPS-Based VMT Mixed-Effects Model

\begin{tabular}{|c|c|c|c|c|}
\hline \multirow[b]{2}{*}{ Name } & \multirow{2}{*}{$\begin{array}{c}\text { Random effects } \\
S D \\
\end{array}$} & \multicolumn{3}{|c|}{ Fixed effects } \\
\hline & & $\beta$ & $S E$ & $t$ value \\
\hline Intercept & 5.62 & 3.27 & 22.46 & 0.15 \\
\hline Segment 2 & 0.17 & 2.13 & 1.81 & 1.18 \\
\hline Gas price & $\mathrm{N} / \mathrm{A}$ & 4.26 & 8.47 & 0.50 \\
\hline PM 2.5 concentration level & $\mathrm{N} / \mathrm{A}$ & -0.04 & 0.04 & -0.89 \\
\hline Temperature & N/A & -0.06 & 0.07 & -0.82 \\
\hline Green versus yellow days & $\mathrm{N} / \mathrm{A}$ & 1.67 & 1.66 & 1.01 \\
\hline Green versus red days & $\mathrm{N} / \mathrm{A}$ & 1.53 & 2.23 & 0.69 \\
\hline $\begin{array}{l}\text { Sunny/fair/clear versus cloudy/partly or mostly } \\
\text { cloudy }\end{array}$ & N/A & -1.35 & 1.21 & -1.11 \\
\hline Sunny/fair/clear versus fog/haze & $\mathrm{N} / \mathrm{A}$ & -2.53 & 1.96 & -1.29 \\
\hline Sunny/fair/clear versus rain & $\mathrm{N} / \mathrm{A}$ & 1.11 & 2.88 & 0.39 \\
\hline $\begin{array}{l}\text { Sunny/fair/clear versus light snow/snow } \\
\text { showers }\end{array}$ & N/A & 0.33 & 1.50 & 0.22 \\
\hline Sunny/fair/clear versus heavy snow & N/A & -4.52 & 3.85 & -1.17 \\
\hline
\end{tabular}

Table 25

Descriptive Statistics for the Perception Items on the Exit Questionnaire from the

Screened Sample

\begin{tabular}{lcc}
\hline Questions & $M$ & $S D$ \\
\hline $\begin{array}{l}\text { On a scale from 1 (Terrible) to 7 (Great), how would you rate your experience } \\
\text { in the intervention? }\end{array}$ & 6.50 & 0.71 \\
$\begin{array}{l}\text { On a scale from 1 (Ineffective) to 7 (Effective), how effective to do you feel } \\
\text { the intervention was in reducing your driving mileage? }\end{array}$ & 5.70 & 1.06 \\
$\begin{array}{l}\text { On the scale from 1 (Low Impact) to 7 (High Impact), identify to what extent } \\
\text { did your knowledge about being monitored by GPS devices impact your } \\
\text { driving mileage? }\end{array}$ & 5.15 & 1.49 \\
$\begin{array}{l}\text { On a scale from 1 (Terrible) to 7 (Great), how would you rate the prizes you } \\
\text { won from the prize bowl? } \\
\begin{array}{l}\text { On a scale from one 1 (Terrible) to 7 (Great), how would rate the weekly } \\
\text { drawings? }\end{array}\end{array}$ & 6.00 & 6.05 \\
\hline
\end{tabular}


Table 26 contains a summary of responses coded into groups. The most frequent comment about what they liked most about the intervention was the increased awareness about driving behavior and patterns. For example, one participant said, "I was more aware of the miles I drove" and another said, "The intervention really did help me to realize the impact of my driving and that I can plan my driving habits better."

Participants were also asked "What did you like least about the intervention?" Table 27 provides a summary of their coded responses. Participants reported disliking the occasional inconvenience of altering their driving behaviors or dealing with the GPS device. For example, one participant said, "inhibited driving 'freedom"” and another said "problems with GPS requiring additional meeting to fix."

Participants were asked to comment on what they did to reduce their driving. Table 28 provides a summary of their responses. The most frequently stated method of reducing their VMT was planning their trips. For example, participants said, "we tried to

Table 26

Summary of the Open-Ended Questionnaire Item, "What did you like most about the intervention?"

\begin{tabular}{lcc}
\hline Response & $n$ & $\%$ \\
\hline Awareness about driving/impact & 7 & 31.82 \\
Prizes & 4 & 18.18 \\
Trip planning & 3 & 13.64 \\
Meeting new people & 2 & 9.09 \\
Easy to participate & 2 & 9.09 \\
Challenge to reduce driving miles & 2 & 9.09 \\
Ride the bus more & 1 & 4.55 \\
Ride my bike more & 1 & 4.55 \\
Total responses & 22 & 100.00 \\
\hline
\end{tabular}


Table 27

Summary of the Open-Ended Questionnaire Item, "What did

you like least about the intervention?"

\begin{tabular}{lcc}
\hline Response & $n$ & $\%$ \\
\hline Inconvenient sometimes & 7 & 41.18 \\
Daily totals rather than overall & 3 & 17.65 \\
Problems with GPS & 2 & 11.77 \\
Used bus more & 1 & 5.88 \\
Nothing & 1 & 5.88 \\
Luck of pulling certain prizes & 1 & 5.88 \\
Total responses & 17 & 100.00 \\
\hline
\end{tabular}

Table 28

Summary of the Open-Ended Questionnaire Item,

"What did you do to reduce your driving?"

\begin{tabular}{lrc}
\hline Response & \multicolumn{1}{c}{$n$} & $\%$ \\
\hline Trip planning & 13 & 52.00 \\
Rode the bus & 4 & 16.00 \\
Carpooled & 3 & 12.00 \\
Walked & 3 & 12.00 \\
Rode my bike & 2 & 8.00 \\
Total Responses & 25 & 100.00 \\
\hline
\end{tabular}

consolidate the trips we made," "I also made sure to combine trips to the store and plan other driving destinations (work, school, church activities) with these trips," and "limit activities requiring driving." Four of the 10 participants reported using the public bus more often. Additionally, participants were asked, "Compared to your driving before the study begun, did your knowledge about being monitored cause you to drive less, more, or 
the same?" Eight of the 10 participants reported driving less and two reported driving about the same.

Participants were also asked about which prizes they liked most and least (see Tables 29 and 30). Participants reported enjoying the gift cards from local stores and restaurants. The participants reported that their least favorite prizes were the cheap small prizes and junk food.

\section{Table 29}

Summary of the Open-Ended Questionnaire Item,

"Which prizes did you like most?"

\begin{tabular}{lrr}
\hline Response & $n$ & $\%$ \\
\hline Gift cards: Food/merchandise & 10 & 47.62 \\
Food & 3 & 14.29 \\
General statement about prizes & 3 & 14.29 \\
Variety of the prize selection & 2 & 9.52 \\
Specific prizes mentioned & 2 & 9.52 \\
Getting to pick what you want & 1 & 4.76 \\
Total responses & 21 & 100.00 \\
\hline
\end{tabular}

Table 30

Summary of the Open-ended Questionnaire item,

"Which prizes did you like least?"

\begin{tabular}{lcc}
\hline Response & $n$ & $\%$ \\
\hline Small prizes/junk food & 5 & 41.17 \\
Clothes & 3 & 25.00 \\
None & 2 & 16.67 \\
Coffee & 1 & 8.33 \\
Furniture & 1 & 8.33 \\
Total responses & 12 & 100.00 \\
\hline
\end{tabular}


Participants were asked about what they liked most and least about the weekly drawings on Wednesday night at the health department. Table 31 includes a summary of what they liked most about the drawings. Table 32 contains a brief summary of what they liked least.

Table 31

Summary of the Open-Ended Questionnaire Item, "What did you like most about the weekly drawings?"

\begin{tabular}{lcc}
\hline Response & $n$ & $\%$ \\
\hline Prizes & 3 & 20.00 \\
Something to look forward to/surprise/anticipation & 2 & 13.33 \\
Friendly host/Researcher & 2 & 13.33 \\
Talk and get to know other people & 2 & 13.33 \\
See how other people are doing & 2 & 13.33 \\
Help me try harder to reduce my driving & 1 & 6.67 \\
Consistency of the drawings & 1 & 6.67 \\
Flexible times each Wednesday night & 1 & 6.67 \\
Option to choose prize & 1 & 6.67 \\
Total Responses & 15 & 100.00 \\
\hline
\end{tabular}

\section{Table 32}

Summary of the Open-Ended Questionnaire Item, "What did you like least about the weekly drawings?"

\begin{tabular}{lcc}
\hline Response & $n$ & $\%$ \\
\hline Cheap prizes & 4 & 40.00 \\
Timing of the drawings (Wednesday evening) & 3 & 30.00 \\
Cheating & 1 & 10.00 \\
Nothing & 1 & 10.00 \\
No big prizes pulled during intervention & 1 & 10.00 \\
Total responses & 10 & 100.00 \\
\hline
\end{tabular}


Participants were asked if they would be part of a driving reduction intervention like this one in the future and all said "yes." They were also asked to explain why they would take part in a driving reduction intervention in the future. Table 33 provides a summary of their responses. The most important reasons that they would participate in a driving reduction intervention was the prizes, help motivate them to drive fewer miles, and increased their awareness of their driving behavior. Some participants said, "love the challenge and opportunities to win prizes," "I liked the motivation to drive less and prizes were great," and "it was a good way to force me to drive less...it made me always aware of what I really needed or if I could wait or take another form of transport."

Finally, participants were asked, "What other suggestions, comments, and/or ideas do you have that would improve our driving reduction intervention?" Table 34 includes a summary of their most interesting suggestions. The most common suggestion was to improve data collection with the GPS device. Other suggestions such as giving

\section{Table 33}

Summary of the Reason Why They Would Participate in a Driving Reduction Intervention like This in the Future

\begin{tabular}{lcc}
\hline Response & $n$ & $\%$ \\
\hline Prizes & 6 & 31.58 \\
Motivation to drive less/do better & 4 & 21.05 \\
Increased awareness of driving & 4 & 21.05 \\
Fun & 2 & 10.53 \\
Easy & 2 & 10.53 \\
Helped me use alternative transportation & 1 & 5.26 \\
Total Responses & 20 & 100.00 \\
\hline
\end{tabular}


Table 34

Descriptive Summary of the Suggestions to Improve the

Driving Reduction Intervention

\begin{tabular}{lcc}
\hline Response & $n$ & $\%$ \\
\hline Improve data collection with GPS & 4 & 33.33 \\
Give more info on bus/bus schedule & 2 & 16.67 \\
Track overall mileage & 2 & 16.67 \\
Set reduction goals and plan & 2 & 16.67 \\
Show money saved in gas & 2 & 16.67 \\
Total Responses & 12 & 100.00 \\
\hline
\end{tabular}

them a bus schedule, helping them plan their driving behavior, and providing them information of the amount of money saved in gas may also improve the effectiveness of the intervention. 


\section{CHAPTER V}

\section{DISCUSSSION}

The results of this driving reduction intervention are promising. The purpose of this discussion section is to summarize the results of the intervention and how the previous measurement and methodological issues found in many previous driving reduction interventions were addressed in the current intervention. The limitations and practical consideration of the current driving reduction interventions on future driving intervention research were also discussed.

\section{Treatment Efficacy}

Overall, the results of this driving reduction intervention suggest a treatment effect. Specially, when the pooled participant average server-based VMT data from each stage (baseline, intervention, and return-to-baseline) was compared, that both a shortterm and long-term treatment effect was found. The average daily server-based VMT decreased significantly from the baseline $(M=15.66)$ to the intervention stage $(M=$ 8.19). This short-term treatment effect supports previous research using voucher- and prize-based contingency management systems to promote abstinence of a target behavior by Higgins and colleagues (1991, 1993, 2000), Petry and Martin (2002), Petry, Peirce, and colleagues (2005), Silverman, Wong, and colleagues (1996), and Silverman, Higgins, and colleagues (1996).

It was also found that this treatment effect persisted for three weeks following the removal of the prize-based contingency management system and resulted in a slight 
increase in average server-based VMT from the intervention $(M=8.19)$ to return-tobaseline $(M=9.77)$ stage. This long-term post-intervention maintenance of the target behavior supports the findings of previous research using prize-based contingency management systems in community-based interventions by Higgins, Wong, and colleagues (2000), Petry, Alessi, and colleagues (2005), and Petry, Peirce, and colleagues (2005).

The pooled GPS-based VMT also indicated a slight increase in VMT from the intervention $(M=10.78)$ to the return-to-baseline $(M=13.99)$ stage. Again, these results are consistent with previous research on voucher- and prized-based contingency management systems by Silverman and colleagues (1996).

\section{Participant-Level Treatment Efficacy}

Results of the participant-level data also suggest that for some people the prizebased contingency system used in this driving reduction intervention may an effective treatment in reducing their daily VMT. It was found six of the 10 participants significantly reduced their average daily VMT from the baseline stage to the intervention stage and maintained those reductions following the removal of the prize-based contingency management system during the return-to-baseline stage. On closer inspection, it was also found that the other four participants also reduced their average daily VMT from the baseline to intervention stage and slightly increased their average daily VMT from the intervention to the return-to-baseline stage but these differences were not found to be statistically significant. However, these reductions are of practically significant. Even small reductions in daily VMT in high-risk air pollution areas such as 
Cache County, Utah, can have a significant impact on air quality. No demographic differences were found between the six participants that responded favorably to the prizebased contingency management system and the four participants that did not. For these four participants, the prizes may not have been salient enough to beneficially impact the target behavior. This supports the conclusions of Petry and colleagues (2004) that the beneficial effects of prize reinforcements may be dependent on the magnitude of the prizes for people with more severe problematic behaviors. Future research should test for the possible differences between prize magnitudes on VMT.

Another variable that may be particularly import is socioeconomic status (SES). Three of the four participants that did not exhibit reductions at the statistically significant level were the only participants with full-time employment and yearly earnings of $\$ 30,000$ or more per year. These participants may not have reacted as favorably to the prize-based contingency system because they may not have perceived the prizes as salient enough to promote driving behavior change. It may be that people that make less than $\$ 30,000$ annually respond more favorably to the prizes that were given in this intervention. It may require prizes of greater retail value or offering experiences such as vacation packages for some people reduce their driving behavior. Also, their jobs/careers require that they commute each day back and forth to work. Therefore, they may not be able to make major reductions in their driving behavior without significant altering their commuting behavior by carpooling or riding the bus. Some people may not drive much more than their daily commute, leaving little room for reductions in their overall daily driving mileage (i.e., floor effects) especially when no alternative mode of transportation 
is available.

\section{Interaction Effects}

No interaction effect was found between the prize-based contingency management system and the "Choose Clean Air" social marketing campaign on driving reductions. The results suggest there no differences between daily VMT reductions on days with high levels of air pollution (PM 2.5) or on air pollution alert days ("Red" and "Yellow Air Days") and days with low levels of air pollution ("Green Air Days"). Gas prices and temperature also had little effect on daily VMT. However, it was found that when compared to sunny, fair, and clear days participants drove fewer miles on fog/haze days. This visible evidence of air pollution may have encouraged participants to reduce their daily VMT even further.

\section{Treatment Dosage or Length}

The length of this driving reduction intervention is significantly longer than previous driving reduction intervention research. As outlined in the meta-analysis, most of the previous driving reduction interventions lasted approximately 2 to 4 weeks in length. The present intervention lasted a total of 14 weeks and included a pre- and postintervention-monitoring period. Our results suggest that conducting an intervention of this length can provide more detailed VMT and driving behavior data than can be retrieved in an intervention that lasts only two weeks. Specifically, this longitudinal VMT data can more accurately track driving trends and patterns. These data can also be used to determine how, when, and for purposes people use their personal vehicles. 
Future research using these methodologies should also consider reducing the intervention period (from 8 weeks to 6 or 4 weeks). It may be possible to realize shortand long-term reductions in average daily VMT in fewer weeks. To determine the longterm impact of the treatment, future research should also consider an additional follow-up data collection period at a year.

\section{Support for Prize-Based Contingency Management Systems}

The results of this intervention provide additional support for the three basic tenets of contingency management systems proposed by Petry (2000). First, with the assistance of the in-car GPS tracking devices, vehicle miles of travel (target behavior) was easily detected, and objectively and frequently measured during the 14-week intervention. Despite missing data issues, the in-car GPS tracking devices showed promise as a reliable and valid data collection instrument that can be used in future driving behavior research. Second, the vouchers (reinforcers; chance to win a prize) were immediately and consistently delivered when participants' daily VMT were reduced below their average baseline VMT. In this intervention, participants received a daily email that contained information about their previous day's VMT, whether or not they earned a voucher, and their total voucher earnings for the week. In the exit questionnaire, participants reported that they enjoyed the array of and process of prize selection. Specifically, they reported that choosing a prize from a list prize was better than being assigned a prize they may or may not like. Finally, the vouchers were consistently withheld when reductions were not achieved. The daily email informed the participants 
whether or not they achieved a reduction in VMT from the previous day. These finding are consistent with the research on the magnitude of the prizes available, immediate and consistent delivery of prizes, benefits of choosing a prize and wide prize selections conducted by Petry (2006a, 2006b) and Petry and colleagues (2000).

\section{Prize-Based Contingency Management with Donations}

This driving reduction intervention also provides additional evidence that supports prize-based contingency management systems with donations from local business an effective and lower cost alternative to traditional voucher-based system (i.e., Amass and Kamien, 2004; Lewis, 2008; Petry, 2000; Petry, Alessi, et al., 2005; Olmstead \& Petry, 2009). In this intervention, the donations retrieved from local businesses reduced the financial burden necessary to conduct this study and added significantly to the overall selection of prices available to participants to win. Future driving reduction interventions should explore the possible long-term sustainability of a prize-based contingency system with donations.

\section{Implications for Psychological Theory}

This dissertation research project applied a well-established behavioral model from drug reduction and abstinence research to a novel problem, setting, and population. The results of this project provide further evidence for the application or external validity of prize-based contingency management systems in other areas of behavioral research. This also supports the previous findings from Gellar, Fox and colleagues on encouraging 
proenvironmental (Witmer \& Geller, 1976) and prosocial behaviors (Boyce \& Geller, 2000; Fox et al., 1987) through contingency management systems, Additional research is needed to determine the efficacy of interventions that employ contingency management systems to reduce or encourage other pro-environmental and pro-social behaviors in other populations and settings.

\section{Measurement Issues}

Previous driving reduction interventions have had some measurement issues including an over-reliance on self-report measures of driving behavior such as travel diaries to collect driving behavior data. The electronic in-car GPS tracking devices in this intervention were used as a replacement for travel diaries. They were found to be relatively useful and accurate data collection instruments in tracking daily VMT. These findings supports previous research findings on GPS tracking devices as data collection instruments by Kochan and colleagues (2005), Ohmori and colleagues (2004), Wolf and colleagues (1999), and Zhou and Golledge (2000).

It was also found that the GPS tracking devices used in this study experienced similar software and hardware problems reported in previous studies by Bellemans and colleagues (2005), Ohmori and colleagues (2005, 2006), Wolf and colleagues (1999), and Zhou and Golledge (2000). Some of these issues included general software malfunctions, limited storage capacity, delayed connections between the SIM card and the server, and problematic connections between GPS device and satellites that must be addressed in future research. In future studies, the in-car GPS tracking device should either be 
installed with more storage space (memory) or efforts should be made to retrieve data every 3 or 4 weeks during the study to prevent data loss.

The transmission of data points through the phone service data plan was not always successful because of network connection problems and air pollution-related issues (e.g., high concentrations of air pollution would cause calls to be dropped). The phone service also had some difficulties connecting with the network in some areas of Cache County, Utah because of poor cell tower coverage. Additionally, the GPS device was only programmed to transmit data points through the cell phone network once and then record them on its internal memory. Unfortunately, when the internal memory was full it would write over previous recordings. This led to significant data loss. In the future, it is recommended to use a cell phone service with the best and widest coverage in the target area of the study and program the device to continue transmitting the data points until the connection with the remote server is successfully completed.

The in-car GPS tracking device also had some difficulties connecting with the GPS satellite constellation during the initial start-up of the engine or during the trip. This would result in missing data points; however, this can be corrected by tracking the participant's driving patterns on a road map. By tracking their driving patterns visually on a road map, missing points or delayed starts can be accounted for and the proper mileage estimates can be recalculated.

The device should also be powered continuously rather than just when the engine is running. To prevent missing data points, the device can be programmed to check in every 10 minutes with the off-site server to determine location and software issues. 


\section{Practical Significance and Future Recommendations}

Although the results of this driving reduction intervention indicate a treatment effect, caution must be used when interpreting and generalizing the results of this study. Transmission issues between the in-car GPS device and off-site server were a cause of significant data loss and major threat to internal validity. Consequently, further replication is necessary to improve in-car GPS software and hardware and determine treatment effects in different settings and populations.

Despite the success of this driving reduction intervention on a small scale, it may be extremely difficult and costly to conduct this project on a larger scale such as in a community. The average per vehicle cost for the in-car GPS device and associated services costs around $\$ 550$ with another $\$ 500$ in prize costs per person (2010 US dollars). With technological advances and improvements in donation collection, these costs can be significantly reduced. Even with these cost reductions, however, an intervention like this may still be cost prohibitive for some communities to conduct. To conduct this type of intervention with a larger community (group design), there are a number of issues to consider such as how VMT will be measured and recorded, the type of prizes or rewards given to residents, and the system that would be used to deliver these prizes. It may be possible to use Department of Motor Vehicle VMT data from yearly vehicle inspections and registrations. In this way, the residents' VMT can be tracked and compared to previous years. If reductions are made from previous years, a prize-bowl system can still be used to reward people. Another prize option may be to use some type of tax credit system, where residents' are given a tax credit based on the degree to which they have 
reduced their VMT from the previous year. Residents can also be taxed proportionate to their increases in their VMT from the previous year.

Other variables to consider when developing a large scale driving reduction intervention are the characteristics of the community and the support of community leaders. Specifically, researchers must consider the potential impact that socioeconomic status (i.e., low versus high SES status), employment status (i.e., full-time versus parttime; blue collar versus white collar work), ethnic and cultural background, access to alternative forms of transportation (i.e., bus or subway system; carpooling; walk/ride bicycle), local (i.e., rural, urban, or suburban; safe or dangerous neighbors), and the support of the community (i.e., presence air pollution abatement strategies; leader support at the family, community, religious, political level). Support from community and opinion leaders is vital to the success of the intervention. With the help of opinion leaders, social marketing campaigns can be created to generate norms of reduced driving. Additional research is needed to determine the impact of these factors on the efficacy of a community-wide driving reduction intervention.

Overall, the results of this driving reduction intervention are promising but additional research and replication is still needed. Future research should consider further use and testing of an in-car GPS tracking device to improve both the software and hardware of these devices. Additional steps should also be made to improve data recording, transmission, and retrieval to prevent data loss. Specifically, a reliable phone service should be used to transmit data remotely. The in-car GPS device should be programmed to continually transmit data until data delivery is confirmed. Also, software 
needs to be developed to check for errors in the data collection process, self-correct, and automatize the conversion latitudinal and longitudinal data points to VMT data. For these reasons, this type of prize-based contingency management driving reduction intervention is also time, financially, and human resource intensive. People will need to be employed to manage the hardware and software of the in-car GPS devices, the VMT data, prize acquisition and delivery, and daily communication with participants and community. Considerations should also be made to employ a group research design to determine the possible differences (i.e., demographic) between those that respond favorably to the prize-based contingency management system and those that do not. Future research should also test the possible differences between prize delivery systems (immediate versus delayed), prize magnitude (low versus high dollar amounts) on driving behaviors, and potential problem of floor effects with commuting/driving behavior. 


\section{REFERENCES}

Alessi, S.M., Hanson, T., Wieners, M., \& Petry, N.M. (2007). Low-cost contingency management in community clinics: Delivering incentives partially in group therapy. Experimental and Clinical Psychopharmacology, 15, 293-300.

Amass, L., \& Kamien, J. (2004). A tale of two cities: Financing two voucher programs for substance abusers through community donations. Experimental and Clinical Psychopharmacology, 12, 147-155.

Bellemans, T., Kochan, B., Janssens, D., \& Wets, G. (2005). Collecting activity-travel diary data by means of a GPS enabled personal digital assistant. Colloquium Vervoersplanologisch Speurwerk, 32, 2111-2131.

Bernard, H.R., Killworth, D., Kronenfeld, D., \& Sailor, L. (1984). The problem of informant accuracy: The validity of retrospective data. Annual Review of Anthropology, 13, 495-517.

Bickel, W.K., Amass, L., Higgins, S.T., Badger, G.J., \& Esch, R. (1997). Behavioral treatment improves outcomes during opioid detoxification with buprenophine. Journal of Consulting and Clinical Psychology, 65, 803-810.

Boyce, T.E., \& Geller, E.S. (2000). A community-wide intervention to improve pedestrian safety: Guidelines for institutionalizing large-scale behavior change. Environment and Behavior, 32, 502-520.

Briere, J., Downes, A., \& Spensely, J. (1983). Summer in the city: Urban weather conditions and psychiatric emergency-room visits. Journal of Abnormal Psychology, 92, 77-80.

Brunekreef, B., \& Holgate, S. (2002). Air pollution and health. The Lancet, 360, 1233 1242.

Budney, A.J., Higgins, S.T., Radonovich, K.J., \& Novy, P.L. (2000). Adding voucherbased incentives to coping skills and motivational enhancement improves outcomes during treatment for marijuana dependence. Journal of Consulting and Clinical Psychology, 68, 1051-1061.

Bullinger, M. (1989). Psychological effects of air pollution on healthy residents: A timeseries approach. Journal of Environmental Psychology, 9, 103-118.

Campbell, L.M., Sullivan, F., \& Murray, T.S. (1995). Videotaping of general practice consultations: Effect on patient satisfaction. British Medical Journal, 311, 236. 
Carroll, K.M., Sinha, R., Nich, C., Babuscio, T., \& Rounsaville, B.J. (2002). Contingency management to enhance naltrexone treatment of opioid dependence: A randomized clinical trial of reinforcement magnitude, Experimental and Clinical Psychopharmacology, 10, 54-63.

Chattopadhyay, P.K., Som, B., \& Mukhopadhyay, P. (1995). Air pollution and health hazards in human subjects: Physiological and self-report indices. Journal of Environmental Psychology, 15, 327-331.

Chutuape, M.A., Silverman, K., \& Stitzer, M. (1999). Contingency reinforcement sustains post-detoxification abstinence from multiple drugs: A preliminary study with methadone patients. Drug and Alcohol Dependence, 54, 69-81.

Cleland, F. (2007). Reducing numbers of vehicle trips and vehicle miles of travel through customized travel options. Transportation Research Record, 1711, 39-45.

Delucchi, M.A., Murphy, J.J., \& McCubbin, D.R. (2002). The health and visibility cost of air pollution: A comparison of estimation methods. Journal of Environmental Management, 64, 139-152.

Deutscher, I. (1973). What we say/what we do: Sentiments and acts. Glenview, IL: Foresman.

Drebing, C.E., Van Ormer, E.A., Mueller, L., Hebert, M., Penk, W.E., Rosenheck R,, \& Rounsaville, B. (2007). Adding contingency management intervention to vocational rehabilitation: Outcomes for dually diagnosed veterans. Journal of Rehabilitation Research \& Development, 44, 851-866.

Edwards, A.L. (1957). The social desirability variable in personality assessment and research. Fort Worth, TX: Dryden.

Environmental Protection Agency (EPA). (2009a). Toxic air pollutants. Retrieved from http://www.epa.gov/air/toxicair/newtoxics.html

Environmental Protection Agency (EPA). (2009b). About air toxics. Retrieved from http://www.epa.gov/air/toxicair/newtoxics.html\#effects

Eriksson, L., Garvill, J., \& Nordlund, A.M. (2008). Interrupting habitual car use: The importance of car habit strength and moral motivation for personal car use reduction. Transportation Research Part F, 11, 10-23.

Evans, G.W., \& Campbell, J.M. (1983). Psychological perspectives on air pollution and health. Basic and Applied Social Psychology, 4, 137-169. 
Evans, G.W., Colome, S.D., \& Shearer, D.F. (1988). Psychological reaction to air pollution. Environmental Research, 45, 1-15.

Evans, G.W., \& Jacobs, S.V. (1981). Air pollution and human behavior. Journal of Social Issues, 37, 95-125.

Evans, G.W., \& Jacobs, S.V. (1982). Air pollution and human behavior. In G.W. Evans (Ed.), Environmental stress (pp. 105-132). Cambridge, MA: Cambridge University Press.

Fauroux, B., Sampil, M., Quenel, P., \& Lemoullec, Y. (2000). Ozone: A trigger for pediatric asthma emergency visits. Pediatric Pulmonology, 30, 41-46.

Ferster, C.B. (1958). Reinforcement and punishment in the control of human behavior of social agencies. Psychiatric Research Report, 10, 101-118.

Fisher, R. (1993). Social desirability bias and the validity of indirect questioning. Journal of Consumer Research, 20, 303-15.

Fox, D.K., Hopkins, B.L., \& Anger, W.K. (1987). The long-term effects of a token economy on safety performance in open-pit mining. Journal of Applied Behavior Analysis, 20, 215-224.

Fujii, S., \& Taniguchi, A. (2005). Reducing family car-use by providing travel advice or requesting behavioral plans: An experimental analysis of travel feedback programs. Transportation Research Part D, 10, 385-393.

Fujii, S., \& Taniguchi, A. (2006). Determinants of the effectiveness of travel feedback programs: A review of communicative mobility management measures for changing travel behavior in Japan. Transport Policy, 13, 339-348.

Gardner, G.T., \& Stern, P.C. (2002). Environmental problems and human behavior. Boston, MA: Pearson.

Garling, T., Eek, D., Loukopoulos, P., Fujii, S., Johansson-Stenman, Kitamura, R., ... Vilhelmson, B. (2002). A conceptual analysis of the impact of travel demand management on private car use. Transport Policy, 9, 59-70.

Garling, T., Garling, A., \& Johansson, A. (2000). Household choices of car-use reduction measures. Transportation Research Part A, 34, 309-320. 
Garling, T., Garling, A., \& Loukopoulos, P. (2002). Forecasting psychological consequences of car use reduction: A challenge to an environmental psychology of transportation. Applied Psychology: An International Review, 51, 90-106.

Garling, T., Gillholm, R., \& Garling, A. (1998). Reintroducing attitude theory in travel behavior research. The validity of an interactive interview procedure to predict. Transportation, 25, 129-146.

Garling, T., \& Loukopoulos, P. (2005). Effectiveness, public acceptance, and political feasibility of coercive measures for reducing car traffic. In T. Garling \& L. Stegg (Eds.), Threats from car traffic to the quality of urban life (pp. 313-324). Oxford, England: Elsevier.

Garling, T., \& Marell, A. (1992). Households' strategies for reducing automobile travel (Technical Report \#2). Umea, Sweden: Umea University, Transportation Research Unit.

Garling, T., \& Steg, L. (2005). Threats from car traffic to the quality of urban life: Problems, causes, solutions. Oxford, England: Elsevier.

Gifford, R., \& Steg, L. (2005). The impact of automobile traffic on quality of life. In T. Garling \& L. Stegg (Eds.), Threats from car traffic to the quality of urban life (pp. 33-51). Oxford, England: Elsevier.

Goodwin, P. (1996). Simple arithmetic. Transport Policy, 3, 79-80.

Goodwin, P. (2005). Effectiveness of transport policies in reducing car travel. In T. Garling \& L. Stegg (Eds.), Threats from car traffic to the quality of urban life (pp. 401-424). Oxford, England: Elsevier.

Greene, D.L., \& Wegener, M. (1997). Sustainable transport. Journal of Transport Geography, 5, 177-190.

Greenland, D. (1983). Guidelines for modern resource management: Soil, land, water, and air. Columbus, $\mathrm{OH}$ : Merrill.

Griffith, J.D., Rowan-Szal, G.A., Roark, R.R., \& Simpson, D.D. (2000). Contingency management in outpatient methadone treatment: A meta-analysis. Drug and Alcohol Dependence, 58, 55-66.

Hersen, M., \& Barlow, D.H. (1976). Single case experimental designs: Strategies for studying behavior change. Oxford, England: Pergamon. 
Higgins, S.T., Alessi, S.M., \& Dantona, R.L. (2002). Voucher-based incentives: A substance abuse treatment innovation. Addictive Behavior, 27, 887-910

Higgins, S.T., Badger, G.J., \& Budney, A.J. (2000). Initial abstinence and success in achieving long-term cocaine abstinence. Experimental and Clinical Psychopharmacology, 8, 377-386.

Higgins, S.T., Budney, A.J., Bickel, W.K. Foerg, F.E., Donham, R., \& Badger, G.J. (1994). Incentives improve outcome in patient behavioral treatment of cocaine dependence. Archives of General Psychiatry, 51, 568-576.

Higgins, S.T., Budney, A.J., Bickel, W.K., Hughes, J., Foerg, F.E., \& Badger, G.J. (1993). Achieving cocaine abstinence with a behavioral approach. The American Journal of Psychiatry, 150, 763-769.

Higgins, S.T., Delaney, D.D., Budney, A.J., Bickel, W.K., Hughes, J., Foerg, F., \& Fenwick, J.W. (1991). A behavioral approach to achieving initial cocaine abstinence. The American Journal of Psychiatry, 148, 1218-1224.

Higgins, S.T., \& Petry, N.M. (1999). Contingency management: Incentives for sobriety. Alcohol Research and Health, 23, 122- 127.

Higgins, S.T., Sigmon, S.C., Wong, C.J., Heil, S.H., Badger, G.J., Donham, R., ... Anthony, S. (2003). Community reinforcement therapy for cocaine-dependent outpatients. Archives of General Psychiatry, 60, 1043-1052.

Higgins, S.T., Wong, C.J., Badger, G.J., Ogden, D.E., \& Dantona, R.L. (2000). Contingent reinforcement increases cocaine abstinence during outpatient treatment and 1 year of follow-up. Journal of Consulting and Clinical Psychology, 68, 64-72.

Hofmann-Wellenhof, B., Lichtenegger, H., \& Collins, J. (1997). GPS: Theory and practice $\left(3^{\text {rd }}\right.$ ed.). New York, NY: Springer-Verlag

Holgate, S.T., Samet, J.M., Maynard, R.L., \& Koren, H.S. (Eds.). (1999). Air pollution and health. San Diego, CA: Academic.

Iguchi, M.Y., Stitzer, M.L., Bigelow, G.E., Liebson, I.A. (1988). Contingency management in methadone maintenance: Effects of reinforcing and aversive consequences on illicit polydrug use. Drug and Alcohol Dependence, 22, 17-23.

Jakobsson, C. (2004). Accuracy of household planning of car use: Comparing prospective to actual car logs. Transportation Research Part F, 7, 31-42. 
Jakobsson, C., Fujii, S., \& Garling, T. (2002). Effects of economic disincentives on private car use. Transportation, 29, 349-370.

Kalfs, N., \& Saris, W.E. (1997). New data collection methods in travel surveys. In D.F. Ettema \& H.J.P. Timmermans (Eds.) Activity based approaches to travel analysis (pp. 243-262). Oxford, England: Pergamon.

Kirby, K.C., Benishek, L.A., Dugosh, K.L., \& Kerwin, M.E. (2006). Substance abuse treatment providers' beliefs and objections regarding contingency management: Implications for dissemination. Drug and Alcohol Dependence, 85, 19-27.

Kochan, B., Janssens, D., Bellemans, T., \& Wets, G. (2005, September). Collecting activity-travel diary data by means of a hand-held computer-assisted data collection tool. Paper presented at the $10^{\text {th }}$ EWGT Meeting/ $16^{\text {th }}$ Mini EURO Conference, Poznan, Poland.

Lawental, E., \& Eshkol, D. (2006). A low voucher contingency management programme with Israeli methadone-maintained patients: A pilot evaluation study. Heroin Addiction and Related Clinical Problems, 8, 37-46.

Lewis, M.W. (2008). Application of contingency management-prize reinforcement to community practice with alcohol and drug problems: A critical examination. Behavior and Social Issues, 17, 119-138.

Litman, T. (2003). The online TDM encyclopedia: Mobility management information gateway. Transport Policy, 1, 245-249.

Loukopoulos, P. (2007). The impact of automobile traffic on quality of life. In T. Garling \& L. Stegg (Eds.), Threats from car traffic to the quality of urban life (pp. 275292). Oxford, England: Elsevier.

Malek, E., Davis, T., Martin, R.S., \& Silva, P.J. (2006). Meteorological and environmental aspects of one of the worst air pollution episodes (January 2004) in Logan, Cache Valley, Utah, USA. Atmospheric Research, 79, 108-122.

Martin, E., \& Martin, P.M.L. (1984). The reactions of patients to a video camera in the consulting room. Journal of the Royal College of General Practitioners, 34, 607610.

Moshammer, H., Bartonova, A., Hanke, W., Van Den Hazel, P., Koppe, J.G., Kramer, U., ... Zuurbier, M. (2006). Air pollution: A threat to the health of our children. Acta Paediatrica, 95, 93-105. 
Nickerson, R.S. (2003). Psychology and environmental change. Mahwah, NJ: Erlbaum.

Ohmori, N., Harata, N., \& Ohta, K. (2004, May). Two applications of GIS-based activitytravel simulators. Paper presented at the EIRASS workshop on Progress in Activity-Based Analysis in Maastricht.

Ohmori, N., Nakazato, M., \& Harata, N. (2005). GPS mobile phone-based activity diary survey. Proceedings of the Eastern Asia Society for Transportation Studies, 5, 1104-1115.

Ohmori, N., Nakazato, M., Harata, N., Sasaki, K., \& Nishii, K. (2006, January). Activity diary surveys using GPS mobile phones and PDA. Paper presented at the $85^{\text {th }}$ Annual Meeting of the Transportation Research Board, Washington, DC.

Olmstead, T.A., \& Petry, N.M. (2009). The cost-effectiveness of prized-based and voucher-based contingency management in a population of cocaine- or opioiddependent outpatients. Drug and Alcohol Dependence, 102, 108-115.

Olmstead, T.A., Sindelar, J.L., \& Petry, N.M. (2007). Clinic variation in the costeffectiveness of contingency management. The American Journal of Addictions, 16, 457-460.

Peirce, J.M., Petry, N.M., Stitzer, M.L., Blaine, J.K., Li, R., \& Roll, J.M. (2006). Lowercost incentives increase stimulant abstinence in methadone maintenance community treatment: Results of the national drug abuse treatment clinical trials network multi-site study. Archives of General Psychiatry, 63, 201-208.

Peterson, E.B., \& Hamburg, J.R. (1986). Travel surveys: Current options. Transportation Research Record, 1097, 1-3.

Petry, N.M. (2000). A comprehensive guide to the application of contingency management procedures in general clinic settings. Drug and Alcohol Dependence, 58, 9-25.

Petry, N.M. (2006a). Contingency management treatments. British Journal of Psychiatry, 189, 97-98.

Petry, N.M. (2006b). A clinician's guide for implementing contingency management programs. Retrieved from http://www.drugsandalcohol.ie/13618/

Petry, N.M., Alessi, S.M., Tedford, J., Austin, M., \& Tardif, M. (2005). Vouchers versus prizes: Contingency management treatment of substance abusers in community settings. Journal of Consulting and Clinical Psychology, 73, 1005-1014. 
Petry, N.M., \& Martin, B. (2002). Low-cost contingency management for treating cocaine- and opiod-abusing methadone patients. Journal of Consulting and Clinical Psychology, 70, 398-405.

Petry, N.M., Martin, B., Cooney, J.L., \& Kranzler, H.R. (2000). Give them prizes and they will come: Variable-ratio contingency management for treatment of alcohol dependence. Journal of Consulting and Clinical Psychology, 68, 250-257.

Petry, N.M., Martin, B., \& Finocche, C. (2001). Contingency management in group treatment: A demonstration project in an HIV drop-in center. Journal of Substance Abuse Treatment, 21, 89-96.

Petry, N.M., Martin, B., \& Simcic, F. (2005). Prize reinforcement contingency management for cocaine dependence: Integration with group therapy in a methadone clinic. Journal of Consulting and Clinical Psychology, 73, 354-359.

Petry, N.M., Petrakis, I., Trevisan, L., Wiredu, G., Boutros, N.N., Martin, B., \& Korsten, T.R. (2001). Contingency management interventions: From research to practice. The American Journal of Psychiatry, 158, 694-702.

Petry, N.M., Pierce, J.M, Stitzer, M.L., Blaine, J., Roll, J.M., Cohen, A, .. Li, R. (2005). Effects of prize-based incentives on outcomes in stimulant abusers in outpatient psychosocial treatment programs. Archives of General Psychiatry, 62, 1148-1156.

Petry, N.M., \& Simcic, F. (2002). Contingency management interventions: Clinician and researcher perspectives. Journal of Substance Abuse Treatment, 23, 81-86.

Petry, N.M., Tedford, J., Austin, M., Nich, C., Carroll, K.M., \& Rounsaville, B.J. (2004). Prize reinforcement contingency management for treatment of cocaine abusers: How low can we go, and with whom? Addiction, 99, 349-360.

Piotrowski, N.A, Tusel, D.J., Sees, K.L., Reilly, P.M., Banys, P., Meek, P., \& Hall, S.M. (1999). Contingency contracting with monetary reinforcers for abstinence from multiple drugs in a methadone program. Experimental and Clinical Psychopharmacology, 7, 399-411.

Plitnik, G.R. (1998). Air pollution and air pollution control. In M. Coyne \& C. W. Allin (Eds.), Natural resources (Vol. 1, pp. 13-16). Pasadena, CA: Salem.

Pope, C.A. III, Burnett, R.T., Thun, R.J., Calle, E. E., Krewski, D., Ito, K., \& Thurston, G.D. (2002). Lung cancer, cardiopulmonary mortality, and long-term exposure to fine particulate air pollution. Journal of the American Medical Association, 287, 1132-1141. 
Prendergast, M., Podus, D., Finney, J., Greenwell, L., \& Roll, J. (2006). Contingency management for treatment of substance use disorders: A meta-analysis. Addiction, $101,1546-1560$.

Preston, K.L., Silverman, K. Higgins, S.T., Brooner, R.K., Montoya, I., Schuster, C.R., \& Cone, E.J. (1998). Cocaine use early in treatment predicts outcome in a behavioral treatment program. Journal of Consulting and Clinical Psychology, 66, 691-698.

Preston, K.L., Silverman, K., Umbricht, A., DeJesus, A., Montoya, I.D., \& Schuster, C.R. (1999). Improvement in naltrexone treatment compliance with contingency management. Drug and Alcohol Dependence, 54, 127-135.

Rawson, R.A., Huber, A., McCann, M., Shoptaw, S., Farabee, D., Reiber, C., \& Ling, W. (2002). A comparison of contingency management and cognitive-behavioral approaches during methadone maintenance treatment for cocaine dependence. Archives of General Psychiatry, 59, 817-824.

Rawson, R.A., McCann, M.J., Hasson, A.J., \& Ling, W. (1994). Cocaine abuse among methadone maintenance patients: Are there effective treatment strategies? Journal of Psychoactive Drugs, 26, 129-136.

Reynolds, B., Dallery, J., Shroff, P., Patak, M., \& Leraas, K. (2008). A web-based contingency management program with adolescent smokers. Journal of Applied Behavior Analysis, 41, 597-601.

Roll, J.M., Higgins, S.T., \& Badger, G.J. (1996). An experimental comparison of three different schedules of reinforcement of drug abstinence using cigarette smoking as an exemplar. Journal of Applied Behavior Analysis, 29, 495-505.

Roll, J.M., Petry, N.M., Stitzer, M.L., Brecht, M.L., Pierce, J.M., McCann, M.J., ... Kellog, S. (2006). Contingency management for the treatment of methamphetamine use disorders. American Journal of Psychiatry, 163, 19931999.

Rotton, J., \& Frey, J. (1984). Psychological costs of air pollution: Atmospheric conditions, seasonal trends, and psychiatric emergencies. Population and Environment, 7, 3-16.

Schmitz, J.M., Rhoades, H.M., Elk, R., Creson, D., Hussein, I., \& Grabowski, J. (1998). Medication take-home doses and contingency management. Experimental and Clinical Psychopharmacology, 6, 162-168. 
Servant, J.B., \& Matheson, J.A.B. (1986). Video recording in general practice: The patients do mind. Journal of the Royal College of General Practitioners, 36, 555556.

Shaner, A., Roberts, L.J., Eckman, T.A., Tsuang, J.W., Wilkins, J.N., Mintz, J., \& Tucker, D.E. (1997). Monetary reinforcement of abstinence from cocaine among mentally ill patients with cocaine dependence. Psychiatric Services, 48, 807-810.

Silverman, K., Chutuape, M.A.D., Bigelow, G.E., \& Stitzer, M.L. (1999). Voucher-based reinforcement of cocaine abstinence in treatment-resistant methadone patients: Effects of reinforcement magnitude. Psychopharmacology, 146, 128-138.

Silverman, K., Wong, C., Higgins, S.T., Brooner, R.K., Montoya, I., Contoreggi, C., Umbricht-Schneiter, A., ... Preston, K. (1996). Increasing opiate abstinence through voucher-based reinforcement therapy. Drug and Alcohol Dependence, 41, 157-165.

Silverman, K. Higgins, S.T., Brooner, R.K., \& Montoya, I.D. (1996). Sustained cocaine abstinence in methadone maintenance patients through voucher-based reinforcement therapy. Archives of General Psychiatry, 53, 409-415.

Sindelar, J., Elbel, B., \& Petry, N.M. (2007). What do we get for our money? Costeffective of adding contingency management. Addiction, 102, 309-316.

Steg, L., \& Schuitema, G. (2005). Behavioral responses to transport pricing: A theoretical analysis. In T. Garling \& L. Stegg (Eds.), Threats from car traffic to the quality of urban life (pp. 347- 366). Oxford, England: Elsevier.

Steg, L., \& Vlek, C. (2009). Encouraging pro-environmental behaviour: An integrative review and research agenda. Journal of Environmental Psychology, 29, 309-317.

Stern, P.C. (1992). Psychological dimensions of global environmental change. Annual Review of Psychology, 43, 269-302.

Stitzer, M.L., Bickel, W.K., Bigelow, G.E., \& Liebson, I.A. (1986). Effects of methadone dose contingencies on urinalysis test results of polydrug-abusing methadonemaintenance patients. Drug and Alcohol Dependence, 18, 341-348.

Stitzer, M.L., \& Bigelow, G.E. (1982). Contingent reinforcement for reduced carbon monoxide levels in cigarette smokers. Addictive Behaviors, 7, 403-412.

Stitzer, M.L., \& Bigelow, G.E. (1983). Contingent payment for carbon monoxide reduction: Effect of pay amount. Behavior Therapy, 14, 647-656. 
Stitzer, M.L., Iguchi, M.Y., \& Felch, L.J. (1992). Contingent take-home incentive: Effects on drug use of methadone maintenance patients. Journal of Consulting and Clinical Psychology, 60, 927-934.

Stopher, P.R., FitzGerald, C., \& Xu, M. (2007). Assessing accuracy of the Sydney Household Survey with GPS. Transportation, 34, 723-741.

Stone, A.A., Turkkan, J.S., Bachrach, C.A. Jobe, J.B., Kurtzman, H.S., \& Cain, V.S. Stopher, P.R., \& Greaves, S.P. (2007). Household travel surveys: Where are we going? Transportation Research Part A, 41, 367-381.

(Eds.). (2000). The science of self-report: Implications for research and practice. Mahwah, NJ: Erlbaum.

Taniguchi, A., Suzuki, H., \& Fujii, S. (2007). Mobility management in Japan: Its development and meta-analysis of travel feedback programs. Transportation Research Record, 2021, 100-109.

Tertoolen, G., \& Verstan, E.C.H. (1995). Changing attitudes and behaviour by means of providing information. A study of private car use. Studies in Environmental Science, 65, 1189-1192.

Tertoolen, G., Van Kreveld, D., \& Verstraten, B. (1998). Psychological resistance against attempts to reduce private car use. Transportation Research Part A, 32, 171-181.

U.S. Census Bureau. (2009). State and County QuickFacts: Cache County, Utah. Retrieved from http://quickfacts.census.gov/qfd/states/49/49005.html

Vining, J., \& Ebreo, A. (2002). Emerging theoretical and methodological perspectives on conservation behavior. In R.B. Bechtel \& A. Churchman (Eds.), Handbook of environmental psychology (pp. 541-558). New York, NY: Wiley.

Wagner, D. (1997). Global positioning systems for personal travel surveys: Lexington area travel data collection test. Report to the Federal Highway Administration. Hill Air Force Base, UT: US Department of Transportation, Battelle Memorial Institute.

Weisel, C.P., Cody, R.P., \& Lioy, P.J. (1995). Relationship between summertime ambient ozone levels and emergency department asthma in Central New Jersey. Environmental Health Perspectives, 103(supplemental 2), 97-102.

Witmer, J.F., \& Geller, E.S. (1976). Facilitating paper recycling: Effects of prompts, raffles, and contests, Journal of Applied Behavior Analysis, 9, 315-322. 
Wolf, J., Guensler, R., \& Bachman, W. (2001, January). Elimination of the travel diary: An experiment to derive trip purpose from GPS travel data. Paper presented at the $80^{\text {th }}$ Annual Meeting of the Transportation Research Board, Washington, DC.

Wolf, J., Hallmark, S., Oliveira, M., Guensler, R., \& Sarasua, W. (1999). Accuracy issues with route choice data collection by using global positioning system. Journal of the Transportation Research Board, 1660, 66-74.

Wolf, J., Oliveira, M., \& Thompson, M. (2003). Impact of underreporting on mileage and travel time estimates: Results from global position system-enhanced household travel survey. Transportation Research Record, 1854, 189-198.

Zeidner, M., \& Shechter, M. (1988). Psychological responses to air pollution: Some personality and demographic correlates. Journal of Environmental Psychology, 8, 191-208.

Zhou J., \& Golledge, R. (2000, April). An analysis of variability of travel behavior within one-week period based on GPS. Paper presented at the IGERT Conference, Davis, CA. 
112

APPENDICES 
Appendix A

Recruitment Advertisement 
Recruitment Advertisement

How would you like to be paid 20 dollars for your participation in a research project?

We are testing the functionality of in-car GPS (Global Positioning System) device in people's vehicles. You will be asked to take a short survey and be given 2 dollars for your time. If you are randomly selected to be part the research project, you will be asked keep a GPS device in your car for 3 weeks. Following your participation, you will be paid 20 dollars for your efforts. If you would like to participate in this research project please contact Joshua Marquit at j.marquit@aggiemail.usu.edu or 797-3838. 
Appendix B

Preintervention Questionnaire 


\section{Driving Behavior Questionnaire}

Please answer the following questions related to your driving behavior. You are free to discontinue taking, or not answer questions from, the questionnaire anytime for any reason without penalty. The questionnaire should take between 5 and 20 minutes to complete, but feel free to take as much time as you need to complete the survey.

\section{$\underline{\text { Personal Vehicle Questions }}$}

Please answer the following questions about your vehicle(s) and driving behaviors.

1. Do you have a driver's license? Yes No

2. What is your primary source of transportation?

a. Personal Vehicle e. Moped

b. CVTD Bus f. Bicycle

c. Walk g. Aggie Shuttle

d. Motorcycle

3. Do you own or lease a vehicle?

Yes

No (If you answered "No" to this question, Skip to the Environmental Perception Section)

How many vehicles do you own or lease?

What make(s), model(s), and year(s) is each of the vehicles?

\begin{tabular}{|l|l|l|}
\hline Make & Model & Year \\
\hline & & \\
\hline & & \\
\hline & & \\
\hline & & \\
\hline & & \\
\hline
\end{tabular}

4. On average about how many miles is your commute from work/school back home?

5. On average about how many miles a weekday do you drive? 
6. On average about how many miles per week do you drive?

7. On average about how many miles per year do you drive?

8. On average about how many miles do you drive on Saturday?

9. On average about how many miles do you drive on Sunday?

\section{$\underline{\text { Environmental Perception }}$}

Below are some statements related to environmental perception. Using the scale provided, please indicate the extent to which you agree or disagree with each statement (1- Strongly Disagree to 9 - Strongly Agree).

1. Air pollution is a problem in Cache Valley.

\begin{tabular}{|c|c|c|c|c|c|c|c|c|}
\hline $\begin{array}{c}\text { Strongly } \\
\text { Disagree }\end{array}$ & & & & & & & & $\begin{array}{c}\text { Strongly } \\
\text { Agree }\end{array}$ \\
\hline 1 & 2 & 3 & 4 & 5 & 6 & 7 & 8 & 9 \\
\hline
\end{tabular}

2. Air pollution is only a problem in Cache Valley during the winter.

\begin{tabular}{|c|c|c|c|c|c|c|c|c|}
\hline $\begin{array}{c}\text { Strongly } \\
\text { Disagree }\end{array}$ & & & & & & & & $\begin{array}{c}\text { Strongly } \\
\text { Agree }\end{array}$ \\
\hline 1 & 2 & 3 & 4 & 5 & 6 & 7 & 8 & 9 \\
\hline
\end{tabular}

3. I am doing my part to reduce air pollution in Cache Valley.

\begin{tabular}{|c|c|c|c|c|c|c|c|c|}
\hline $\begin{array}{c}\text { Strongly } \\
\text { Disagree }\end{array}$ & & & & & & & & $\begin{array}{c}\text { Strongly } \\
\text { Agree }\end{array}$ \\
\hline 1 & 2 & 3 & 4 & 5 & 6 & 7 & 8 & 9 \\
\hline
\end{tabular}

4. Personal vehicles are the main cause of air pollution in Cache Valley.

\begin{tabular}{|c|c|c|c|c|c|c|c|c|}
\hline $\begin{array}{c}\text { Strongly } \\
\text { Disagree }\end{array}$ & & & & & & & & $\begin{array}{c}\text { Strongly } \\
\text { Agree }\end{array}$ \\
\hline 1 & 2 & 3 & 4 & 5 & 6 & 7 & 8 & 9 \\
\hline
\end{tabular}

5. Reducing the mileage of our personal vehicles will improve air quality in Cache Valley. 


\begin{tabular}{|c|c|c|c|c|c|c|c|c|}
\hline $\begin{array}{c}\text { Strongly } \\
\text { Disagree }\end{array}$ & & & & & & & & $\begin{array}{c}\text { Strongly } \\
\text { Agree }\end{array}$ \\
\hline 1 & 2 & 3 & 4 & 5 & 6 & 7 & 8 & 9 \\
\hline
\end{tabular}

6. I try to reduce my driving during the winter inversion in Cache Valley to improve air quality.

\begin{tabular}{|c|c|c|c|c|c|c|c|c|}
\hline $\begin{array}{c}\text { Strongly } \\
\text { Disagree }\end{array}$ & 2 & & & & & & & $\begin{array}{c}\text { Strongly } \\
\text { Agree }\end{array}$ \\
\hline 1 & 2 & 3 & 4 & 5 & 6 & 7 & 8 & 9 \\
\hline
\end{tabular}

7. I use public transit often

\begin{tabular}{|c|c|c|c|c|c|c|c|c|}
\hline $\begin{array}{c}\text { Strongly } \\
\text { Disagree }\end{array}$ & 2 & 3 & 4 & 5 & 6 & 7 & 8 & 9 \\
\hline 1 & 2 & 3 & & & & & $\begin{array}{c}\text { Strongly } \\
\text { Agree }\end{array}$ \\
\hline
\end{tabular}

8. I consider myself an environmentally concerned individual.

\begin{tabular}{|c|c|c|c|c|c|c|c|c|}
\hline $\begin{array}{c}\text { Strongly } \\
\text { Disagree }\end{array}$ & & & & & & & & $\begin{array}{c}\text { Strongly } \\
\text { Agree }\end{array}$ \\
\hline 1 & 2 & 3 & 4 & 5 & 6 & 7 & 8 & 9 \\
\hline
\end{tabular}

\section{Demographic Questions}

Please answer the following question about yourself.

1. What is your age?

2. What is your gender? Male Female

3. Are you a permanent resident of Cache Valley? Yes No

4. What is your marital status? Married Single Divorced Widowed

5. How many children live in your household (newborn to 18 years of age)?

6. How many school-aged ( 5 or older) children in your home?

7. How many driving-aged ( 16 or older) children in your home?

8. Are you fluent in English? Yes No 
9. Do you own or rent your home? Own Rent

10. What is your political orientation? Republican Democrat Independent Other

11. Would you consider yourself a: Conservative Moderate Liberal Other

12. What is your average annual household income range?
a. Under $\$ 10,000$
f. $\$ 50,001$ to $\$ 60,000$
j. $\$ 100,001$ to $\$ 110,000$
b. $\$ 10,001$ to $\$ 20,000$
g. $\$ 60,001$ to $\$ 70,000$
k. $\$ 110,001$ to $\$ 120,000$
c. $\$ 20,001$ to $\$ 30,000$
h. $\$ 70,001$ to $\$ 80,000$
1. Over $\$ 120,000$
d. $\$ 30,001$ to $\$ 40,000$
i. $\$ 80,001$ to $\$ 90,000$
e. $\$ 40,001$ to $\$ 50,000$
i. $\$ 90,001$ to $\$ 100,000$ 
Appendix C

CT630 Picture and Technical Specifications 


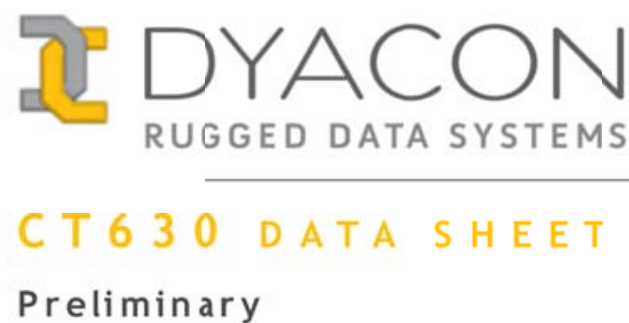

\section{FEATURE SUMMARY}

$\begin{array}{ll}\text { - C-compatible OS } & \cdot J 1708 \text { vehicle data bus } \\ \text { - Programmable with } & \cdot J 1939 \text { vehicle data bus } \\ \text { open-source tools } & \cdot \text { RS-232 port } \\ \text { - Transaction-based flash } & \text {. RS232/485 port } \\ \text { file system } & \text { - Digital I/O } \\ \text { - Internal un-interuptible } & \text { - Wide operating } \\ \text { power supply } & \text { temperature } \\ \text { - Wide input voltage range, } & \cdot \text { Liquid sealed } \\ 7.5-36 \mathrm{~V} & \cdot \text { GSM/GPRS (option) } \\ \text { - Electrical transient } & \cdot \text { Internal GPS (option) } \\ \text { protection } & \text { - Bluetooth Transceiver } \\ & \text { (option) }\end{array}$

\section{Description}

The Dyacon CT630 builds on the successful CT6xx series of vehicle interface and communication computers. The CT630 paves the way for the wireless cab by providing Bluetooth connectivity to laptops, hand held computers or other in-cab electronics.

The CT630 includes both $\mathrm{J} 1708$ and J1939 vehicle data connections as well as two serial ports, cell phone, GPS, highcurrent digital outputs, and digital inputs.

The C-programmable operating system opens the CT630 to many applications where vehicle monitoring, tracking, and remote data communications are required.

\section{Applications}

In the standard configuration, the CT630 may be programmed to monitor vehicle status through $\mathrm{J} 1708$ and J1939, provide geofencing features, manage data traffic over a connected satellite transceiver, and enhance security.

With the optional industrial GPS receiver and cell phone modules, the CT630 can serve as a multi-mode communication modem; select least-cost message routing via external satellite, external 802.11, o: internal cell phone.

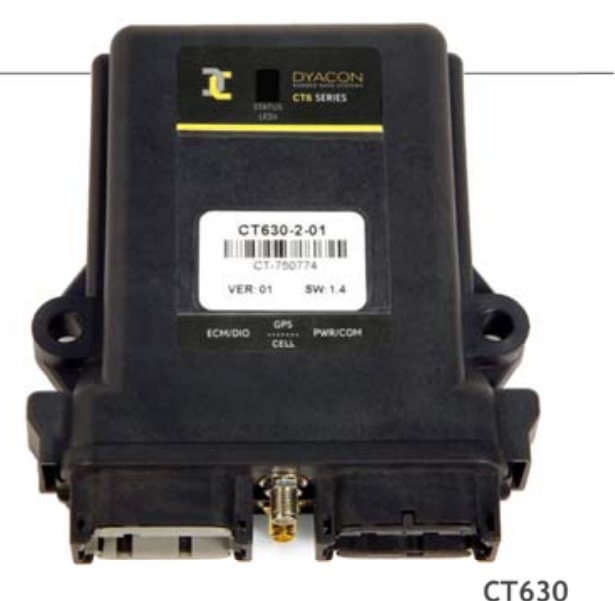

\section{Key Features}

J1708 and J1939: The SAE J1708 and J1939 vehicle data buses are used in heavy-duty trucks. Vehicle parameters such as road speed, fuel usage, engine RPM, and throttle position are among the hundreds of values available.

These messages may be used for vehicle diagnostics, logging, security, or monitoring of driver behavior.

Bluetooth: Hand held computers can now connect to the vehicle through the CT630 for vehicle, GPS, and cell phone data. This provides the benefits of a tethered in-cab computer while maintaining the portabe convenience of the hand held.

UPS: The CT630 incluces and integrated un-interruptible power supply that will typically sustain full run mode after power loss. The application may use the power-good interrupt to set flags or save data during UPS operation.

Flash File System: A transaction-based flash memory file system ensures data is preserved in any situation.

Open-source Tools: Development on the CT630 is inexpensive with open-source programming tools. A hardware abstraction layer reduces the learning curve by providing high-level functions for the embedded hardware.

Hardware Configuration: The CT630 can be configured for price and feature optimization specific to the communication system. 


\section{EN VIRONMENTAL}

\begin{tabular}{l|l}
\hline Operating Temp & $-35{ }^{\circ} \mathrm{C}$ to $75{ }^{\circ} \mathrm{C}$ \\
\hline Storage Temp & $-40{ }^{\circ} \mathrm{C}$ to $85{ }^{\circ} \mathrm{C}$ \\
\hline Humidity & $90 \% \mathrm{RH}$, non-condensing \\
\hline Vibration Operating & SAE J1455 Section 4.9 (5.2 grms) \\
\hline Sealing, Liquid & Submersible to $3 \mathrm{ft}$ (base configuration) \\
\hline
\end{tabular}

\section{J1708 CONTROLLER}

\begin{tabular}{l|l}
\hline \multirow{2}{*}{ API Interface } & Filtering for up to 30 MID/PIDs \\
\cline { 2 - 2 } & MID wild card \\
\cline { 2 - 2 } & Send message w/priority control \\
\hline Firmware & Field upgradeable \\
\hline \multirow{2}{*}{ J1939 Feature } & (Pre liminary) \\
\hline API Interface & Filtering for up to 30 messages \\
\hline & wild card \\
\hline & Send message \\
\hline
\end{tabular}

\section{POWER FEATURES}

\begin{tabular}{l|l}
\hline \multirow{2}{*}{ nnput } & $7.5 \mathrm{~V}$ to $36 \mathrm{~V}$ \\
\cline { 2 - 2 } & Transient protected \\
\cline { 2 - 2 } & Reverse voltage protected \\
\cline { 2 - 2 } & Less than 40 mA max avg. @ 13 V \\
\hline Low power mode < 10 mA @ 13 V \\
\hline Unterruptible Supply & $\begin{array}{l}\text { 3o s full run mode } \\
\text { (Dependant on software controls and } \\
\text { hardware configuration.) }\end{array}$ \\
\cline { 2 - 2 } & Bad-power detection signal \\
\hline Ultra-capacitor & UPS Support \\
\hline
\end{tabular}

\section{I/O AND CONNECTORS}

\begin{tabular}{|c|c|}
\hline \multirow[t]{7}{*}{ Connector 1} & Deutsch sealed connector \\
\hline & J1708 Vehicle Data Bus \\
\hline & J1939 Vehicle Data Bus \\
\hline & Digital outputs 1 and 2 \\
\hline & Digital input 2 \\
\hline & Ground \\
\hline & Debug/Console port (RXD, TXD) \\
\hline \multirow[t]{6}{*}{ Connector 2} & Deutsch sealed connector \\
\hline & Com 1: RS-232 (RXD, TXD, RTS, CTS) \\
\hline & $\begin{array}{l}\text { Com 2: RS-232/485 } \\
\text { (Sofware selectable, full duplex) }\end{array}$ \\
\hline & Digital input 1 \\
\hline & Power \\
\hline & Ground \\
\hline Antenna Connector 1 & SMA for optional GPS receiver \\
\hline Antenna Connector 2 & SMA for optional cell phone transceiver \\
\hline \multirow[t]{2}{*}{ System Wake Inputs } & $\begin{array}{l}\text { Incoming data on cell phone, Com 1, } \\
\text { Debug/Console }\end{array}$ \\
\hline & Low-power detection \\
\hline
\end{tabular}

OS, MEMORY, \& YP

\begin{tabular}{l|l}
\hline \multirow{2}{*}{ os } & C-compatible \\
\cline { 2 - 2 } & Open-source tools \\
\cline { 2 - 2 } & Hardware abstraction layer \\
\cline { 2 - 2 } & Field upgradeable \\
\hline Processor & $144 \mathrm{MHz}$ \\
\cline { 2 - 2 } & Freescale Dragonball i.MXL, ARM920T \\
\hline RAM & $16 \mathrm{MB}$ \\
\hline Flash & $16 \mathrm{MB}$ \\
\hline
\end{tabular}

MECHAN ICAL

\begin{tabular}{l|l}
\hline Enclosure & Deutsch case \\
\cline { 2 - 2 } & Thermoplastic \\
\cline { 2 - 2 } Silicon Elastomer seals \\
\hline $\begin{array}{l}\text { O.29" dia mounting holes at 4" O.C. } \\
(7.4 \mathrm{~mm} \text { dia at } 102 \mathrm{~mm} \text { O.C. })\end{array}$ \\
\hline Dimensions & $\begin{array}{l}1.5 " \mathrm{H} \times 4.8 \text { " W } \times 5.5 " \mathrm{D} \\
(36.5 \mathrm{~mm} \times 118 \mathrm{~mm} \times 134 \mathrm{~mm})\end{array}$ \\
\hline
\end{tabular}

\section{RE G ULATO RY}

\begin{tabular}{l|l}
\hline Emissions & FCC Part 15 Class A \\
\hline \multirow{2}{*}{ m munity } & EN 6100o-4-2, ESD \\
\cline { 2 - 2 } & EN 6100o-4-3, Radiated \\
\cline { 2 - 2 } & EN 6100o-4-4, Elec. Fast Transient \\
\cline { 2 - 2 } & EN 6100o-4-6, RF Conducted \\
\hline
\end{tabular}

\section{USER INTERFACE}

\begin{tabular}{l|l}
\hline Indicators & Red LED, software controlled \\
\cline { 2 - 2 } & Green LED, software controlled \\
\cline { 2 - 2 } & Blue LED, cell phone controlled \\
\cline { 2 - 2 } Wellow LED, Bluetooth controlled \\
\hline \multirow{4}{*}{ Wire le s S Fe a t u re s } \\
\hline Cell Phone & Embedded GSM/GPRS modem \\
\hline GPS & 20 channel internal GPS receiver \\
\hline Bluetooth & Antenna open and short circuit detection \\
\hline & Bluetooth 2.0 \\
\cline { 2 - 2 } & Class 2 \\
\cline { 2 - 2 } & SPP Mode \\
\hline
\end{tabular}


Appendix D

Contract with Dycaon, Inc. 
Dyacon Inc. has agreed to supply Joshua D. Marquit ten CT630 devices and the associated software necessary to track vehicle miles of travel during his dissertation research project. Josh will use these devices for his dissertation work during the months of October 2009 to March 2010. At the end of the data collection period in April, all ten devices will be returned to Dyacon Ine.

Josh will purchase all external hardware such as antenna and connection cables. Josh may also pay a nominal fee to rent some of the CT630 devices.

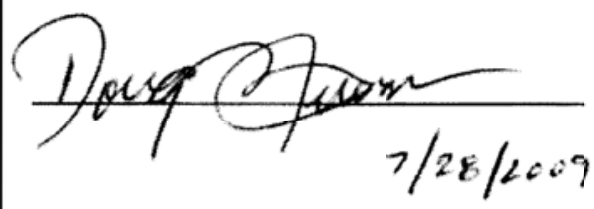

Doug Jensen

Date

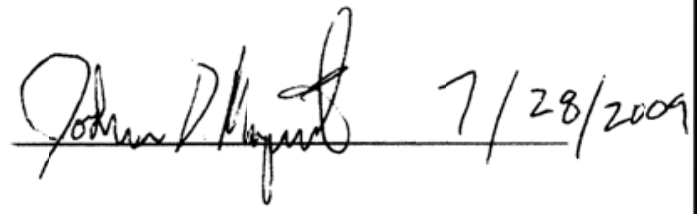

Joshua D. Marquit 
Appendix E

Behavioral Contract 


\section{Behavioral Contract}

I certify that I understand and consent to having my vehicle miles of travel monitored by an in-car GPS device for the purpose of this research project. I fully understand my role in this research project, the purpose of the intervention, and the voucher/prize system. I will be rewarded with a voucher that can be exchanged for a chance to pull a slip from the prize bowl each day that my daily vehicle miles of travel is lower than my average daily vehicle miles of travel collected during the baseline period of this research project. By signing the behavioral contract, I agree to this arrangement and commit to reducing the number of miles that I drive each day. Additionally, I commit to attending the prize-bowl drawings at to the Bear River Health Department. I am free to discontinue this research project at any time for any reason without penalty. If I discontinue this research project, I am still free to exchange each voucher I received for a chance to pull a slip from the prize bowl.

Signature

Date 
Appendix F

Informed Consent: Baseline Data Collection 


\section{Informed Consent}

Introduction/ Purpose: Professor Richard N. Roberts in the Department of Psychology at Utah State University is conducting a research study to find out more about the functionality (reliability and validity) of an in-car Global Positioning System (GPS) in personal vehicles to measure driving patterns in Cache County, Utah. You have been asked to take part because you are an adult (18 years of age or older), you live in Cache County, and own or lease a vehicle. There will be approximately 30 total participants in this research. This project will last approximately 3 weeks in length.

Procedures: If you agree to be in this research study, the following will happen to you.

1. You will fill out a short questionnaire about your driving behavior.

2. After the completion of the questionnaire, you will be given a $\$ 2$ dollar gift certificate.

3. Volunteers will be randomly selected from those that complete this questionnaire.

4. If you are selected, you will be invited to participate in research project that will test the functionality of an in-car GPS device.

5. If you agree to participate, you will have an in-car Global Positioning System professionally installed by an employee at Dyacon, Inc. (708 W $1800 \mathrm{~N}$ Ste 1a, Logan, UT 84321) in your personal vehicle.

6. The GPS device must remain in your vehicle and plugged in throughout the duration of the project.

7. At the end of the three weeks, an employee at Dyacon, Inc. will remove the GPS device from your vehicle.

8. At this time, you will be awarded $\$ 20$ dollars in cash.

New Findings: During the course of this research study, you will be informed of any significant new findings (either good or bad), such as changes in the risks or benefits resulting from participation in the research, or new alternatives to participation that might cause you to change your mind about continuing in the study. If new information is obtained that is relevant or useful to you, or if the procedures and/or methods change at any time throughout this study, your consent to continue participating in this study will be obtained again.

Risks: Participation in this research study may involve some added risks or discomforts. There are minimal risks involved in the study. These include:

1. The GPS device will be powered through your personal vehicle's cigarette lighter and under extraordinary conditions the car battery could be drained. So, in an effort to prevent this from occurring we will program the GPS device to activate only when the car is use and turn off when the car is not is operation. In cases where the battery is damaged by the GPS device, a new battery will be provided.

2. To ensure confidentiality, all questionnaires will be stored in a locked file at the Early Intervention Research Institute at Utah State University. Only Richard N. Roberts and Joshua D. Marquit will have access to the survey data. After two years, the questionnaires will be destroyed.

Benefits: There are direct benefits to you from these procedures. You will receive $\$ 2$ gift 
certificate to complete a questionnaire and if you are selected to be part of the GPS device study you can earn an additional $\$ 20$ in cash to participate. The investigator may also learn more about the functionality of the GPS device in monitoring driving patterns in personal vehicles.

Explanation \& offer to answer questions: Joshua D. Marquit has explained this research study to you and answered your questions. If you have other questions or research-related problems, you may reach Professor Richard N. Roberts at 797- 3346 (or richard.roberts@usu.edu) or Joshua D. Marquit at 797-3838 (or j.marquit@aggiemail.usu.edu).

Extra Cost(s): The only cost to you will be the 3-week period of your time needed to complete the study.

Payment/Compensation: You will be paid a \$2 gift certificate for completing the questionnaire and another $\$ 20$ dollars for your participation in this study. Joshua D. Marquit will give you these compensations. The $\$ 2$ gift certificate will be given at the completion of the questionnaire. For those that are selected to be part of the study, $\$ 20$ dollars will be given at the completion of the 3-week GPS device study. If you will receive payments, gift cards or similar items of value for participating in this research, the Internal Revenue Service (IRS) has determined that if the amount you get from this study, plus any prior amounts you have received from USU since January of this year total $\$ 600$ or more, USU must report this income to the federal government. If you are a USU employee, any payment you receive from this study will be included in your regular payroll. If you have other questions or compensation-related problems, you may reach Professor Richard N. Roberts at 797- 3346 (or richard.roberts@usu.edu) or Joshua D. Marquit at 797-3838 (or j.marquit@aggiemail.usu.edu). Voluntary nature of participation and right to withdraw without consequence: Participation in research is entirely voluntary. You may refuse to participate or withdraw at any time without consequence or loss of benefits. However, the \$20 payment will only be given to those that do not complete the 3-week study period. You may be withdrawn from this study without your consent by the investigator if you unplug the GPS device from the power source or remove it completely from your car. In this circumstance you will be withdrawn from the study and not compensated for your time.

Confidentiality: Research records will be kept confidential, consistent with federal and state regulations. Only the investigator and Joshua D. Marquit will have access to the data that will be kept on a secured server at Dyacon, Inc. Data on this server can only be accessed through a encrypted and password-protected web page. Personal, identifiable information will be kept from the questionnaire will be kept for a year in a locked cabinet and then destroyed.

IRB Approval Statement: The Institutional Review Board for the protection of human participants at USU has approved this research study. If you have any pertinent questions or concerns about your rights or a research-related injury, you may contact the IRB Administrator at (435) 797-0567 or email irb@usu.edu. If you have a concern or complaint about the research and you would like to contact someone other than the research team, you may contact the IRB Administrator to obtain information or to offer 
input.

Copy of consent: You have been given two copies of this Informed Consent. Please sign both copies and retain one copy for your files.

Investigator Statement: "I certify that the research study has been explained to the individual, by me or my research staff, and that the individual understands the nature and purpose, the possible risks and benefits associated with taking part in this research study. Any questions that have been raised have been answered."

\section{Signature of PI \& student or Co-PI}

Principal Investigator Student Researcher

Richard N. Roberts Joshua D. Marquit

Phone: 797- 3346 Phone: 797-3839

Email: richard.roberts@usu.edu Email: j.marquit@aggiemail.usu.edu

Signature of Participant: By signing below, I agree to participate. 
Appendix G

Informed Consent: Intervention 


\section{Informed Consent}

Introduction/ Purpose: Professor Richard N. Roberts in the Department of Psychology at Utah State University is conducting a research study to reduce vehicle miles of travel in your personal vehicle in Cache County, Utah during the winter inversion. To encourage reductions in your driving mileage, participants of this project will be given an opportunity to earn performance-based (mileage reductions) vouchers that can be exchanged for a chance to pull a prize slip from a prize bowl. You have been asked to take part because you completed the 3-week data collection period. There will be approximately 10 participants in this research study. This project will last approximately 11 weeks in length (8-week intervention and 3-week final stage).

Procedures: If you agree to be in this research study, the following will happen to you.

1. Upon reading and signing this form and the behavioral contract, you will receive a $\$ 10$ gift certificate.

2. You will have an in-car Global Positioning System professionally re-installed by Dyacon, Inc. (708 W $1800 \mathrm{~N}$ Ste 1a, Logan, UT 84321) in your personal vehicle.

3. The GPS device must remain in your vehicle and plugged in throughout the duration of the project.

4. Each evening at 11:00, Joshua D. Marquit will log onto the Dyacon, Inc. website and access your mileage data.

5. Each morning at 10:00, Joshua D. Marquit will email or call you with your daily mileage and average from the 3-week data collection period that occurred prior to this study. If your daily mileage is lower than your average daily baseline mileage, you will be awarded a voucher. Joshua D. Marquit will keep track of your prize vouchers for each weekly drawing.

6. Prizes will vary in value from $\$ 1$ to $\$ 100$.

7. Each week at a designated time and date, you and the other participants will meet at the Bear River Health Department (655 East 1300 North, Logan, UT, 84341) to exchange your vouchers in for a chance to pull a slip from the prize bowl.

8. In an effort to not artificially inflate your mileage, your trip mileage to the weekly drawings will be subtracted from that day's total mileage.

9. The order in which you will pull slips from the prize bowl will be determined by pulling one of ten slips numbered 1 through 10 from a separate bowl. The person with the 1 on their slip will go first, followed by the person with a 2 and the order will continue in ascending order.

10. Following all of the drawings, prize slips will be exchanged for the corresponding prize and not returned to the prize bowl.

11. At the end of the 8-week intervention, the prize system will be removed and the in-car GPS device will remain in your car to determine the long-term impact of the intervention on your driving behavior.

12. At the end of the eleven weeks, the GPS device will be removed from your vehicle by an employee at Dyacon, Inc., you will asked to complete an exit questionnaire about your experience in the intervention, and given a $\$ 20$ gift 
certificate for your efforts.

13. After the intervention is complete, the Herald Journal may write a story about the intervention.

New Findings: During the course of this research study, you will be informed of any significant new findings (either good or bad), such as changes in the risks or benefits resulting from participation in the research, or new alternatives to participation that might cause you to change your mind about continuing in the study. If new information is obtained that is relevant or useful to you, or if the procedures and/or methods change at any time throughout this study, your consent to continue participating in this study will be obtained again.

Risks: Participation in this research study may involve some added risks or discomforts. There are minimal risks involved in the study. These include:

1. The GPS device will be powered through your personal vehicle's cigarette lighter and under extraordinary conditions the car battery could be drained. So, in an effort to prevent this from occurring we will program the GPS device to activate only when the car is use and turn off when the car is not is operation. In cases where the battery is damaged by the GPS device, a new battery will be provided.

2. To ensure confidentiality, all questionnaires will be stored in a locked file at the Early Intervention Research Institute at Utah State University and all GPS mileage data will be encrypted and stored on a secure server at Dyacon, Inc. Only Richard N. Roberts and Joshua D. Marquit will have access to the questionnaire and GPS data. After two years, the questionnaires and GPS data will be destroyed.

2. Monitoring your mileage or not earning vouchers may cause some minimal anxiety, stress, or disappointment. If necessary, we will assist you in finding professional help to relieve these emotions.

Benefits: There are direct benefits to you from these procedures. You will receive vouchers that can be used to exchange for prizes that range from $\$ 1$ to $\$ 100$. You will also be awarded a $\$ 20$ gift certificate to participate in the final stage of the project (3 weeks) and fill out a short exit questionnaire about your experience. The investigator may also learn more about how to encourage people to reduce their driving during the winter inversion here in Cache Valley.

Explanation \& offer to answer questions: Joshua D. Marquit has explained this research study to you and answered your questions. If you have other questions or research-related problems, you may reach Professor Richard N. Roberts at 797- 3346 (or richard.roberts@usu.edu) or Joshua D. Marquit at 797-3838 (or j.marquit@aggiemail.usu.edu).

Extra Cost(s): The only cost to you will be the 11-week period of your time needed to complete the study and time needed to attend the weekly drawings.

Payment/Compensation: You will be given prizes based on your ability to reduce your driving mileage below a pre-determined average of your daily mileage total. The vouchers will only be awarded to you if you are able to reduce your daily mileage total below your average daily total from the 3-week data collection period. You will also be 
paid a \$20 gift certificate for completing the exit questionnaire and completing the final 3 -week stage of the project. Joshua D. Marquit will give you these compensations. If you will receive payments, gift cards or similar items of value for participating in this research, the Internal Revenue Service (IRS) has determined that if the amount you get from this study, plus any prior amounts you have received from USU since January of this year total $\$ 600$ or more, USU must report this income to the federal government. If you are a USU employee, any payment you receive from this study will be included in your regular payroll. If you have other questions or compensation-related problems, you may reach Professor Richard N. Roberts at 797- 3346 (or richard.roberts@usu.edu) or Joshua D. Marquit at 797-3838 (or j.marquit@aggiemail.usu.edu). Voluntary nature of participation and right to withdraw without consequence: Participation in research is entirely voluntary. You may refuse to participate or withdraw at any time without consequence or loss of benefits. Any vouchers earned before withdrawal can be exchanged for a chance to pull prizes from the prize bowl. You may be withdrawn from this study without your consent by the investigator if you unplug the GPS device from the power source or remove it completely from your car. In this circumstance you will be withdrawn from the study and not compensated for your time. Confidentiality: Research records will be kept confidential, consistent with federal and state regulations. Only the investigator and Joshua D. Marquit will have access to the data that will be kept on a secured server at Dyacon, Inc. Data on this server can only be accessed through a encrypted and password-protected web page. Personal, identifiable information will be kept from the questionnaire will be kept for two years in a locked cabinet and then destroyed.

IRB Approval Statement: The Institutional Review Board for the protection of human participants at USU has approved this research study. If you have any pertinent questions or concerns about your rights or a research-related injury, you may contact the IRB Administrator at (435) 797-0567 or email irb@usu.edu. If you have a concern or complaint about the research and you would like to contact someone other than the research team, you may contact the IRB Administrator to obtain information or to offer input.

Copy of consent: You have been given two copies of this Informed Consent. Please sign both copies and retain one copy for your files.

Investigator Statement: "I certify that the research study has been explained to the individual, by me or my research staff, and that the individual understands the nature and purpose, the possible risks and benefits associated with taking part in this research study. Any questions that have been raised have been answered."

\title{
Signature of PI \& student or Co-PI
}

\author{
Principal Investigator Student Researcher \\ Richard N. Roberts Joshua D. Marquit \\ Phone: 797- 3346 \\ Email: richard.roberts@usu.edu Email: j.marquit@aggiemail.usu.edu
}


Signature of Participant: By signing below, I agree to participate.

Participant's signature

Date 
Appendix $\mathrm{H}$

Suggestion List to Reduce Vehicle Miles of Travel 
Suggestion List to Reduce Your Vehicle Miles of Travel

1. Use public transit

2. Carpool

3. When possible, Walk

4. When possible, Ride a Bicycle

5. Work from home or telecommute

6. Postpone errands to Green Air Days

7. Combine all of your errands in one trip rather than multiple trips

8. When possible, park in a central location and walk to work, lunch, or other errands 
Appendix I

Donation Solicitation Email 
My name is Joshua Marquit and I'm a graduate student in the psychology program at Utah State University. The reason I have contacted you is that I need your help with a community-based intervention that has been designed in an effort to improve air quality in Cache Valley:

Purpose: Encourage residents of Cache Valley to reduce their driving mileage during the winter inversion to improve air quality in the valley.

How: When participants in our study are able to reduce their daily driving mileage from their baseline driving average, they will be given a voucher that can be used to pull a prize from a prize-bowl drawing that will held each week at the Bear River Health Department.

When: January 2010 and April 2010.

How You Can Help:

- $\quad$ Prize donations (merchandise and/or gift certificates)

- $\quad$ Any donation that you can give would be appreciated.

Benefits for You:

- $\quad$ Free Publicity: The Herald Journal may be covering the project in the local paper at the end of the project.

- Possible tax write-offs

- $\quad$ Possible benefits to the community may include improved air quality

If you would like to donate prizes/merchandise or have any questions, please contact me by phone or email.

Email: j.marquit@aggiemail.usu.edu

Phone Number: (435) 797-3838

Thank you for your time and consideration in this matter.

Best Regards,

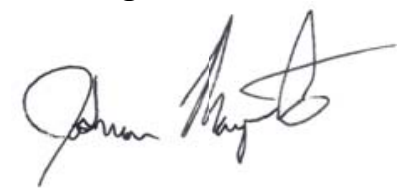

Joshua Marquit, M.S. 
Appendix $\mathbf{J}$

Exit Questionnaire 


\section{Post- Intervention Questionnaire}

Please answer the following questions related to your experience as a volunteer in the driving reduction intervention. You are free to discontinue taking, or not answer questions from, the questionnaire anytime for any reason without penalty. The questionnaire should take between 10 and 15 minutes to complete, but feel free to take as much time as you need to complete the survey.

Below are some questions related to the driving reduction intervention. Please answer the following questions.

1.a. On a scale from 1 (Terrible) to 7 (Great), how would you rate your experience in the intervention? (Please circle your response)

\begin{tabular}{|c|c|c|c|c|c|c|}
\hline Terrible & & & & & & Great \\
\hline 1 & 2 & 3 & 4 & 5 & 6 & 7 \\
\hline
\end{tabular}

1.b. What did you like most about the intervention?

1.c. What did you like least about the intervention?

2.a. On a scale from 1 (Ineffective) to 7 (Effective), how effective to do you feel the intervention was in reducing your driving mileage? (Please circle your response)

\begin{tabular}{|c|c|c|c|c|c|c|}
\hline Ineffective & & & & & & Effective \\
\hline 1 & 2 & 3 & 4 & 5 & 6 & 7 \\
\hline
\end{tabular}

2.b. What did you do to reduce your driving mileage? 
3.a. On the scale from 1 (Low Impact) to 7 (High Impact), identify to what extent did your knowledge about being monitored by GPS devices impact your driving mileage?

\begin{tabular}{|c|c|c|c|c|c|c|}
\hline $\begin{array}{c}\text { Low } \\
\text { Impact }\end{array}$ & & & & & & $\begin{array}{c}\text { High } \\
\text { Impact }\end{array}$ \\
\hline 1 & 2 & 3 & 4 & 5 & 6 & 7 \\
\hline
\end{tabular}

3.b. Compared to your driving before the study began, did your knowledge about being monitored cause you to drive less, more, or the same? (Please write your answer on the line provided.)

4.a. On a scale from 1 (Terrible) to 7 (Great), how would you rate the prizes you won from the prize bowl? (Please circle your response)

\begin{tabular}{|c|c|c|c|c|c|c|}
\hline Terrible & & & & & & Great \\
\hline 1 & 2 & 3 & 4 & 5 & 6 & 7 \\
\hline
\end{tabular}

4.b. Which prizes did you like most?

4.c. Which prizes did you like least?

5.a. On a scale from one 1 (Terrible) to 7 (Great), how would rate the weekly drawings? (Please circle your response)

\begin{tabular}{|c|c|c|c|c|c|c|}
\hline Terrible & & & & & & Great \\
\hline 1 & 2 & 3 & 4 & 5 & 6 & 7 \\
\hline
\end{tabular}

5.b. What did you like most about the weekly drawings?

5.c. What did you like least about the weekly drawings? 
6. Would you be part of a driving reduction intervention like this one in the future? (Please circle your answer)

a. Yes b. No

Why or Why not?

7. What other suggestions, comments, and/or ideas do you have that would improve our driving reduction intervention?

Thank you for your participation in the study! 
CURRICULUM VITAE

JOSHUA D. MARQUIT

\section{Contact Information}

Utah State University:

Department of Psychology - UMC 2810

Logan, UT 84322-2810

Cell Phone: (435) 757-7023

Email: j.marquit@aggiemail.usu.edu

\section{EDUCATION}

2011 Utah State University, Psychology (Ph.D.)

Emphasis: Experimental and Applied Psychological Science

Dissertation: Prized-Based Contingency Management: A Vehicle Miles Of

Travel Reduction Intervention

Current Advisor: Jamison D. Fargo, Ph.D.

Previous Advisor: Richard N. Roberts, Ph.D.

GPA: 3.92

2008 Utah State University, Psychology (M.S.)

Emphasis: Experimental and Applied Psychological Science

Thesis: Threat Perception as a Determinant of Pro-Environmental Behaviors:

Public Involvement in Air Pollution Abatement in Cache Valley, Utah.

Advisor: Scott C. Bates, Ph.D.

GPA: 3.93

2004 Southern Utah University, Applied Psychology (B.S.)

Thesis: Economic and Environmental Assessment of the Zion National Park

Shuttle System in the Gateway Community of Springdale, Utah

Minor: Business Management

Advisor: Britton L. Mace, Ph.D.

GPA: 3.79

\section{PROFESSIONAL/TEACHING EXPERIENCE}

2011 Instructor of Record for PSY 6570 (Online): Introduction to Educational and Psychological Research in the Department of Psychology in the Department of Psychology at Utah State University, Logan Main Campus, Logan, UT. 
2011 Graduate Teaching Assistant for PSY 7670 (On-Campus): Literature Review in Education and Psychology in the Department of Psychology for Professor Karl White, Ph.D. at Utah State University, Logan Main Campus, Logan, UT.

2011 Graduate Teaching Assistant for PSY/EDUC 6570 (On-Campus): Introduction to Educational and Psychological Research in the Department of Psychology for Research Assistant Professor Susan G. Friedman, Ph.D. at Utah State University, Logan Main Campus, Logan, UT.

2011 Graduate Teaching Assistant for PSY/EDUC 6010 (Online): Introduction to Program Evaluation in the Department of Psychology for Research Assistant Professor Lisa Boyce, Ph.D. at Utah State University, Logan Main Campus, Logan, UT.

2010 Instructor of Record for PSY 3500 (Interactive Broadcast): Scientific Thinking and Methods in Psychology in the Department of Psychology at Utah State University, Logan Main Campus, Logan, UT.

2010 Graduate Teaching Assistant for PSY 3500 (Online): Scientific Thinking and Methods in Psychology in the Department of Psychology for Assistant Professor Christopher J. Johnson, Ph.D. at Utah State University, Ephraim Campus, Ephraim, UT.

2010 Graduate Teaching Assistant for PSY 5100 (On-Campus): History \& Systems in the Department of Psychology for Temporary Assistant Professor Kyle M. Hancock, Ph.D. at Utah State University, Logan, UT.

2008-09 Graduate Research Assistant at the Early Intervention Research Institute (EIRI) Research Extension for Director Richard N. Roberts, Ph.D. at Utah State University, Logan, UT.

2005-09 Graduate Research Assistant in the Department of Psychology for Assistant Professor Scott C. Bates, Ph.D. at Utah State University, Logan, UT.

2005 Graduate Research Technician for Doctoral Candidate Bill Spain at Utah State University, Logan, UT.

2003 Undergraduate Teaching Assistant for Associate Professor Britton L. Mace, Ph.D. at the Department of Psychology, Cedar City, UT.

2003 Undergraduate Tutor for Psychology at The Student Support Center, Cedar City, UT. 


\section{GUEST LECTURES}

Marquit, J.D. (2010, March). Prized-based contingency management: A vehicle miles of travel reduction intervention, Presented at the Social and Environmental Psychology of Natural Resources (ENVS 6900) graduate course, Utah State University, Logan, UT.

Marquit, J.D. (2008, November). Air quality survey, Presented at the Social Behavior undergraduate lab for the General Psychology (PSY 1010) undergraduate course, Utah State University, Logan, UT.

Marquit, J.D. (2008, March). Perception to Action: Cleaning Up Cache Valley Air, Presented at the Social Behavior undergraduate lab for the General Psychology (PSY 1010) undergraduate course, Utah State University, Logan, UT.

Marquit, J.D. (2008, March). Air pollution and Human Behavior: The Impact Cache Valley Air Quality on Pro-environmental Behaviors, Presented at the Environmental Psychology (PSY 3500) undergraduate course, Southern Utah University, Cedar City, UT.

Marquit, J.D. (2007, November) Thesis Presentation: Air Quality Project, Presented at the REM Program Seminar for graduate students, Utah State University, Logan, UT.

Marquit, J.D. (2007, October) Appling Social-Environmental Theory to Solving RealWorld Problems, Presented at the Social Psychology (PSY 3510) undergraduate course, Utah State University, Logan, UT.

Marquit, J.D. (2005, October) Introduction to Environmental Psychology and CrossDiscipline Use in Health Psychology, Presented at the Health Psychology (PSY 3110) undergraduate course, Utah State University, Logan, UT.

\section{RESEARCH EXPERIENCE}

2009-10 Graduate Student Researcher. Self-funded project with some donations: $A$ vehicle miles of travel reduction intervention using prized-based contingency management.

Total Donations Awarded: $\$ 6,000$.

2007-09 Graduate Student Researcher. Utah State University New Faculty Research Grant. Perceptions and Actions Related to Air Quality in Salt Lake County. Utah State University New Faculty Research Grant.

Principal Investigator: Michael Dietz, Ph.D.

Total Award: \$10,117. 
2006-07 Graduate Student Researcher. Bear River Health Department Grant: Air Quality Perception Survey in Cache Valley, Utah.

Total Award: \$2,800.

2007-11 Graduate Student Researcher. National Aeronautics and Space Administration (NASA) Grant: Validating Vegetable Production Unit: Plants, Protocols, Procedures and Requirements (P3R) Using Currently Existing Flight Resources.

Principal Investigator: Scott C. Bates, Ph.D.

Total Award: \$800,000.

2005-06 Graduate Student Researcher. National Aeronautics and Space Administration (NASA) Grant: Validating Vegetable Production Unit Plants, Protocols, Procedures and Requirements (P3R) Using Currently Existing Flight Resources.

Total Award: \$120,000.

2005 Graduate Student Technician. Utah State Division of Parks and Recreation Grant: Recreational Water Use Capacity on Utah's Lakes and Reservoirs.

Principal Investigator: Steve Burr, Ph.D.

Total Award: $\$ 52,800$

2004 Undergraduate Student Researcher. Self-Funded: Bryce Canyon National Park Visitor Experience Survey.

2003 Undergraduate Student Researcher. Self-Funded: Economic and Environmental Assessment of the Zion National Park Shuttle System in the Gateway Community of Springdale, Utah.

2002-03 Undergraduate Student Researcher. Self-Funded: An Evaluation of the Social and Physical Elements of the Work Environment at DCI of Utah, INC.

\section{HONORS \& AWARDS}

2008 Graduated Magna Cum Laude in Psychology (Master of Science degree), Utah State University, Logan, UT.

2005 Utah Recreation and Parks Association (URPA) Graduate Student Scholarship, Utah State University, Logan, UT.

2004 Graduated Magna Cum Laude in Applied Psychology (Bachelor of Science degree), Southern Utah University, Cedar City, UT. 
2004 Outstanding Student in Applied Psychology, Department of Psychology, Southern Utah University, Cedar City, UT.

2004 Student Faculty Scholarship, Fifth Annual Student/Faculty Scholarship/Creativity Day, Southern Utah University, Cedar City, UT.

2001-04 Non-Residential Full-Tuition Academic Scholarship, Southern Utah University, Cedar City, UT.

\section{PUBLICATIONS}

\section{Manuscripts in Preparation}

Marquit, J.D., Bates, S.C., Redd, E.H., \& Schroder, K. Environmental threat perception as a determinant of air pollution control-related pro-environmental and avoidance behaviors.

Marquit, J.D., Mace, B. \& Bates, S.C. The Zion National Park alternative transportation system: A survey of business owners and employees.

Mace, B.L., Marquit, J.D., \& Bates, S.C. Visitor Assessment of the Zion National Park Alternative Transportation System.

\section{Manuscripts Under Review}

Marquit, J.D. \& Dietz, M.E, Clearing the air: Attitudes and actions related to air pollution in Salt Lake County, Utah.

\section{Refereed Publications}

Bates, S.C. \& Marquit, J.D. (2010). Space psychology: Natural elements in habitation design. Personal and Ubiquitous Computing, Online First.

Bates, S.C., Gushin, V., Bingham, G., Vinokhodova, A., Marquit, J.D., \& Sychev, V. (2009). Plants as countermeasures: A review of the literature and application to habitation systems for humans living in isolated or extreme environments. Habitation, 12(1), 33-40.

Marquit, J.D., Bates, S.C., Gushin, V.I., Sychev, V.N., Levinskikh, M.A., Podolsky, I.G., Marchant, C., \& Bingham, G.E. (2009). Testing crew responses to varied higher plant presentations in the Mars 500-Day mission simulation. Journal of Gravitational Physiology, 15(1), P161-162. 


\section{Refereed Book Chapters}

Bates, S.C., \& Marquit, J.D. (2010). Psychology: Natural elements as a well-being stimuli in outer space. In H. Benaroya (Ed.), Lunar Settlements (pp. 215 - 224). London, UK: CRC Press.

\section{PRESENTATIONS AT REGIONAL, NATIONAL, AND INTERNATIONAL MEETINGS}

Marquit, J.D., Roberts, R.N., \& Fargo, J.D. (2011, June). Prized-based contingency management: A vehicle miles of travel reduction intervention. Accepted for presentation at the 2011 International Symposium of Society \& Natural Resource Management Madison Conference: Integrating Conservation and Sustainable Living, Madison, WI.

Marquit, J.D., Roberts, R.N., \& Fargo, J.D. (2011, April). Prized-based contingency management: A vehicle miles of travel reduction intervention. Presentation at the 2011 Rocky Mountain Psychological Association Salt Lake City Conference, Salt Lake City, UT.

Marquit, J.D., Bates, S.C., \& Redd, E.H. (2009, January). Cache Valley air quality survey. Presented at the National Children's Study Innovative Research Meeting, Department of Pediatrics, University of Utah, Salt Lake City, UT.

Marquit, J.D., Bates, S.C., Gushin, V.I., Sychev, V.N., Levinskikh, M.A. Podolsky, I.G., Marchant, C.C, \& Bingham, G.E. (2008, June). Testing crew response to varied higher plant presentations in the Mars 500-day mission simulation. Presented at Life in Space for Life on Earth and joint meetings of the ESA, ISGP, ASGSB, ELGRA, Angers, France.

Bauman, A.A.L., Thomas, W.P., Bates, S.C., Marquit, J.D., \& Odum, A.L. (2008, May). Discounting of delayed and probabilisitic increases in temperature as a result of climate change. Poster presented at the $31^{\text {st }}$ Annual Conference of the Society for the Quantitative Analyses of Behavior, Chicago, IL.

Marquit, J.D., Bates, S.C., Redd, E.H. (2008, April). Cache Valley Air Quality: Community-Member Perceptions of Severity and Impact. Presented at the 2008 Rocky Mountain Psychological Association Convention (RMPA) in the Environmental Psychology Symposium, Boise, ID.

Thomas, W.P., Bates, S.C., Baumann, A.A.L., Marquit, J.D., \& Odum, A.L. (2008, April). Discounting and global climate change: Implications for community action. Poster presented at the $11^{\text {th }}$ Annual Intermountain Graduate Student Research Symposium at Utah State University, Logan, UT. 
Marquit, J.D. (2008, March). Preparing for Graduate School. Presented for Undergraduate Research and Scholarship Program at Southern Utah University, Cedar City, UT.

Bingham, G.E., Bates, S.C., Gushin, V.I., Vinokhodova, A., Marquit, J.D., \& Sychev, V.N. (2007, October). Plants as Countermeasures for Humans Living in Isolated or Extreme Environments Such as Long Term Space Flight. Presented at the American Society for Gravitational and Space Biology, Moffett Field, CA.

Marquit, J.D., Bates, S.C., Redd, E.H, \& Members of the Air Quality Task Force. (2007, July). Air quality survey. Presented at the Cache County Council, Logan, UT.

Marquit, J.D., Bates, S.C., \& Redd, E.H. (2007, June). Perception to action?: Findings from the Cache Valley air quality perception survey. Poster presented at the $13^{\text {th }}$ International Symposium on Society \& Resource Management, Park City, UT.

Marquit, J.D., Bates, S.C., \& Redd, E.H. (2007, May). Air Quality Survey. Presented at the Air Quality Task Force Meeting, North Logan, UT.

Bates, S.C., Gushin, V., Marquit, J.D., Bingham, G., \& Sychev, V. (2007, March). Plants as Countermeasures in Long-Duration space Missions: A Review of the Literature and Research Strategy. Presented at the European Space Agency Workshop: Tools for Psychological Support, Noordwijk, The Netherlands

Mace, B.L., Marquit, J.D., \& Kay, R. (2006, June) Six years of mandatory shuttle use in Zion National Park: a longitudinal analysis of the visitor experience. Presented at $12^{\text {th }}$ International Symposium on Society \& Resource Management, Vancouver, BC, Canada.

Bates, S.C., \& Marquit, J.D. (2006, February). The benefits of plants: a review of the literature and application to habitation systems for humans living in isolated or extreme environment. Poster presented at the Conference on Habitation Research and Technology Development, Orlando, FL.

Bates, S.C., \& Marquit, J.D. (2006, February). Psychological values of plant tending among humans: A critical review of the literature. Presented at the first international symposium on Environment, Behaviour and Society, Sydney, NWS, Australia.

Mace, B.L., \& Marquit, J.D. (2004, June) Evaluating the Impact of the Zion National Park Shuttle System on Visitors and Local Businesses, Presented at the, $10^{\text {th }}$ International Symposium on Society and Resource Management in the Transportation in Natural Resource Planning Seminar, Keystone, CO. 
Marquit, J.D., \& Mace, B.L. (2004, April) Economic and Environmental Assessment of the Zion National Park Shuttle System in the Gateway Community of Springdale, Utah, Presented at the Fifth Annual Student-Faculty Scholarship/Creativity Day, Southern Utah University, Cedar City, UT.

Marquit, J.D., \& Mace, B.L. (2004, April) Economic and Environmental Assessment of the Zion National Park Shuttle System in the Gateway Community of Springdale, Utah, Presented at Rocky Mountain Psychological Association (RMPA) in the Symposium for Environmental Psychology, Reno, NV.

Marquit, J.D., \& Mace, B.L. (2003, November) Results of the Zion National Park Shuttle Service Survey, Presented at the Springdale Town Council Meeting, Springdale, UT.

Marquit, J.D., Mace, B.L., \& Powell, G.J. (2003, February) Results of the Job Satisfaction Survey, Presented at the DCI Executive Meeting, DCI of Utah INC, Cedar City, UT.

\section{LEADERSHIP AND VOLUNTEER WORK}

2007 Graduate Student Representative, Department Representative for the Psychology Department in the College of Education and Human Services, Utah State University, Logan, UT.

2007 REM Seminar Planning Committee, Utah State University, Logan, UT

2007-08 Experimental and Applied Psychological Science (EAPS) Student Representative, Utah State University, Logan, UT.

2006-09 Member of Air Quality Task Force, Logan, UT.

2003 Research Chairman of Psi Chi Honor Society of the Department of Psychology, Southern Utah University, Cedar City, UT.

1999-01 Missionary for The Church of Jesus Christ of Latter-Day Saints in San Pablo Philippines Mission, Philippines.

MEMBERSHIPS

2010-Present

2007-Present

2004-Present
American Psychological Association

International Association for Society \& Natural Resources

Rocky Mountain Psychological Association 
2003-Present

Psi Chi Honor Society

\section{COMPUTER/SOFTWARE LITERACY}

Blackboard

Excel

Microsoft Word

MPlus

PowerPoint

$\mathrm{R}$

SPSS

Skype

SurveyMonkey

\section{LANGUAGES}

English

Tagalog (Philippines) 